Florida International University FIU Digital Commons

3-13-2008

\title{
Assessing Administrative and Political Factors in Implementing a Living Wage Ordinance
}

Teodoro Enrique Carrasco

Florida International University

DOI: $10.25148 /$ etd.FI08081506

Follow this and additional works at: https://digitalcommons.fiu.edu/etd

Part of the Public Affairs, Public Policy and Public Administration Commons

\section{Recommended Citation}

Carrasco, Teodoro Enrique, "Assessing Administrative and Political Factors in Implementing a Living Wage Ordinance" (2008). FIU Electronic Theses and Dissertations. 9.

https://digitalcommons.fiu.edu/etd/9 


\title{
FLORIDA INTERNATIONAL UNIVERSITY
}

Miami, Florida

\section{ASSESSING ADMINISTRATIVE AND POLITICAL FACTORS \\ IN IMPLEMENTING A LIVING WAGE ORDINANCE}

\author{
A dissertation submitted in partial fulfillment of the \\ requirements for the degree of \\ DOCTOR OF PHILOSOPHY \\ in \\ PUBLIC MANAGEMENT \\ by
}

Teodoro Enrique Carrasco

2008 
To: Dean Ray Thomlison

College of Social Work, Justice, and Public Affairs

This dissertation, written by Teodoro Enrique Carrasco, and entitled Assessing

Administrative and Political Factors in Implementing a Living Wage Ordinance, having been approved in respect to style and intellectual content, is referred to you for judgment.

We have read this dissertation and recommend that it be approved.

Esteban G. Dalehite

Bruce Nissen

Ronald M. Berkman

Howard A. Frank, Major Professor

Date of Defense: March 13, 2008

The dissertation of Teodoro Enrique Carrasco is approved.

Dean Ray Thomlison

College of Social Work, Justice, and Public Affairs

Dean George Walker

University Graduate School

Florida International University, 2008 
C Copyright 2008 by Teodoro Enrique Carrasco

All rights reserved. 


\section{DEDICATION}

To my wife Vivienne for her patience, love, and understanding through the years. To my daughter, Angelica, and son, Matthew, for teaching me the true value of life.

To my mother and brother for their support. To my father and the promise I kept. 


\section{ACKNOWLEDGMENTS}

I would like to thank the members of my committee for their time and effort in guiding me through the dissertation process. Dr. Howard Frank, thank you for your patience through the years and helping me to reach my goal. Dr. Ronald Berkman, it has been a true privilege having you on my committee. Thank you for your advice and guidance both personal and professional throughout my graduate career. Dr. Esteban Dalehite, thank you for your help and advice regarding my dissertation. Dr. Bruce Nissen, without your influence, I would have never chosen my research topic. Thank you for your help and expertise in researching living wages. Thanks also to Drs. James Carroll and Terry Buss for their help in the early stages of my dissertation.

I would like to acknowledge the participants from Broward County and Miami-Dade County for all of their efforts in providing me with the best information on their living wages ordinances. They are quoted throughout these chapters because their words illuminate and amplify this study. To protect their anonymity, I note without citation where I drew quoted material from my interviews.

I would also like to thank everyone at the College of Social Work, Justice, and Public Affairs who assisted me in every way possible, including Dr. Meredith Newman. I would especially like to thank Dr. Lourdes Rassi, Elizabeth Bejar, and Christy Cole for everything they did for me and my family. I cannot imagine ever completing my studies and dissertation without their help.

Lastly, thanks to Dr. Donald Klingner for convincing me to enroll in the Ph.D. program and Dr. Robert Cavazos for curing my fear of statistics and helping me remain focused in the early stages of my dissertation. Thank you for setting me on the right path. 


\title{
ABSTRACT OF THE DISSERTATION \\ ASSESSING ADMINISTRATIVE AND POLITICAL FACTORS \\ IN IMPLEMENTING A LIVING WAGE ORDINANCE
}

\author{
by
}

Teodoro Enrique Carrasco

Florida International University, 2008

Miami, Florida

\section{Professor Howard A. Frank, Major Professor}

Since 2000, the number of living wage ordinances has steadily increased throughout the country. While most of the current research has focused on the beneficial outcomes of living wages, little has been published on their administrative practices. To address this shortcoming, this study focused on the identification of key administrative and political factors involved impacting the implementation of living wage ordinances in Miami-Dade and Broward Counties.

The study utilized a triangulation of interviews, surveys, and direct observation. The author conducted interviews of administrators and members of the living wage oversight boards in both counties and observed the monthly meetings held by each county's oversight board from January 2006 to June 2007. These findings were buttressed with a national survey of senior staff in other living wage communities. The study utilized descriptive statistics, Chi Square, Cronbach's Alpha, and Spearman's Rank Correlation Coefficient (Spearman's rho).

Interviews indicated that administrators in Dade and Broward are seriously understaffed and budgeted. Ambiguities in the enabling ordinances have lead to loopholes that 
undermine implementation and accountability for participating contractors. Survey results showed that policy ambiguity, organizational politics, and a lack of organizational capacity were significant negative factors in the implementation process while an organizational culture emphasizing consistent enforcement was a positive factor.

Without the proper inputs, an organization hinders itself from meeting its outputs and outcomes. This study finds that Broward and Miami-Dade Counties do not provide the necessary administrative support to implement a living wage effectively - in stark contrast to the high hopes and strong political support behind their passage. For a living wage to succeed, it first needs an organizational culture committed to providing the necessary resources for implementation as well as transparent, consistent accountability mechanisms. 


\section{TABLE OF CONTENTS}

CHAPTER

PAGE

PREFACE …........................................................ 1

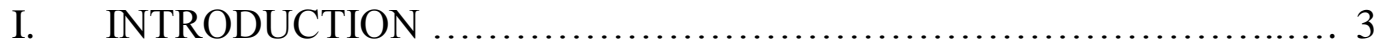

Research Issue .............................................. 3

Significance to Public Administration ............................. 8

Purpose ....................................................... 12

Research Question(s) ......................................... 14

II. LITERATURE REVIEW ........................................... 15

Policy Implementation ......................................... 15

Organizational Capability/Capacity ...................................19

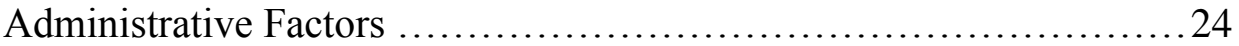

Political Factors ................................................. 28

Organizational Politics ............................................. 28

Organizational Culture ............................................... 29

Stakeholders .................................................. 32

Living Wage Implementation .................................... 33

New Public Management ........................................ 34

III. METHODOLOGY ....................................................... 41

Research Question ............................................. 41

Research Design ............................................ 43

Site Selection ................................................... 44

Qualitative Analysis ........................................ 45

Quantitative Analysis ........................................ 48

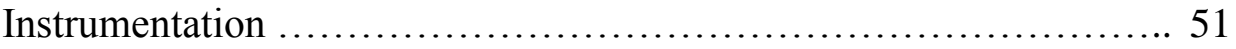

Reliability and Validity .......................................... 55

IV. BROWARD COUNTY, FLORIDA ….............................. 58

Broward County's Living Wage Ordinance ......................... 58

Broward County Living Wage Advisory Board .................... 63

Broward County Administrative Personnel ........................... 71

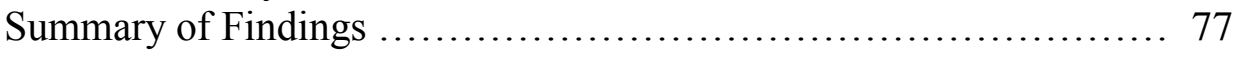

V. MIAMI-DADE COUNTY, FLORIDA …......................... 85

Miami-Dade County's Living Wage Ordinance ...................... 85

Miami-Dade County Living Wage Commission ...................... 90

Miami-Dade County Administrative Personnel ...................... 100

Summary of Findings ......................................... 111 
VI. QUANTITATIVE RESULTS AND ANALYSIS ........................... 118

Sample Characteristics .......................................... 118

Constructs Reliability Tests .................................... 120

Policy Ambiguity ............................................ 121

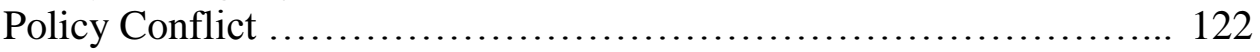

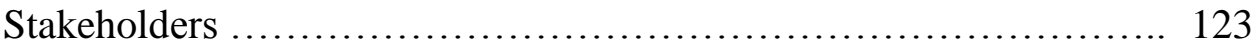

Organizational Culture …..................................... 123

Organizational Capacity ...................................... 126

Organizational Politics ....................................... 126

Hypothesis Testing .......................................... 127

Open-Ended Questions Results .................................. 133

VII. SUMMARY AND CONCLUSIONS ..................................... 138

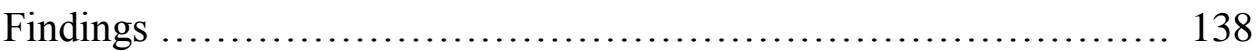

Successful Implementation ........................................ 139

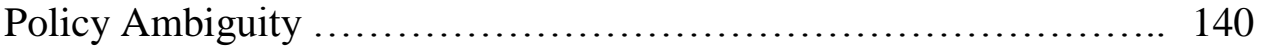

Policy Conflict ...................................................... 141

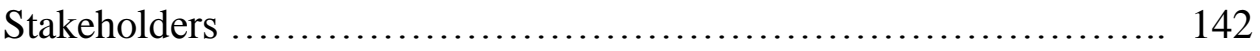

Organizational Culture ......................................... 143

Organizational Capacity ......................................... 145

Organizational Politics ........................................... 147

Living Wages and Learning Organizations ............................. 149

Limitations ..................................................... 154

Policy Recommendations ......................................... 155

Suggestions for Future Research .............................. 158

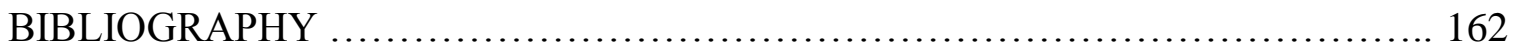

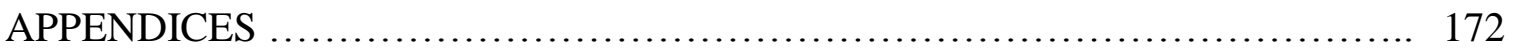

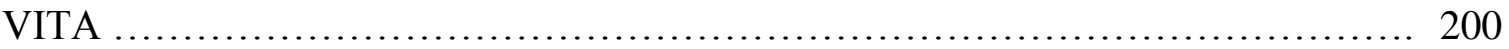




\section{LIST OF TABLES}

TABLE

PAGE

3-1 Qualitative Factors of Interest in Living Wage Implementation ................. 47

3-2 Independent Variable Definitions and Constructs ..................... 49

3-3 County Administrator Interview Questions ........................... 52

3-4 Living Wage Advisory Board Interview Questions ..................... 53

5-1 Miami-Dade County Living Wage Violations ............................. 101

6-1 Sample Characteristic Kurtosis and Skewness Values ..................... 119

6-2 Sample Characteristics Chi-Square Values ............................. 119

6-3 Policy Ambiguity Cronbach's Alpha Values ........................... 122

6-4 Policy Conflict Cronbach's Alpha Values ............................. 122

6-5 Stakeholder Influence Cronbach's Alpha Values ......................... 123

6-6 Org. Culture (Information) Cronbach's Alpha Values .................... 125

6-7 Org. Culture (Monitoring and Enforcement) Cronbach's Alpha Values ........ 125

6-8 Organizational Capacity Cronbach's Alpha Values ........................ 126

6-9 Organizational Politics Cronbach's Alpha Values ........................ 127

6-10 List of Hypotheses ............................................ 127

6-11 Spearman's rho Values by Construct Group ............................ 128

6-12 Vending Solution for Social Goals Response Rate ..................... 133

6-13 Needs Proposed to Improve Implementation Process $\ldots \ldots \ldots \ldots \ldots \ldots \ldots \ldots \ldots \ldots . \ldots \ldots$

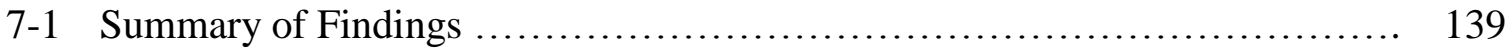

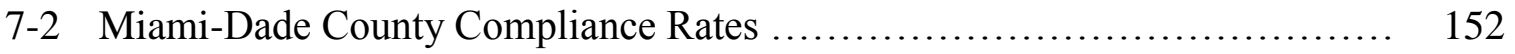




\section{LIST OF FIGURES}

FIGURE

PAGE

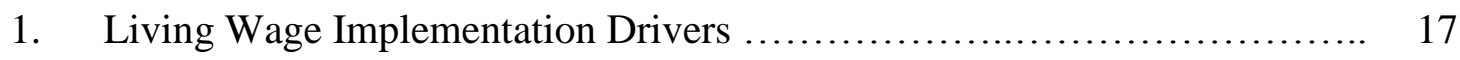

2. Organizational Capacity Effect on Organizational Performance ........... 20

3. Rational Management Process .................................... 23

4. Broward County Living Wage Implementation Organizational Model ...... 60

5. Miami-Dade County Living Wage Implementation Organizational Model ... 86

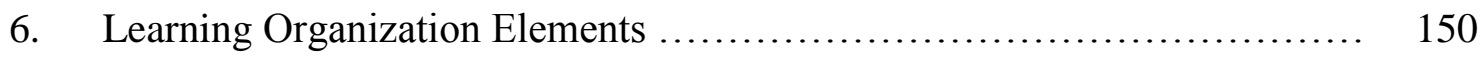

7. Living Wage Implementation Challenges ........................... 151 


\section{PREFACE}

Several events occurred during the course of writing this dissertation having potentially significant implications on the living wage ordinances in Miami-Dade and Broward County.

In January 2007, the County's organizational structure shifted to a strong-mayor form of government. This in essence removed some authority for the Board of County Commissioners and resulted in the evaluations of most departments within the County. As a result, the County dissolved the Department of Business Development (DBD) in the wake of the release of its director and transferred all responsibilities to the Department of Procurement Management (DPM) in April 2007. The transfer appeared to be seamless whereby County administrators continued to monitor and enforce the living wage ordinance as they had under DBD. While this study focuses on DBD and its efforts to manage the living wage ordinance, the situation facing the County remains unchanged and the policy recommendations provided would apply the same to DPM as it would have for DBD.

Another major incident taking place is the continuing efforts by the State Legislature to reduce property taxes. In June 2007, the Legislature approved a reduction in property taxes that resulted in the rollback to the operating funds of every jurisdiction in Florida. In January 2008, Florida's electorate subsequently voted in favor to amend the state's constitution for additional property tax relief and further municipal operating revenue reductions. As a result, most jurisdictions in Florida made drastic personnel and servicerelated cuts to meet these changes. Specifically in Broward County, the property tax issue forced it to review its services and explored eliminating its living wage ordinance as 
a cost-saving measure. While still in its early stages, Broward County appears to have some support to eliminate the living wage. However, the possibility exists if further property tax cuts continue to affect the operating budgets of Florida's municipalities. 


\section{CHAPTER I}

\section{INTRODUCTION}

The aim of this study is to develop a model identifying the principal factors involved when jurisdictions implement a living wage ordinance. That said, examining the administrative and political dynamics of the process is the primary focus.

From an administrative perspective, an organization's structure should help to outline roles and responsibilities to establish specific guidelines for the implementation process. From a political perspective, stakeholders (elected officials, contractors, etc.) represent those responsible for the political complexities that define organizational culture and action. Organizational culture represents how the organization understands its purpose and prioritizes its objectives and methods to fulfill this purpose. Consequently, organizational politics influences an organization's decision-making process by filtering stakeholder preferences and balancing power struggles and conflicting interests. It also dictates an organization's internal and external relationships because of such bargaining. A combination of these political and administrative perspectives determines the style of implementation which bounded by legal and financial capacities. These organizational capacities relate to specific factors that can limit implementation efforts (time, funding, labor, and knowledge). This study proposes that a combination of administrative and political factors plays positive and negative roles when implementing a living wage resulting in a deficient effort to address the poverty situation in South Florida.

\section{Research Issue}

The purpose of the ordinance is to make certain that county and third-party employees earn a reasonable salary to support themselves and their families without the 
threat of living in poverty. In addition to increasing wages, living wage ordinances help provide workers with health insurance options they would possibly not have otherwise. In 1988, Des Moines, Iowa, took the first step towards implementing a living wage ordinance. Since that time, over 140 jurisdictions and other government entities adopted living wages. In fact, since 2000, 89 jurisdictions implemented living wage-related legislations with 116 more campaigns currently seeking enactment throughout the country. (http://www.livingwagecampaign.org) ${ }^{1}$ However, passage of these living wage ordinances offers no indication or guarantee of enforcement or implementation.

According to Luce (2004), upon ratifying most ordinances, governments demonstrate little effort in monitoring and/or evaluating implementation because of a low level of commitment by the governments to implement the ordinance successfully, political conflicts, and/or the lack of organizational capacity.

In May 1999, the Miami-Dade County Commission unanimously approved a living wage ordinance fixed on increasing minimum wages from $\$ 5.15$ an hour to $\$ 8.56$ per hour with health benefits or $\$ 9.81$ without benefits for all county employees. (Nissen, 1998) Moreover, this ordinance also covers service-oriented workers subcontracting through the county (janitorial, food service, security, parking lot attendants, and clerical workers) and airport licensees.

According to Luce (2004), Miami-Dade County is perhaps one of the most active local governments in the country implementing its living wage ordinance and strives to improve its administrative policies continuously. Regardless, the Miami-Dade County

\footnotetext{
${ }^{1}$ The current campaigns comprise of jurisdictions, universities, and states in general seeking to create living wage legislation.
} 
Living Wage Commission (LWC) believes that the county needs to be more diligent in executing a more comprehensive monitoring and evaluating initiative. (Miami-Dade County Living Wage Commission, 2004) At present, the County does not acknowledge deficiencies in its effort to implement its living wage ordinance. (Miami-Dade County Living Wage Commission, 2004) Based on its needs assessment report, the county cannot meet expectations because of poorly trained employees, inaccessible data, and insufficient staffing. Efforts by the LWC to make County Commissioners aware of the situation are unsuccessful in garnering the necessary resources to implement the ordinance as expected and pose the question of how committed Miami-Dade County is to the living wage. As a result, the opportunity presents itself where contractors fail to comply with the provisions stated in the ordinance.

Miami-Dade County's Departments of Procurement Management (DPM) and Business Development (DBD) shared the responsibilities of monitoring and enforcing the ordinance directly. However, DPM is accountable for ensuring that living wage standards are applicable to all relevant county contracts while DBD performs the necessary monitoring and enforcement of the ordinance. Additionally, the Miami-Dade Board of County Commissioners (MDBCC) occasionally reviews and passes legislation to expand the scope of the county's living wage. For the purposes of this study, "MiamiDade County" refers to the relevant departments together since each department collectively represents Miami-Dade County's efforts to implement a living wage ordinance. However, categorizing interview responses into the following respondent groups allows the author to identify the respondent's role in the implementation process while preserving their anonymity: 
- Contract Compliance Officers - represents every contract compliance office in Miami-Dade County regardless of seniority or rank.

- Living Wage Committee Members - represents all current and former members of the Living Wage Committee regardless of seniority or rank.

- Senior-Level Management - represents those within DPM and DBD who possess management responsibilities within their respective departments.

This study's findings indicate that Miami-Dade County's main challenge is to coordinate its personnel to monitor and evaluate the outcomes of the ordinance. (Living Wage Commission Meeting, September 16, 2004) This results from poor communication and inconsistent data collection. As a result, the county claims it cannot generate an accurate assessment of the ordinance's cost and/or effectiveness. (Miami-Dade County Living Wage Commission, September 16, 2004) DBD has also admitted that its limited staff cannot enforce the ordinance to its fullest. (Living Wage Commission Meeting, September 16,2004$)$ These factors have lead to various instances of living wage contract noncompliance. In fact, since the ordinance went into effect in 2000, there have been 62 reported instances of noncompliance, $71 \%$ of which occurred in 2005 alone. ${ }^{2}$ MiamiDade County reports an estimated 90\% compliance rate; however, administrators believe that some instances of noncompliance go unreported. (Miami-Dade County Department of Business Development, 2006) Unfortunately, Miami-Dade County is not the only government having this problem. In fact, Luce (2004) states that more than $80 \%$ of other administrations face similar challenges.

\footnotetext{
${ }^{2}$ As of January 19, 2006.
} 
Broward County passed its ordinance in 2002. Much like Miami-Dade County, Broward County has taken similar approaches in its efforts to implement its ordinance. The Purchasing Division is responsible for all procurement transactions in Broward County. It also has the Office of Professional Standards (OPS) to investigate complaints and monitor contract compliance. The Broward County Commission (BCC) is responsible for any legislative issues that might arise with the living wage. For the purposes of this study, "Broward County" refers to the relevant departments together since each department collectively represents Broward County's efforts to implement a living wage ordinance. However, categorizing interview responses into the following respondent groups allows the author to identify the respondent's role in the implementation process while preserving their anonymity:

- Contract Administrators - represents the contract administrators in Broward County interviewed regardless of seniority or rank.

- Living Wage Advisory Board Members - represents all current and former members of the Living Wage Advisory Board regardless of seniority or rank.

- Department Directors - represents the department directors identified as critical actors in Broward County's living wage implementation process.

- Purchasing Personnel - represents those within the Purchasing Division that manage or oversee the implementation of the living wage to some capacity. While Broward County is similar to Miami-Dade County (Broward used MiamiDade's ordinance as a model to develop theirs), the challenges faced appear more pressing internally than externally. Miami-Dade County seems to struggle mostly with contractors at Miami International Airport and inadequate resources dedicated for living 
wage implementation, while Broward seems to have communication gaps amongst its personnel in addition to a non-supportive culture impeding the process. Thus, both counties offer different perspectives as to the political and administrative challenges jurisdictions face when implementing a living wage. This case study will also demonstrate how jurisdictions and their policies evolve as time passes since the creation of their ordinances.

\section{Significance to Public Administration}

As both Goodnow (1900) and Wilson (1887) explain, the political/administrative dichotomy in public management and policymaking is at the foundation of most public actions. Their argument is that a symbiotic relationship exists where the administrative portion concentrates on order and consistency while the political side represents the interests of the parties involved and how power is distributed. Neither has a purpose to exist if not for the other. However, Waldo (1948) argues that a fusion between politics and administration presumes the dichotomy does not exist since all administrative actions are inherently political.

Nevertheless, while both intertwine, they each possess distinguishing characteristics. This debate concerning the relationship between politics and administration eventually formulated a theory examining the rationality of bureaucratic behavior. Long (1949) believes the administrative rationality theory depends on a spectrum of acquiring, managing, and losing of power. Each component cannot exist without the other and still manage to define and produce effective governance. That said, as the primary focus on living wages is on the administrative processes involved, living wages are driven mainly through political forces and the culture in which they operate. In fact, Koven (1999) 
states that political cultures and subcultures are fundamental drivers in public and budgetary policymaking. Understanding how these forces affect policies will help to explain the administrative processes more clearly.

One of the essential goals in public administration is to bring about order from disorder - to manage individuals, organizations, and resources in a manner that maximizes effectiveness and efficiency. Another goal discussed by Wilson (1887) and Goodnow (1900) relates to public service and state that a public administrator's primary concern is to address the needs of the public through organization and a systematic approach to governance. Wilson (1887) mentions that politics corrupts bureaucracy and impedes the process of effective governance. It brings about confusion and diverts government from its intended purpose of instilling order and not pandering to political interests. Straightforward policies are capable of bridging administrative principles in a way that would bring about clarity and understanding to policy objectives. Weber (1946) applies the same argument in his theory of bureaucracy and states that only through clarity and control can an organization act rationally and efficiently. However, if we were to accept Goodnow's (1900) statement, the will of the state would represent the aggregate interests and demands of the public. This means that regardless of the amount of administrative control possible, political negotiations and conflict still play a vital role in legitimizing the bureaucracy.

Frederickson and Smith (2003) mention that political control of bureaucracy is limited and contingent on what the bureaucracy permits. It would appear that bureaucratic restraint controls political influences as politics affects administrative factors similarly. It is in this political arena that budgets are developed and approved to allocate 
resources; however, it is through rational administrative practices that governments execute their budgets. (Mikesell, 1999) Overall, a common assumption is that politics has a negative influence on governance, hindering the effectiveness of authority and administration. Lowi (1969) argues that it skews government's focus from policymaking to cater towards interest groups. Simon (1946) suggests that it prevents an organization from achieving administrative efficiency since it brings about conflict and ambiguity in policymaking. However, negotiations and bargaining help the parties involved to reach a common ground providing a clearer understanding as to the issue(s) government needs to address. In this case, it is possible to prevent politics from playing a negative role in governance and perhaps even motivates government to act more effectively. In fact, Lipsky (1978) mentions that politics helps to promote innovation and discussion in policymaking. Living wages are an example as Luce (2004) explains that most emerge from aggressive grassroots campaigning.

It appears that the challenges to living wage implementation are both political and administrative. On the one hand, there are significant political complexities resulting from conflicting demands by stakeholders. On the other hand, the legislation implemented tends to develop ambiguous goals and conflicting policies while placing more responsibilities on already inadequate organizational capacities for implementation. Luce (2004) attributes the ambiguous goals to policymakers appeasing other stakeholders in order to get the living wage ordinance passed. While the administrative portion should resolve itself through the language stated in the ordinance, the resulting policies are so diluted that it only provides uncertainty as how to place it into action. Pfeffer (1981) states that similar to any situation where authority's range fades organizational politics 
takes its place. This means that there is a constant struggle between politics and administration and it ultimately reflects on policy and decision-making. Politics can play a major role in the way living wage ordinances are passed and implemented, however, it is the administration's responsibility to keep these influences at bay, focus on its intended goal, and accomplish as much as possible through the organizational culture.

Both political and administrative facets of policymaking have their strengths and weaknesses. An administrator's challenge is utilize to determine a feasible balance that offers the best opportunity for a policy to be effective. According to Matland (1995), policy conflict occurs from differing views as to how one approaches an issue. Policy ambiguity arises from unclear goals, procedures, and roles that provide vague commands as how to carry out certain objectives. To address the effects of policy conflict and ambiguity during implementation, Matland recommends one use a combination of implementation methods that invoke the rationales of political and administrative control. Thus, incorporating administrative controls, such as strict rules and procedures, and political tactics, such as bargaining stakeholder preferences allows one to reach a negotiated policy focused on clear goals and measures.

Living wages apply similarly to Pressman and Wildavsky's (1973) case study. Living wages need transparent legislation passed and funds committed to secure the outcome intended. It is important for stakeholders to interact with each other to set goals and procedures in hopes of achieving them. Communication from internal and external stakeholders is a critical component that allows administrators to understand the scope of the implementation challenge facing them, and determine the best course of action when considering these administrative and political factors. Prior research and experience 
suggest that policymakers overlook the administrative challenge of implementing and enforcing a living wage when developing legislation. Such a politically symbolic piece of legislation is prone to ignore the complex dynamics of political relationships revolving around organizations that define the implementation scenario. In creating living wage ordinances, as with any legislation, there needs to be as much consideration to the means implemented as to the policy's desired objectives. Pressman and Wildavsky (1973) stress that without a properly designed plan, the implementation of any policy would like end in failure.

\section{Purpose}

The criticisms of current living wage research regard the focus on the legislation's potential rather than on actual effects and costs. This is because government officials interested in implementing a living wage policy have been more concerned with shortterm economic forecasts than with long-term potential outcomes. This argument supports the thesis that living wage ordinances serve more as a public demonstration by officials to help their constituents rather than a sincere, properly funded effort that addresses the long-term well-being of those the ordinance intends to cover. In fact, elected officials publicly support legislation increasing wages for low-income workers, but lose interest shortly upon adopting the ordinance and public interest disappears. (Luce, 2004) Unfortunately, those who diligently pressed for the ordinance are not critical actors during the implementation process. This is because of a need to pass the legislation elsewhere and supporters assume that the government would effectively implement and enforce the ordinance. For the most part, passing living wage laws has generally been more symbolic than substantive causing the ratification and implementation process to be 
politically driven. As a result, the administrative component lacks sufficient power to establish order and direction. As Luce (2004) states, by the time jurisdictions adopt a living wage ordinance, the result is a weak and diluted policy that makes the law even tougher to monitor and enforce. The vague policy not only causes conflict amongst stakeholders, but also exploits the policy's limitations and potential for failure. Consequently, contractors take advantage and work around the system causing workers not to collect the wages as stated in the ordinance.

In summary, the objective of this study is to develop a model explaining the implementation process for living wage legislation. Overall, this study is important to public administration because it examines how the political/administrative dichotomy influences policymaking and organizational behavior. It also examines the relationship between bureaucracy and democracy while contributing to the general research of living wage policy.

To determine if a jurisdiction implemented its living wage ordinance according to the goals set, one must first define the contexts. The primary objective is to identify the administrative and political factors that influence the implementation process. Identifying the contexts would allow for a better understanding as to how the relevant administrative and political factors apply. For the purposes of this study, administrative factors will relate to organizational structure and capacity. Politics plays an equally important role in policymaking in conjunction with organizational culture.

Implementation policy is context specific in that it is dependent on specific issues, goals, and stakeholders related to the problem. How these factors influence the policy's implementation and outcome will be the focus of this study. 


\section{Research Question(s)}

This study examines the following question and sub-questions:

Which administrative and political factors influence living wage implementation and to what extent?

\section{Research Sub-questions}

- How does organizational capacity influence living wage implementation?

- How does organizational culture influence living wage implementation?

- How do stakeholder interests influence living wage implementation?

- Does a deep-rooted, permanent, political commitment exist in support of a living wage in Broward and Miami-Dade Counties? What is the impact of its presence or absence?

- How do grassroots movements influence living wage implementation? 


\section{CHAPTER II}

\section{LITERATURE REVIEW}

This section focuses on defining the terms and theories relevant to this study as well as reviewing literature on implementation. First, the author addresses a need for clarification as to what successful implementation means. Understanding this context is essential if one is to assess the effectiveness of living wage efforts. Second, examinations of the administrative and political factors explain how these factors can play significant roles in living wage implementation. Third, a discussion on New Public Management concepts and Luce's (2004) theory on living wage implementation helps to provide better knowledge of the literature on implementation and organizational theory.

This dissertation frames itself on Daft's (1998) definition of an organization where an organization is a social arrangement linked by its internal components (departments, workers, and so forth) and common goals and priorities to address the demands of its external environment. When discussing the organization, the concept will pertain to an organization's structure, goals, personnel, culture, and capacity. Even as the concept of sub-organizations arises, these would follow the same properties as a general organization would. Sub-organizations are entities within organizations specialized to manage particular issues that allows the larger organization to accomplish its objectives. An example of these sub-organizations would be the different agencies and departments that make up a government hierarchy.

\section{Policy Implementation}

Brewer and deLeon (1983) state that defining implementation can be relative. Put into a problem-solving context, implementation is a linear step in a rational model 
designed for initiating, planning, implementing, and evaluating a strategy to address a problem. (Brewer and deLeon, 1983) According to Pressman and Wildavsky (1973), policies also imply theories. Therefore, a chain of causality would determine if the initial condition representing $(\mathrm{X})$ would eventually produce the desired outcome $(\mathrm{Y})$ by means of implementing the policy. This is what makes implementation critical since the application of such a treatment to a problem determines the likelihood of accomplishing an outcome. Successful implementation results from addressing a particular issue through policy while achieving desired results in the process. It consists of accomplishing goals and/or objectives by utilizing clear orders to outline organizational roles and responsibilities. These orders must take into account the organization's capabilities as well as how workers in lower hierarchical levels would apply the policy. However, as part of this study, the additional goal is to understand how the driving administrative and political factors discussed would influence the implementation of living wages.

In regards to living wages, the compliance rate set by the amount of contractors adhering to the provisions of the ordinance is the primary measure of success for implementing a living wage. For example, Broward and Miami-Dade Counties claim that $100 \%$ and about $90 \%$ of their contractors respectively pay their employees living wage rates on a consistent and timely basis, post information regarding the ordinance visible to employees, and provide health benefits when applicable. These actions combined define contact compliance in Broward and Miami-Dade Counties. 


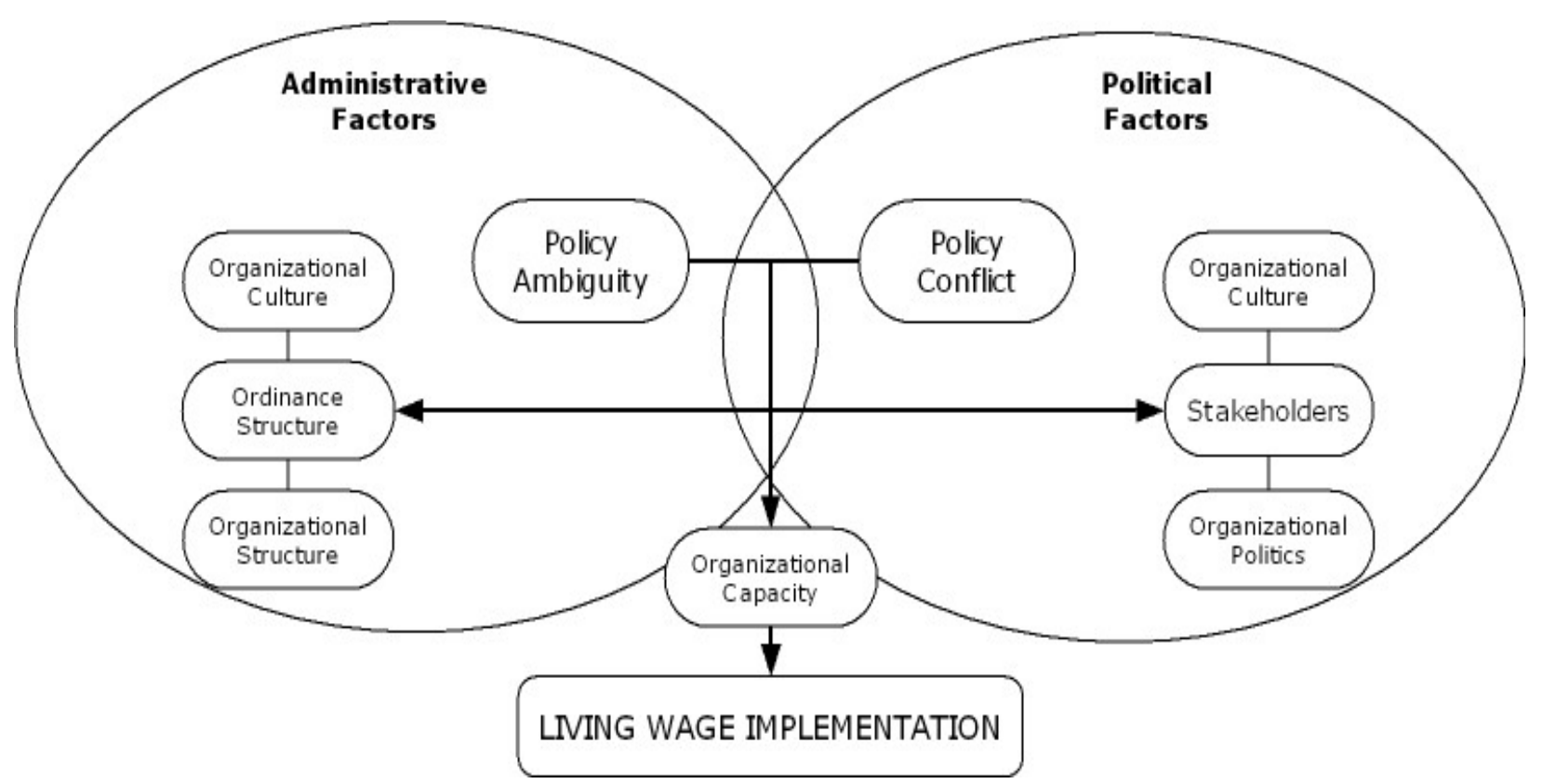

Figure 1 - Living Wage Implementation Drivers

However, Van Meter and Van Horn (1975) state that implementing a policy is more challenging than one might believe given the level of complexity involved during the process. Specifically, policy implementation consists of diverse administrative and political factors that can support and/or hinder the execution of a plan. Figure 1 illustrates how each of these factors would apply to living wage implementation upon passage of legislation.

Consistent with prior research in this area states that policy conflicts and ambiguities influence living wage implementation efforts. (Luce, 2004) Matland (1995) defines policy conflict in which actors have incompatible views on how to define and carry out goals. The less conflict, the greater the possibility for successful implementation. Policy ambiguity refers to a vagueness of either goals and/or means. However, Matland (1995) states that the clearer the goals and/or means are the more susceptible they are to conflict. This relates to the idea that ends and means are rarely agreeable by most stakeholders. 
Ambiguity can make roles and responsibilities unclear, as well as the level of involvement by each stakeholder.

Brewer and deLeon (1983) also state that politics and ambiguity complicate matters by interfering with the implementation process. For scholars like Brewer and deLeon and Van Meter and Van Horn (1975), implementation consists of meeting desired goals through rational, controlled, and/or scientific processes. These authors support the idea of strict protocol and control among events, individuals, and resources dedicated towards implementing a policy. Policy ambiguity and conflicts force policymakers to deviate from their original course of action. Strong administrative control would help to regulate the effects of policy ambiguities through clear organizational roles, structural design, and worker compliance. In addition, open communication and clear policy objectives would also help to limit political influences on policymaking.

Conversely, Bardach (1977) states that the implementation process is a game of bargaining and negotiations in response to unknown conditions and circumstances. Under ambiguous situations, stakeholders use their power to collect as much control as possible to ensure the policy's outcome accommodates most to their favor. While Pressman and Wildavsky (1973) disagree and argue that politics is a minor factor in implementation, Boleman and Deal (2003) state that politics is an integral component for most organizational operations. Rather than trying to eliminate politics from the implementation equation, the best course of action is to accept it and manage it as best as possible. Contrary to the belief that politics encourages inefficiency and corruption, Boleman and Deal mention that it actually provides an opportunity for innovation and 
competition. Regardless whether politics is a positive or negative influence, it plays an important role in policymaking.

Lipsky (1978) admits that a rational, administrative approach is actually how policy implementation should occur; however, there are circumstances when a "street-level" perspective would be more effective. Even when basing implementation on a worker's discretion, policymakers should take those delivering the policy into consideration when planning. Success depends on how they apply the policy themselves. This means that those working to deliver the policy are the focal point of implementation.

Matland (1995) states that a workforce facing implementation challenges firsthand must do what is necessary as long as it remains consistent to the prescribed goals. However, the critical juncture separating both viewpoints occurs when workers begin to think and act for themselves. At this point, the instance when workers act independently would depend on the degree of policy conflict and ambiguity. Increased conflict and ambiguity result in workers using more discretion in accomplishing its objectives. In the case of living wages, the lack of clarity would present the opportunity for contractors not to comply with the ordinance. Matland believes that rules and regulations can limit the effects of ambiguity. Nevertheless, he supports the idea that the right balance of bargaining and central authority can help to control both conflict and ambiguity depending on the situation.

\section{Organizational Capability/Capacity}

Aside from conflicts, politics, and administrative control, organizational capability is also a critical factor to consider when defining implementation. Ulrich and Lake (1990) state that organizational capability relating to an organization should be flexible to adapt 
quickly to different internal and external threats. Flexibility, or lack thereof, by the organizational structure would play a significant role in successfully dealing with both types of threats. Other constraints are staff sizing and training, as well as political influences. The purpose for understanding the capabilities of an organization is to know what its strengths and limits are. Doing so not only allow managers to handle resources efficiently, but also set feasible goals based on the organization's capacity and time available. Figure 2 illustrates a model by Horton, et. al (2003) demonstrating how organizational capacity affects organizational performance. Technological, economic, cultural, and other managerial constraints limit an organization when implementing a policy. How an organization manages its capabilities to reach a goal determines its success and effectiveness.

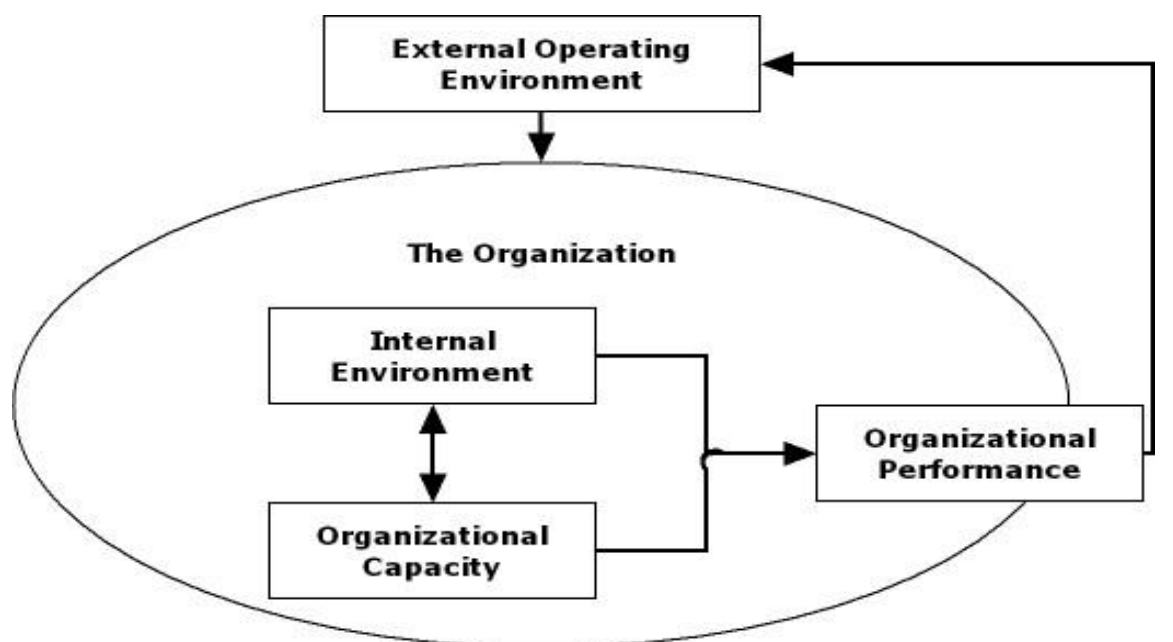

Figure 2 - Organizational Capacity Effect on Organizational Performance

How does this apply to living wage ordinances? By passing a living wage ordinance, the public's expectation is for the jurisdiction to effectively enforce, monitor, and evaluate its progress. In most cases, elected officials pass the legislation and then shift responsibility through the bureaucracy for implementation. Rules and regulations 
delineate how orders pass from administrators to lower departments to execute. That said, living wages require an implementation process consisting of clear and strict administrative controls for developing the ordinance and outlining roles and responsibilities during its execution. However, Ulrich and Lake (1990) state that a situation having policy conflicts and/or ambiguities provide workers more discretion as how to carry out their tasks. No approach can be effective if it is not within the capacity of the organization to incorporate it in the first place.

For living wages, one threat to organizational capability is the lack of resources dedicated to their implementation. This is a circumstance noted in living wage implementation efforts as explained by Luce (2004). Even as policies are developed, there are no guarantees that the resources would be available to carry them out especially if those able to provide the resources do not support the policies themselves. As Luce (2004) mentions, in some cases, policymakers preferring to see the living wage fail would allow the ordinances to be passed and not provide the necessary resources - a result of a resistant organizational culture.

Political influences in this case would play a negative role in the living wage implementation culture because of a lack of political commitment. Administrators would be prone in cases to delay policy decisions, provide minimal enforcement, neglect to monitor and enforce, and/or remain accountable to the policy's success or lack thereof. As to why this would occur, Tullock (1965) and Downs (1967) suggest that bureaucrats tend to utilize their own self-interest at times to administer a policy. In addition, Downs (1967) mentions that a bureaucrat's personal goals could also interfere by establishing the amount of responsibility one would be willing to accept over implementing such a policy. 
Combinations of these factors without internal organizational checks or external stakeholder pressures limit the living wage's effectiveness.

To implement a policy successfully, there is a need for a rational approach at the core of the process to provide a structured and organized method of decision-making. Bowsher (1985) and Daft (1998) believe that a rational model for effective and efficient policymaking and implementation should consist of the following five components:

- Defining the goal/objective - Daft (1998) mentions that one must properly identify goals or objectives before taking further steps. Identifying them would allow policymakers to decide on the appropriate course(s) of action in anticipation to potential challenges during implementation.

- Planning - Bowsher (1985) describes this step as systematically sifting through alternatives to determine the best approach to address the problem. It is also the point where personnel and objectives are clearly drawn and tied together. Daft (1998) identifies this step as developing and evaluating the alternatives through statistical techniques or prior personal experiences.

- Budgeting - As mentioned, resource allocation is critical for the success of any policy. At this point, one must identify the necessary funding, personnel, and technology while developing a plan to ensure their availability when required. Bowsher (1985) believes that this is required in addition to justifying their purpose to allocate the right resources to implementing the policy correctly.

- Execution - With a course of action determined and the necessary resources allocated, one then carries out the policy. Daft (1998) mentions that the monitoring phase begins during implementation to evaluate its effectiveness 
eventually. Also, Bowsher (1985) states that the purpose of identifying roles and objectives in the planning phase is to monitor them during implementation.

- Evaluation - Bowsher (1985) states that the purpose of designing a policy "roadmap" is to hold those accountable to the objectives assigned to them. In this phase, one identifies the strengths and weaknesses of the entire process and develops solutions to improve the policy.

Figure 3 illustrates how each step relates to each other and how the rational process is cyclical in nature. Daft (1998) mentions that the rational approach is a continuous process wherein an organization must assess the effectiveness of the policy and identify areas for possible improvement. This is part of a learning process the organization must partake to improve its policies. Senge (1990) states that an organization should strive to learn from its actions in order to meet future demands and changes. It is a collective effort that goes beyond an organization's continued evolution, but that of human intelligence itself.

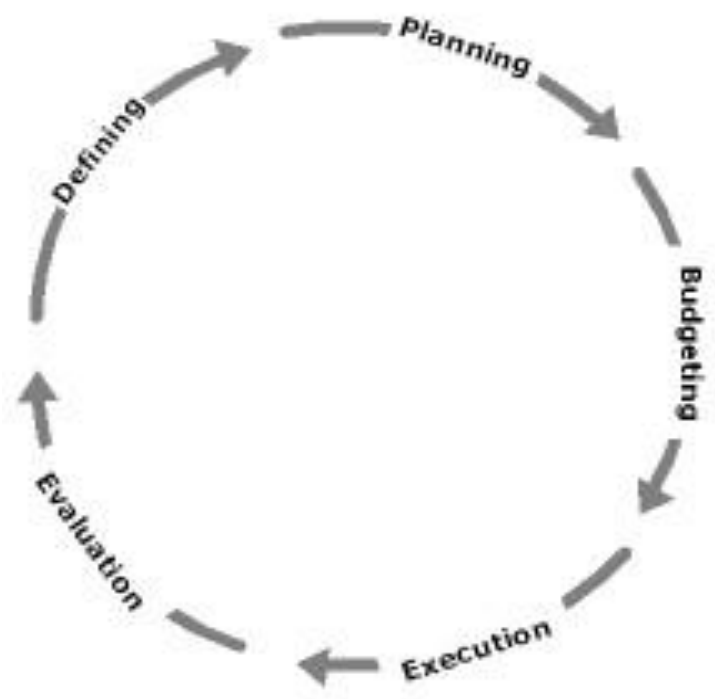

Figure 3 - Rational Management Process 


\section{Administrative Factors}

This section examines the administrative component of implementation, its fundamental factors, and approach. To begin with, an organization's structure serves as a foundation illustrating how divisions of labor are developed and managed. By delegating authority to subordinates, it details roles and responsibilities downward through the hierarchy to execute a policy.

\section{Organizational Structure}

Boleman and Deal (2003) define organizational structure as "a blueprint for formal expectations and exchanges among internal players (executives, managers, employees) and external constituencies (customers and clients).” (p. 46) It is essentially the fundamental instrument for an organization to achieve its desired outcome. Weber (1946) envisioned organizational structure as a means for managing power and accountability. The authority that emerges from this type of structure establishes specific rules and procedures for subordinates to adhere to for establishing control within the organization and minimize political hurdles. Burns and Stalker (1961) mention that structure can support an organization in a stable environment in the following ways:

- Specialized differentiation of functional tasks

- Vertical interaction - superior to subordinate

- Precise definition of roles, responsibilities, and procedures to each functional role

- Reinforcement of hierarchical levels from higher levels

- Chain of command where decisions are made by supervisors only

- Loyalty and faith in supervisors by subordinates

One purpose of an organizational structure is to standardize processes based on clarity and understanding amongst every level within the organization thus allowing for an effective managerial approach to link policies with organizational action. Hummel 
(2008) supports Weber's idea and states that the purpose of organization and information sharing is to distinguish simple actions from rational organized action. The difference is that through rational, organized action, one understands how it relates to a goal or objective. Understanding one's role would allow for better productivity in the end. Taylor's (1916) idea of scientific management utilizes a well-organized structure with hierarchical levels of authority that would allow the organization to perform at optimal levels. Therefore, it would represent the most efficient design intended to coordinate systematically all organizational efforts to a common purpose.

While Weber (1946) argues that the bureaucratic structure, like Taylor's (1916), is the most efficient organizational model available, hierarchies of authority bring about promise that a properly structured organization can optimize its effectiveness. As Mintzberg (1979) mentions, a hierarchy of authority develops as organizations become more complex. It evolves from managers to workers outlining roles and responsibilities. Moreover, Jacques (1990) believes that hierarchies create a system that would allow organizations to infuse accountability, allowing workers to stake claim to the products and services produced. Its intention is to maximize knowledge and skill as it relates to the complexity of the work accomplished. However, the effective way to apply authority is to focus on the ends more than the means.

Contrary to Weber's (1946) and Taylor's (1916) arguments, Blau and Scott (1962) argue that tasks should flow through guidelines and suggestions and not as orders to give workers the needed flexibility to do the task while remaining within the desired control of those higher in the organization. Follett (1926) mentions that providing workers with this flexibility would grant them a sense of empowerment that would ensure greater 
productivity and efficiency. This establishes some limitations on structure itself that would allow for some flexibility in cases when internal and external environments shift rapidly.

Luce (2004) mentions that accountability is an important factor usually missing in implementation. Accountability is applicable to living wages from an internal and external organizational perspective. Externally, contractors must comply with the ordinance and provide applicable employees with the living wage. Internally, organizations expect their administrators to fulfill their roles meaning that contract administrators should monitor contractors; living wage advisory members are to oversee the implementation process and report their status to commissioners; commissioners are to allocate the necessary resources to departments to fulfill their roles as expected. As a result, an organization instituting a sound structure emphasizing clear and simple methods of control, communication, and accountability is essential for policy implementation success.

For this to occur, a rational approach towards implementation is necessary for an organization to function appropriately. However, implementation does not occur on its own. It is necessary to have a policy in place beforehand with clear goals and means to apply it.

Van Meter and Van Horn (1975) identify six components to effective implementation. These components relate to the rational models provided by Daft (1998) and Bowsher (1985):

- Healthy environment supporting actors and the implementation process

- Incentive for actors to carry out the implementation

- Formal structures and procedures 
- Policies representing goals and purpose

- Committed implementation performance

- Feedback on policies and performance

A strong culture and healthy environment supporting these components would limit the politics and ambiguity capable of opposing the implementation process from its intended purpose. Assuming the necessary commitment to implement the plan was available, clearly outlined schedules and procedures would help to ensure everyone understood their role and purpose. This coincides with Weber's (1946) idea that clarity allows for more commitment and participation by workers, thus increasing an organization's overall level of performance. Lastly, feedback is critical not only for the final evaluation of the process, but also its continuous monitoring. Periodic evaluations during implementation are essential in order to spot problems in their early stages.

There are several factors for the implementation process critical to simplifying the procedure: (1) a capable staff to carry out the policy; (2) hierarchical control; and (3) open communications. Overall, administrators at the top of an organizational hierarchy should be capable of making decisions and entrust their subordinates to carry their directives into action. However, even if workers faithfully adopt the directives, Van Meter and Van Horn (1975) believe that managers should monitor the implementation progress closely. Palumbo, et al. (1984) acknowledge that superiors are somewhat disconnected from the lower levels of an organization's hierarchy. Trusting workers to implement a policy as expected relies mainly on the regulations in place rather than the subordinates themselves. There is a need for transparency not only in the directives handed down, but also in the feedback to decision-makers by participants throughout the 
organization and external stakeholders. This allows for better understanding all-around and the likelihood of a stronger implementation process because ambiguity is limited.

\section{Political Factors}

This section focuses on the political component of the administrative/political dichotomy. It aims to examine the dynamics of politics and organizational theory as to how negotiations and bargaining can serve as a critical component during implementation. To begin with, an explanation on organizational politics outlines the potential effects on organizational decision-making. The following section dispels the negative typecast relating to how politics hinders implementation when in fact it can offer the potential for flexibility and innovation. Second, the discussion on organizational culture and stakeholders helps to define the concepts and examine their abilities to influence policies.

\section{Organizational Politics}

Organizational behavior is the result of the confluence between two or more parties. This is contrary to the beliefs of those favoring an administrative approach based on authority and compliance. In fact, the administrative perspective is viewed as being naïve and unrealistic from the political perspective. Politics result from having scarce resources where two or more parties share a common interest. Mintzberg (1983) mentions that there are five bases of power aiming to control (a) a resource, (b) a technical skill, (c) knowledge, (d) authority to control, and (e) access to these four. Each

of these bases of power represents a conflict for a limited resource or advantage one party might have or want over another. Nevertheless, these conflicts can be a necessary and healthy component to an organization's effectiveness. Politics can play a negative role 
given its characteristic of being self-serving; however, it does provide a positive influence by creating a positive scenario for networks and communication linkages to succeed. Nevertheless, Boleman and Deal (2003) mention that if the conflict cannot be resolved, the question then becomes how to manage it. Ultimately, the organization would have to act in the interests of those with the most collected power in order to appease the stronger stakeholders.

A fundamental aspect in understanding how organizations operate is first to recognize the influence power has over authority and management theory. Pfeffer (1981) believes there are certain ways in which power can influence an organization. For instance, authority manages to impose values and guidelines on people. Authority is legitimate power once subordinates choose and accept its influence. This explanation simply describes how power influences the organizational decision-making processes. When combining this process with administrative controls, one can have a better rationalization as to how and why organizations act as they do.

\section{Organizational Culture}

Organizational culture defines the nature of an organization. Schein (1992) believes there are two dimensions of organizational culture - internal and external. The internal culture concentrates on integrating needed changes in order to allow the external culture to adapt to environmental changes. From an external perspective, the culture can be multifaceted to reflect the external environment's dynamics. It serves to control behavior and encourage stability in how an organization manages its resources and objectives. At that point, organizational culture can possess a strong influence on both administrative and political components of the policy dichotomy. The culture strength, as Daft (1998) 
states, represents an organizations acceptance or rejection of its organizational values. The stronger the consensus, the more fluidly an organization should operate. Conversely, the stronger the opposition, the more likely the process could run into challenges and potential failure. Overall, organizational culture helps to rationalize how an organization identifies its purpose, develops courses of action, resolves conflicts, and responds to change. It helps to promote consistency and character, however, its reluctance to accept change and diversity can explain why organizations may fail.

Another point to consider is the fact that organizations are capable of having more than one culture. As Trice and Beyer (1993) explain, detailed divisions of labor in large organizations that sub-organizations develop their own subcultures to function properly. Consequently, the larger organization's culture represents all the subcultures combined. Subcultures, like normal organizational cultures, have internal and external dynamics focused on internal integration and external adaptation. In their case, subculture adaptations relate to fulfilling the roles demanded by the larger organization. Similar to regular cultures, subcultures also define the nature of the sub-organization. In fact, even as its primary focus is to work towards the goal of the general organization, how it perceives and manages its tasks can differ from that of the organization. The subculture can diverge from the general culture. That said, how a sub-organization integrates and interacts can be different from other sub-organizations. This means that their interactions and reactions to external factors beyond the general organization can be completely different from how the organization responds. As a result, the administrative and political factors driving each sub-organization can be different and one must recognize these distinctions accordingly. 
The culture defining the external environment also plays a significant role in defining an organization's internal culture, as illustrated in Figure 2. South Florida's economic and political culture, for example, is not conducive to support living wage legislation. As Koven (1999) explains, Southern states, like Florida, tend to support a more conservative, traditional, individualistic budgeting and political culture. This means budgetary and public policies follow a hierarchical system responsive mainly to elites and their interests. For example, Florida is a right-to-work state. This suggests that Florida's economic and political conservative culture might not generate adequate support for living wages to succeed and continuously receive political support. Even if this type of legislation passes, it could be susceptible to inadequate enforcement due to budget policies based heavily on social ties and longstanding business relationships.

South Florida also has an extensive history of mismanaged social programs in which political cronyism diverts most benefits to elites rather than to those originally designed to help. In 2007 alone, the Miami Herald exposed the Miami-Dade County Housing Agency and the Miami-Dade Empowerment Trust for questionable contracting practices, cronyism, and failed to assist the projects actually intended. In fact, Miami-Dade County recently surrendered control of the Housing Agency to U.S. Housing and Urban Development to investigate the extent of the corruption and to develop better ways to ensure the department is effective and accountable. (Pinzur, 2007) The Empowerment Zone has been a major disappointment in the community by failing to meet any of its expectations. Instead, the Empowerment Zone funded pet projects of local officials, failed to attract or maintain businesses in its target area or support the local labor force. (Grotto and Hiassen, 2007) These examples demonstrate that the political culture is not 
entirely conducive to support such socially targeted projects and Miami-Dade County may not support an implicitly redistributive policy such as the living wage.

\section{Stakeholders}

Daft (1998) mentions that satisfying stakeholder groups is one way to measure organizational effectiveness. Stakeholders are any interested and/or affected parties resulting from an organization's policies and/or performance. Pfeffer (1981) points out that to understand the political climate surrounding a policy, one must focus on the stakeholders involved and their influence. He explains that power flows within an organization and those staking a claim to an organization's policy. Mintzberg (1983) believes that internal and external stakeholders play an equal role in determining how an organization acts. Internal stakeholders jockey their positions to maintain their place or move higher in the organizational hierarchy. External stakeholders maneuver to influence the decision-making of an organization in attempts to develop policies in their favor. Figure 2 demonstrates this idea. Luce (2005) states that advocates have the influential power over governments with living wages to promote strict monitoring and enforcement in addition to transparent policy evaluations.

From a living wage standpoint, the stakeholder interests involved complicate the policy implementation process. Since these interests are motivated by distinct political economies, implementing a policy is not as simple as forcing it down an organizational hierarchy. Mill (1863) states that it is human nature for an individual to maximize his/her utility. From a governing perspective, this also relates to both legislators and the public. Downs (1957) argues that legislators would act on the preference of the median voter. 
Since the public is trying to maximize its utility, the public official will side with what the majority of the public wants to increase his/her chances of political victory.

These groups create alliances to consolidate their power and become a stronger force to influence government action. This is evident in most living wage campaigns since they normally begin at the grassroots level. Given Luce's (2004) skepticism concerning government efforts to implement a living wage effectively, the extent to which a community involves itself in the implementation process can help to determine a policy's success. The benefit of a strong community presence is that it can serve as a watchdog overseeing a policy's implementation. Moreover, communities also command an influence over policymaking through "protest politics" where complaint letters and demonstrations serve as effective methods to voice their opinion over government action. In cases where individual voices are ineffective, one could see where the emergence of such alliances and community action would evolve.

\section{Living Wage Implementation}

Roles and responsibilities remain in question since the focus in living wage policy is to pass the ordinance while leaving implementation overlooked. As Luce (2004) mentions, "city councils may pass the ordinances, but support for policy passage is not the same thing as support for enforcement.” (p. 99) While she believes that clear lines of authority and a manageable political environment are needed, a key factor overlooked in living wage implementation is how the "street-level bureaucrats" play a critical role in the process. Luce (2004) explains, "while it is useful to distinguish between the role of the legislators and administrators, the bulk of this research misses one crucial aspect of policy implementation: the role of the community.” (p. 5) 
Luce (2004) asks, "How is it that a policy can be passed with enthusiastic support and then never be implemented?" (p. 95) The factors that lead to living wage implementation failures are a combination of policy ambiguity, miscommunication, incongruent goals, organizational capacity, and failure to commit necessary resources. (Luce, 2004) The administrative effort to draft and pass living wage legislation simply gets the process started. How stakeholders accept the legislation and how far they are willing to participate should be the primary concern. One solution is through strict and consistent penalties compelling contractors to comply, an idea shared by Van Meter and Van Horn (1975). Another would be to have the opportunities for communication and negotiations amongst stakeholders to develop acceptable means and ends to the policy.

New Public Management

Since the 1990's, governments have taken a different approach in providing public services by supporting better customer service, greater accountability, and improved service quality through decentralization, performance measurements, and open competitive bidding processes. The aim was not only to provide better public service, but also to redefine government and closely monitor the policy inputs, outputs, and outcomes that determine how effective and efficient governments actually are. Measuring these factors is critical to an organization's success as well. Joyce (1993) mentions that by properly defining its measures, an organization is capable of accurately assessing its strengths, limitations, challenges, and objectives. Performance measurements serve as motivational tools to encourage organizations to strive to meet performance goals. These concepts not only "reinvented" government management and service provisions, as 
Osborne and Gaebler (1993) explain, but public policymaking as well. (Frederickson and Smith, 2003)

Kettl (2000) provides six core issues that define the New Public Management (NPM) movement. They serve to identify a government's policy mission, role, capacity, and internal and external relationships. These core issues are:

- Productivity - With demands for public services increasing, it is a challenge for governments to provide a consistent level of service with limited resources. Governments are aware of the public pressure more than ever to "do more with less." This calls for an assessment of services and processes to determine better and more efficient practices allowing governments to reallocate resources to provide additional services without sacrificing their current levels of provision.

- Marketization - Governments began to contract their services out to other organizations by utilizing the markets to develop competitive biddings and benchmarking and compelling potential bidders to provide public services. Utilizing scorecard methodologies and other criteria, governments are able to choose objectively the lowest bidding contractor capable of providing the best quality service.

- Service Orientation - Governments have had to implement a more customerfriendly approach in dealing with the public. The aim has been to redevelop the public trust and improve customer satisfaction of public services. Efforts made by governments to determine what the public needs and work towards meeting those goals in addition to serving other public demands is a priority. 
- Decentralization - The intention of decentralizing services is not only to restructure governments by flattening hierarchies and making them more responsive to public demand, but also to create a productive partnership with other organizations in providing public services. In the process, greater accountability placed on contract selections, performance benchmarks, and policy inputs and outputs ensure that services provided are at the best quality and efficiency possible.

- Policy - By becoming more efficient, governments are able to be more successful seeing as strategically allocated resources can address additional public demands while not sacrificing the quality and effectiveness of current policies.

- Accountability - Government must accomplish what they promise to garner the public's trust. There needs to be an emphasis on developing clearer roles, policies, and procedures to make government's overall processes more transparent to the public. The shift would make specific agencies and individuals directly responsible for the success of a policy. In the process, this would help to identify policy strengths and weaknesses better during policy evaluations.

Aside from these core issues, several strategies reflect the NPM ideals suggested by Osborne and Plastrick (2000) that would be applicable to living wage implementation. One goal is to apply greater clarity to policy goals and objectives to simplify processes. Osborne and Plastrick (2000) state that communication and transparency are critical to policy evaluation. Another is to create an incentive-based methodology that allows for greater transparency and competition amongst public, private, non-government 
organizations delivering public services. The following examples briefly explain how performance measurements help to make organizations more effective.

- Competitive Benchmarking - Benchmarking serves as an effective tool to manage a policy or organization strategically. Based on a specific criterion, one can assess strengths and weaknesses and develop best practices to ensure the achievement of the most effective and efficient outcome. Competitive benchmarking relates to comparing several organizations to the criteria set to determine the better organization. Two benefits stand out by doing this. First, organizations clearly understand what their expectations are and they need to plan accordingly. Second, given the competitive nature of the process, organizations are compelled to outperform other organizations in order to gain an advantage. The result is a rational, transparent process developed through systematic planning and evaluation that encourages organizations to perform at their best. Osborne and Plastrick (2000)

- Performance Contracting - A part of the competitive benchmarking process is to develop an agreement with a contractor to perform a service and to meet certain results. The performance benchmarks serve as a measuring tool to determine whether an organization's performance was above, below, or simply average. The benefit of this approach is that top managers are accountable for the organization's performance and meeting the contract's goals. Osborne and Plastrick (2000)

- Employee Suggestion Programs - These are programs where employees have an open line of communication with top administrators to make suggestions to 
improve performance and implement better practices. In some cases, like whistleblower programs, they help to identify improper, even criminal, actions. Living wage enforcement depends heavily on contracted workers reporting if they receive adequate and consistent payment for their labor. However, many refuse to do this out of fear possibly losing their jobs. Ensuring that such programs exist and that workers are safe to notify when a contractor is not complying with the ordinance is critical to the living wage's success. (Luce, 2004)

NPM's goal is for organizations to understand how inputs, outputs, and outcomes formulate a successful policy during which performance measurements would serve as the measuring tool to evaluate an organization's capabilities for success. To implement a policy successfully, there needs to be a clear understanding as to who is involved and to what capacity. There also needs to be a clear delineation of goals, objectives, and procedures to prevent the policy from deviating from its intended course. Another critical component NPM emphasizes is communication and information sharing by all parties involved. The more open the lines of communication are, the better one can assess the challenges, capacities, and effectiveness by each stakeholder to remain successful. In other words, without proper communication there cannot be accurate information that would allow an organization to remain aware of the status of both its internal and external environment. Lastly, organizations must be fully attentive to their strengths and weaknesses (and performance measures would serve as the rational tool throughout the entire process) in order for them to plan their objectives and course(s) of action accordingly. The result is an organization designed to learn from its experiences and those of others in order to improve its service delivery and implementation. 
The ability and willingness for an organization to learn is essential to its development. Cook and Yanow (1993) state that individuals within an organization must first demonstrate the capacity and willingness to learn before the organization has a chance. In other words, the aggregate effect of what individuals learned would represent what the organization learns. Schön (1983) believes that to learn, one must reflect on the problem faced, examine the steps taken to resolve the problem, redefine the problem after post-implementation, and make any necessary adjustments if needed until one solves the problem. This relates to the rational management process discussed earlier, however, the emphasis at this point is that organizations purposely make the effort to understand its past actions to improve on them in the future. However, having individual development equate to organizational learning and developing is a challenge if the organizational culture is not supportive. Cook and Yanow (1993) and Schön (1983) agree that having a culture unsupportive of reflecting on organizational actions would hamper organizational development. To counter such a culture and allow the organization to evolve, Senge (1990) believes that communication is critical to share ideas, express concerns, and allow feedback to travel throughout the organization.

Overall, policy ambiguity and conflict confound and hinder administrators from implementing a policy as effectively and efficiently as possible. The administrative and political factors discussed in this chapter represent stakeholder interests and organizational protocols that reflect in mixed, and at times inconsistent, internal and external organizational cultures that amount to an organization's effort to implement a policy. Applying the New Public Management ideals would allow for more accountability and strategic planning of a policy, however, without communication, an 
organization is not capable of assessing a policy’s progress accurately. Ultimately, a policy's implementation depends on open lines of communication where clearly defined roles and responsibilities, in conjunction with stakeholder input, allow for strategically planned policies meet their intended goals. 


\section{CHAPTER III}

\section{METHODOLOGY}

This chapter provides an overview of the qualitative and quantitative methods employed in this study. Through a qualitative approach, this study examined the relationships and actions influencing the living wage implementation processes of Miami-Dade and Broward Counties. Through a quantitative approach, the survey utilized helped to generalize the case study findings to jurisdictions nationwide. This chapter provides the rationale for each approach. In addition to the comprehensive description of the research design, this chapter examines the dependent and independent variables and survey instrumentation.

\section{Research Question}

The literature review concluded that research is limited in living wage policy. This study examines the following research question to help fill this research gap:

Which administrative and political factors influence living wage implementation and to what extent?

The purpose is to develop a model detailing the complexities of living wage implementation. This study aims to examine the effects administrative and political factors can have on living wage policy. As a result, the sub-questions presented below examine these contexts:

- How does organizational capacity influence living wage implementation?

- How does organizational culture influence living wage implementation?

- How do stakeholder interests influence living wage implementation?

- Does a deep-rooted, permanent, political commitment exist in support of a living wage in Broward and Miami-Dade Counties? What is the impact of its presence or absence?

- How do grassroots movements influence living wage implementation? 
Three theories - Wilson (1887) and Goodnow’s (1900) Administrative/Political Dichotomy, Matland's (1995) Ambiguity/Conflict Matrix, and Luce's (2004) living wage implementation model - were presented in the literature review to serve as foundations for this study's premise in order to help detail the intricacies of living wage implementation. These theories apply to this study's assumptions as such:

- Wilson (1887) and Goodnow (1900) state that a combination of administrative and political factors exist in all facets of public policy decision-making. This study plans to detail these factors and their significance in living wage implementation. For example, Broward and Miami-Dade Counties claim that $100 \%$ and about $90 \%$ of their contractors respectively pay their employees living wage rates on a consistent and timely basis, post information regarding the ordinance visible to employees, and provide health benefits when applicable. However, to expand on the theory, this study intends to show that the more prevalent factors can dictate the implementation approach (top-down or bottomup).

- Matland's (1995) matrix argues that the level of policy conflict and ambiguity determines the effectiveness of administrative and political factors in policy implementation. The greater the level of conflict and ambiguity that arises, the more political the implementation process becomes.

- Luce's (2004) implementation model emphasizes the importance of grassroots movements. The presence of grassroots influence can increase the likelihood of successful living wage implementation; however, their presence and influence tends to diminish as time passes upon an ordinance's adoption. 


\section{Research Design}

Rosenbloom (1995) states the following regarding case studies:

"Case studies of the implementation of reforms can potentially tell public managers what to do and what to avoid; what works and what does not in specific circumstances. They can improve understanding of the changes that are under way. Cases may also help the field to frame concepts, theories and research in ways that advance systematic knowledge about public administration." (p. 44)

The evaluation of policy implementation can be context-specific. Yin (1994) explains that case studies serve best to answer "how" and "why" questions regarding the situation being examined. The case study approach incorporated for this study examines the administrative and political contexts of implementing a living wage in Miami-Dade and Broward Counties.

A qualitative approach is applicable to examining policy implementation emphasizing the contexts involved. As the literature review explains, the contexts to which policy implementation must adhere to can determine the course of action and ultimate outcome. Matland's (1995) matrix can explain the degree of policy conflict and ambiguity based on the implementation situation at hand. The aim is to emphasize the importance of analyzing contextual categories and variables to understand living wage implementation at a greater depth.

Specifically, qualitative studies concentrate more on complex interactions and relationships than quantitative methods do. Qualitative methods seek to understand the intricacies that make cases unique while quantitative methods focus on how to generalize to larger populations. This demonstrates that both methods have their strengths and weaknesses. (Ragin, 1987) Nevertheless, Yin (1994) states that what dictates the 
methods of choice depend on the research question(s). Given that this study intends to identify significant factors that influence policy implementation and how they relate to each stakeholder, a case study design is the most applicable approach to achieve this.

A benefit of case study research is the rich and detailed data it is capable of collecting and analyzing. However, a limitation case studies have is the poor ability to generalize results to a larger population. Different variables are attributable to a phenomenon beyond what a single case study might be able to examine. Therefore, drawing comparisons through surveys on how both Counties, as well as jurisdictions nationwide, apply similar ordinances would increase the significance of the findings.

The objective here is to simplify the complexities resulting from the holistic approach of case studies while still managing to induce causality. In other words, since they reinforce each other, qualitative studies gather support through quantitative analysis and vice versa. As Ragin (1987) states, quantitative and qualitative research methods can achieve one objective, but hardly ever both. The case-oriented strategy incorporating qualitative measures attempts to interpret contextual factors to explain a particular phenomenon. The variable-oriented strategy utilizing quantitative methods dissects cases into variables for the sake of testing hypotheses for a general population. Ragin (1987) proposes a combination of both that would utilize each strategy's strengths in order for case study findings to be more wide-ranging.

\section{Site Selection}

There are several reasons for the selection of Miami-Dade County. First, the County has had its ordinance in place for eight years. Second, the Living Wage Commission overseeing the implementation efforts indicates that the County is committed to ensuring 
the ordinance's proper enforcement. Luce (2004) notes that the County has taken an expansive effort in its implementation process by having an oversight committee and attentiveness to payroll audits of contracted businesses. Third, the County currently has over 300 open living wage-applicable contracts that affect thousands of workers throughout Miami-Dade. These facts demonstrate that the living wage ordinance is an established law that has the potential of making a strong impact on the local community and its economy.

Broward County's selection regarded its proximity to Miami-Dade County and for other reasons. Broward implemented its ordinance in 2002 and relied heavily on MiamiDade County when developing its ordinance and implementation plan. Broward County also handles a fraction of the number of contracts that Miami-Dade County does (roughly 60). There are also differences in the political climates in each county given the number of living wage contracts and efforts by external stakeholders to influence the policy's implementation. Still, their similarities (and differences in some cases) in policies, presence of advisory boards, and implementation plans, and to Miami-Dade County made Broward County a practical jurisdiction to compare and contrast.

\section{Qualitative Analysis}

Yin (1994) suggests that one follow a structured approach when developing a case study incorporating interviews, participant observations of events and interactions, as well as the collection and content analysis of relevant archival documents. Janesick (2000) states a similar point in that a systematic approach to collecting and analyzing data is essential for a rigorous qualitative study. In essence, what both Yin (1994) and Janesick (2000) are proposing is that a solid case study should consist of a triangulation 
of data collection methods. The purpose of triangulation is to strengthen a study's findings by utilizing several methods or data sources to arrive at the same conclusion. As Padgett (1998) states that triangulating research methods adds to the credibility of the eventual findings given that the approach benefits from the strengths of the methods utilized. Patton (1993) adds that it also helps to test for consistencies in the data collected and aids in curtailing the effects of validity threats as further explained below. The result produces a more rigorous study that addresses the limitations of its methods by complimenting it with the strengths of others. That said, this study triangulates data sources by conducting interviews, participant observations, and examination of County records - one of the more applicable and commonly used triangulation approaches according to Patton (1993). The following explains these methods, their purpose, and their application in regards to this study:

- Interviews - Lofland and Lofland (1984) note that interviews are a valuable qualitative research source of information. Interviews will be the main qualitative data collection approach for this study. The benefit of interviewing is that one has greater control over the data collection. (Padgett, 1998) This study's goal is to interview administrators from both counties involved with implementing the living wage to generate a direct perspective as to the critical challenges and relationships influencing how decisions and actions take place within the County governments. Conversely, there were interviews conducted with local labor activists and other stakeholders to develop the external perspective.

- Participant Observation - Lofland and Lofland (1984) state that observations consist of "the interweaving of looking and listening." Living wage commissions 
for both counties conduct monthly meetings in conjunction with several County departments to discuss pressing living wage matters such as violations, legislation, and resident and business concerns. Moreover, both county commissions occasionally discuss living wage issues in their meetings. In keeping with Yin's (1994) case study principles, there was no obtrusive participation conducted in both cases. These observations will consist of attendance as these meetings and informal interviews with government officials and contractors. Padgett (1998) states that the benefit of directly observing a case is to "capture all of the nuances" and collect rich data from different perspectives. (p. 66)

- Archival Records - Patton (1993) states that to understand the context of an organization's actions, it is important to examine its history. With contexts playing such an integral role in case studies, historical analysis is required. Archival records, such as past meeting minutes, memos, and other data, provided a historical perspective that will help to develop a fuller understanding of how each county has responded in implementing its living wage ordinance.

In addition to the research question, Table 3-1 outlines the supporting questions relating to the factors examined. The aim is to develop a better understanding as to how these factors play roles in the implementation efforts by each county and why.

Table 3-1 - Qualitative Factors of Interest in Living Wage Implementation

\begin{tabular}{ll}
\hline \hline Factor & Question \\
\hline \hline Policy Ambiguity/Conflict & $\begin{array}{l}\text { How does policy ambiguity and conflict influence } \\
\text { policymaking? }\end{array}$
\end{tabular}


Table 3-1 (continued) - Qualitative Factors of Interest in Living Wage Implementation

\begin{tabular}{ll}
\hline \hline Factor & Question \\
\hline \hline Symbolic Implementation & Does this apply to living wage implementation? \\
Organizational Culture & What role does this play overall in the implementation \\
& process?
\end{tabular}

Stakeholders How do they influence government action?

Organizational Politics How do politics factor into the decision-making process?

Organizational Capacity How could limited funding and personnel affect how each county implements the living wage?

Quantitative Analysis

A survey administered to jurisdictions nationwide implementing living wage ordinances aimed to assess how other jurisdictions apply their own living wage ordinances and the factors they face in comparison with the findings provided in the case studies. While case studies examine the complexities of dynamics derived from qualitative research, surveys provide researchers with the ability to generalize their findings to larger populations. Fowler (2002) believes that surveys are especially useful in conducting unbiased sampling and standardized measurements. An unbiased sampling would ensure the validity of the data as to how precise the results would represent the population as a whole. Standardized measurements would make certain that the information and measurements were consistent amongst all respondents. Overall, surveys are capable of collecting additional information that qualitative methods perhaps could not do as effectively. 
As mentioned, the foundation of policy analysis depends on the applied contexts. As a result, a critical goal is to define the constructs applying to living wage implementation.

That said, Table 3-2 presents the independent variables that define the constructs.

Table 3-2 - Independent Variable Definitions and Constructs

\begin{tabular}{|c|c|c|}
\hline Construct & Ind. Variable & Definition \\
\hline \multirow[t]{5}{*}{ Policy Ambiguity } & Language Clarity & $\begin{array}{l}\text { The degree of clarity in the ordinance's } \\
\text { language }\end{array}$ \\
\hline & Loopholes & $\begin{array}{l}\text { The effect loopholes have on the } \\
\text { implementation process }\end{array}$ \\
\hline & Policy Ambiguity & Degree ambiguity leads to political challenges \\
\hline & Policy Clarity & $\begin{array}{l}\text { Administrative orders are clear to those } \\
\text { enforcing and monitoring the LWO }\end{array}$ \\
\hline & LWO Understanding & $\begin{array}{l}\text { The degree to which contractors understand } \\
\text { what is expected of them }\end{array}$ \\
\hline \multirow[t]{4}{*}{ Policy Conflict } & Resistance & $\begin{array}{l}\text { Degree of resistance by contractors to } \\
\text { changes to the LWO }\end{array}$ \\
\hline & Policy Conflict & $\begin{array}{l}\text { Degree to where contractors are usually at } \\
\text { odds with LWO regulations }\end{array}$ \\
\hline & Exploiting Loopholes & $\begin{array}{l}\text { The extent to which contractors would go } \\
\text { to exploit loopholes in the LWO }\end{array}$ \\
\hline & Information Sharing & $\begin{array}{l}\text { The extent to which contractors would } \\
\text { inform their employees about the LWO }\end{array}$ \\
\hline \multirow[t]{4}{*}{ Stakeholders } & Elected Officials & $\begin{array}{l}\text { The level of influence elected officials have } \\
\text { on the implementation process }\end{array}$ \\
\hline & Contractors & $\begin{array}{l}\text { The level of influence contractors have on } \\
\text { the implementation process }\end{array}$ \\
\hline & Grassroots & $\begin{array}{l}\text { The level of influence grassroots leaders } \\
\text { have on the implementation process }\end{array}$ \\
\hline & Bureaucracy & $\begin{array}{l}\text { The level of influence county officials have } \\
\text { on the implementation process }\end{array}$ \\
\hline
\end{tabular}


Table 3-2 (continued) - Independent Variable Definitions and Constructs

\begin{tabular}{|c|c|c|}
\hline Construct & Ind. Variable & Definition \\
\hline \multirow[t]{10}{*}{$\begin{array}{l}\text { Org. Culture } \\
\text { (Information) }\end{array}$} & Improvements & $\begin{array}{l}\text { Level of commitment to address LWO } \\
\text { policy errors and shortcomings }\end{array}$ \\
\hline & Information Access & $\begin{array}{l}\text { Degree to which information can be } \\
\text { accessed or shared }\end{array}$ \\
\hline & Sufficient Data & $\begin{array}{l}\text { The amount of data collected meeting the } \\
\text { jurisdiction's needs }\end{array}$ \\
\hline & Stakeholder Input & $\begin{array}{l}\text { The amount of input all stakeholders have } \\
\text { in the implementation of the LWO }\end{array}$ \\
\hline & Consistency & $\begin{array}{l}\text { Enforcement is constant regardless of } \\
\text { vendor }\end{array}$ \\
\hline & $\begin{array}{l}\text { Penalties for Repeat } \\
\text { Offenders }\end{array}$ & $\begin{array}{l}\text { The degree to which penalties increase for } \\
\text { repeat offenders }\end{array}$ \\
\hline & $\begin{array}{l}\text { Proportionate } \\
\text { Penalties }\end{array}$ & $\begin{array}{l}\text { Severity of penalty is relative to the } \\
\text { significance of the violation }\end{array}$ \\
\hline & Investigations & Violations investigated in a timely manner \\
\hline & Timing of Penalty & Timing of penalties after adjudication \\
\hline & LWO Waivers & $\begin{array}{l}\text { Extent vendors try to obtain waivers } \\
\text { exempting themselves from the LWO }\end{array}$ \\
\hline $\begin{array}{l}\text { Organizational } \\
\text { Capacity }\end{array}$ & Staffing & Sufficient staff to manage the LWO \\
\hline Funding & & $\begin{array}{l}\text { Adequate funding dedicated towards } \\
\text { implementing the LWO }\end{array}$ \\
\hline \multirow[t]{2}{*}{$\begin{array}{l}\text { Organizational } \\
\text { Politics }\end{array}$} & Political Support & $\begin{array}{l}\text { Degree elected officials supported passing } \\
\text { the LWO, but not its implementation. }\end{array}$ \\
\hline & Political Influence & $\begin{array}{l}\text { The degree to which politics interferes in } \\
\text { the implementation process }\end{array}$ \\
\hline
\end{tabular}




\section{Instrumentation}

Interviews conducted from January to August 2006 focused on key administrative personnel from Miami-Dade and Broward Counties. These respondents consisted in Miami-Dade County of senior-level administrators in the Department of Business Development and the Department of Procurement Management, Living Wage Commission members, and the contract compliance officers. In Broward County, the respondents consisted of Living Wage Advisory Board members, senior-level administrators in the Purchasing Division, contract administrators, and department directors whose departments played vital roles in the implementation of the LWO. Meetings with administrators in both counties helped to provide the internal administrative perspective to understand the process necessary to manage a living wage. The information collected from advisory board members served to develop the external and/or grassroots perspective. Many, if not all the members on each county's advisory boards identified themselves as living wage advocates, business owners, and generally concerned residents who were concerned to see the ordinance succeed in their counties. Overall, 29 interviews were conducted (16 in Miami-Dade County and 13 in Broward County).

The author taped the interviews requested each respondent to sign a consent form (Appendix D). Only two respondents preferred not to participate in taped interviews. Upon completing the interviewing phase, the author transcribed and coded each interview. As Patton (2002) mentions, coding is essential to organize and classify data into a framework. Overall, coding proved to be useful in preserving accurate details from 
the interviews and identifying trends amongst respondents to various questions and it was these trends that helped develop the basis of the survey administered.

Table 3-3 - County Administrator Interview Questions

\begin{tabular}{|c|c|}
\hline Area of Focus & Interview Questions \\
\hline \multirow[t]{2}{*}{ Defining Success } & Define "successful implementation." \\
\hline & Do politics play a part in your work? How so? \\
\hline \multirow{4}{*}{$\begin{array}{l}\text { Contract } \\
\text { Compliance }\end{array}$} & Define "contract noncompliance." \\
\hline & $\begin{array}{l}\text { How do you resolve noncompliance? Explain your approach to } \\
\text { monitor and enforce the living wage. What do you particularly do? } \\
\text { Provide examples. }\end{array}$ \\
\hline & What is the cause of noncompliance? \\
\hline & What is the strategy to correct this? Do you support your strategy? \\
\hline \multirow[t]{4}{*}{ Work Experience } & How long have you been a part of the implementation process? \\
\hline & Explain your relationship with co-workers and other departments. \\
\hline & What are your challenges to fulfilling your obligation to the LWO? \\
\hline & $\begin{array}{l}\text { What do you think of the following statements? } \\
\text { "Project managers are to blame for this." } \\
\text { "Enforcement is too lenient." } \\
\text { "Not enough is being done." } \\
\text { "We need more dedicated staff." }\end{array}$ \\
\hline
\end{tabular}

Work Experience Is staff turnover an issue?

Ambiguity \&

Conflict / Org.

Culture

How clear is the language in the ordinance?

How well does the county understand the factors it needs to address?

How clear are the ordinance provisions to contractors?

How much weight does the ordinance have in the contracting process? 
Table 3-3 (continued) - County Administrator Interview Questions

\begin{tabular}{ll}
\hline \hline Area of Focus & Interview Questions \\
\hline \hline & How committed is the county to implementing the living wage? \\
Org. Capacity & How does this play a role? Are there any limitations? \\
\hline
\end{tabular}

Table 3-3 presents the interview questions posed to county administrators. Table 3-4 does the same for living wage advisory board members. While both groups were asked similar questions, the questions differed somewhat given that both groups represent different aspects of the implementation process. For instance, advisory board members are mainly responsible with overseeing the implementation of the ordinance while county administrators are mainly responsible for monitoring and enforcing the ordinance on contractors. The aim is to develop different perspectives from both groups on the ordinance's implementation.

Table 3-4 - Living Wage Advisory Board Interview Questions

\begin{tabular}{ll}
\hline \hline Area of Focus & Interview Questions \\
\hline $\begin{array}{l}\text { Defining Successful } \\
\text { Implementation }\end{array}$ & Define "successful implementation." \\
& What are your challenges in implementing the ordinance? \\
& What are the strengths of your implementation approach? \\
& Describe your relationship with your commissioner. \\
& What else could there possibly be done to improve the approach? \\
& $\begin{array}{l}\text { Do you agree or disagree with the way the County is organized to } \\
\text { Org. Structure }\end{array}$ \\
implement the ordinance? \\
$\begin{array}{l}\text { Org. Capacity } \\
\text { Compliance }\end{array}$
\end{tabular}


Table 3-4 (continued) - Living Wage Advisory Board Interview Questions

\begin{tabular}{ll}
\hline \hline Area of Focus & Interview Questions \\
\hline \hline & Describe the relationship with the contractors. \\
& Describe the efforts currently taken to improve compliance. \\
Stakeholders & $\begin{array}{l}\text { Are there any groups or individuals of the county/contractor } \\
\text { relationship that play a role in how the policy is implemented? }\end{array}$ \\
& Are they supportive or obstructive? \\
Ambiguity \& Conflict & How clear is the language in the ordinance? \\
/ Org. Culture & How well does the county understand the factors it needs to \\
address? & How clear are the ordinance provisions to contractors? \\
& How much weight does the ordinance have in the contracting \\
process?
\end{tabular}

A standardized open-ended interview approach allowed respondents to detail their experiences and assessments of implementing a living wage ordinance. Bickman and Rog (1998) state that standardizing interview questions and techniques are essential to have uniformity in the data collected and validity to the study's results. Patton (2002) also mentions that grouping questions into particular topics helps to provide more structure to the interview and allows the respondent to concentrate more on the topics at hand.

The author conducted the survey from June to October 2006 (Appendix B) and contacted each jurisdiction listed by ACORN on its living wage website (http://www.livingwagecampaign.org) by phone and/or email to participate in the survey. 
For those reached, each jurisdiction participated online through a website provided by the author. Overall, 87 of the 118 jurisdictions were contacted (eight ordinances had been repealed or overturned ${ }^{3}$ and 23 jurisdictions could not to be reached). Of those 87 jurisdictions, 45 responded to some degree. Of the 45 respondents, 12 specifically requested not to participate in the survey. This is a systematic pattern included into the final analysis. In addition, there were six cases removed for providing incomplete information thus leaving the sample size at 27 cases and the response rate at $31 \%$. This is an acceptable sample size given the population and accuracy percentage of 50\%. (Weiss, 1999) Chapter 6 explains the specifics on the survey instrument in further detail.

\section{Reliability and Validity}

Validity is crucial to any study as Shadish, et.al (2002) in order to generalize inferences made from this study to general populations and circumstances. They also state that given the lack of a single approach to eliminate the possibility of validity threats triangulating qualitative and quantitative methods as Ragin (1987) proposes would help to control for these threats. Chapter 6 explains the construct and variable reliability measured. However, the application, documentation, and analysis of the methods taken towards each respondent group either interviewed or surveyed are identical to preserve consistent research methods and ensure reliability of each instrument.

Constructs are "the central means of connecting the operations used in an experiment to pertinent theory and the language communities will use to inform practical action." (Shadish, et. al, 2002) Construct validity refers to how operationalized measures can be

\footnotetext{
${ }^{3}$ The following jurisdictions overturned, dissolved, or repealed their living wage ordinances between 2002 and 2005: Eau Claire County, WI, the City of Eau Claire, WI, Hazel Park, MI, Hempstead, NY, Louisville, KY, Monroe County, MI, New Orleans, LA, and Pittsburgh, PA.
} 
inferred to define and explain theoretical constructs. Since implementation policies are context-specific, it is important to a context's validity to properly measure, define, and tie the concepts to the study's conceptual framework. Patton (2002) mentions that probing beyond the basic answers given by respondents would help to expand on the information provided and exposes other details needing focus. This approach helped to identify other factors and groups in the process during interviewing. Shadish, et. al (2002) also recommend that one should "pattern-match" where instances explaining a construct deserve note.

Tables 3-2 through 3-4 present the survey and interview questions used to define certain concepts in an attempt to classify these ideas properly. The approach of utilizing several constructs and various measurement approaches to explain the implementation process also meets another recommendation by Shadish, et. al (2002). This study incorporated different approaches thus allowing different results to combine into one comprehensive definition for each construct. In addition, the survey plays an important role in strengthening the validity that these construct have been adequately defined and operationalized. Bickman and Rog (1998) explain that there is always some degree of error when defining constructs. The survey and quantitative analysis helped to properly define these constructs. However, evidence presented in Chapter 6 suggests that combined methods resulted in reliable constructs.

External validity concerns generalizing inferences to variations of populations, settings, and/or outcomes. (Shadish, et. al, 2002) The author pretested the survey by distributing it to several county administrators before its administration to the entire known population. Upon collecting the data, statistical analysis verified whether 
inferences made were comparable to other settings, populations, and outcomes. The author believes that the triangulated methods resulted in a model that obviated threats to internal validity. 


\section{CHAPTER IV \\ BROWARD COUNTY, FLORIDA}

This chapter presents the results collected through interviews conducted between February and August 2006 with the Broward County Living Wage Advisory Board (LWAB) and County personnel directly involved in the implementation of the living wage ordinance (LWO). To begin with, this chapter offers an examination into Broward County's LWO implementation process, the individuals involved, and their participation. Second, the author provides the interview results from the LWAB and Broward County personnel.

The focus of this chapter is to develop a comprehensive definition as to what a successful implementation of the living wage means in Broward County. The objective is to illustrate how LWAB members and County personnel view the LWO and what their priorities and objectives are. Identifying the administrative and political factors surrounding the implementation process is also a key point. The aim is to examine the effect each dynamic has on the County's LWO implementation efforts.

\section{Broward County's Living Wage Ordinance}

This section introduces the living wage implementation process in Broward County. It offers information as to the provisions contained in the ordinance and summarizes the roles of key actors involved in the implementation process.

The Broward County Board of County Commissioners (BCC) adopted its living wage ordinance on October 1, 2003, by a vote of 5-4. (Anonymous, personal communication, July 14, 2006) As stated in the ordinance, County contracts valued over 
$\$ 100,000$ annually providing the following services must comply with living wage regulations: (Broward County Living Wage Ordinance 2002-45, 2002)

- Food preparation and/or distribution

- Security Services

- Routine maintenance services (custodial, cleaning, refuse removal, repair, refinishing, and recycling)

- Clerical or other non-supervisory work, whether temporary or permanent

- Transportation and parking services

- Printing and reproduction services

- Landscaping, lawn, and/or agricultural services

Provisions in the ordinance also apply to all Broward County employees. At its inception, the ordinance ensured that covered employees working a minimum of 20 hours a week would receive an hourly minimum wage of $\$ 9.57$ with an additional $\$ 1.25 /$ hour towards health benefits or $\$ 10.82 /$ hour without benefits. The County indexes the living wage payroll rate to inflation each year based on the Miami PMSA Consumer Price Index. As of October 2007, the living wage is currently at $\$ 10.63 /$ hour with an additional $\$ 1.39 /$ hour dedicated to employee health benefits or $\$ 12.02 /$ hour without benefits and Broward County had 65 applicable contracts with 900 workers on these contracts earning the living wage or higher ${ }^{4}$. (Broward County Purchasing Division, 2007)

\footnotetext{
${ }^{4}$ A Purchasing administrator explained that of the 900 workers about 300 are earning higher wages because of the ordinance. The rest of the workers were already earning well above the rate because of their specialized labor (mechanic, elevator repairman, etc.). (Anonymous, personal communication, October 9 , 2007)
} 


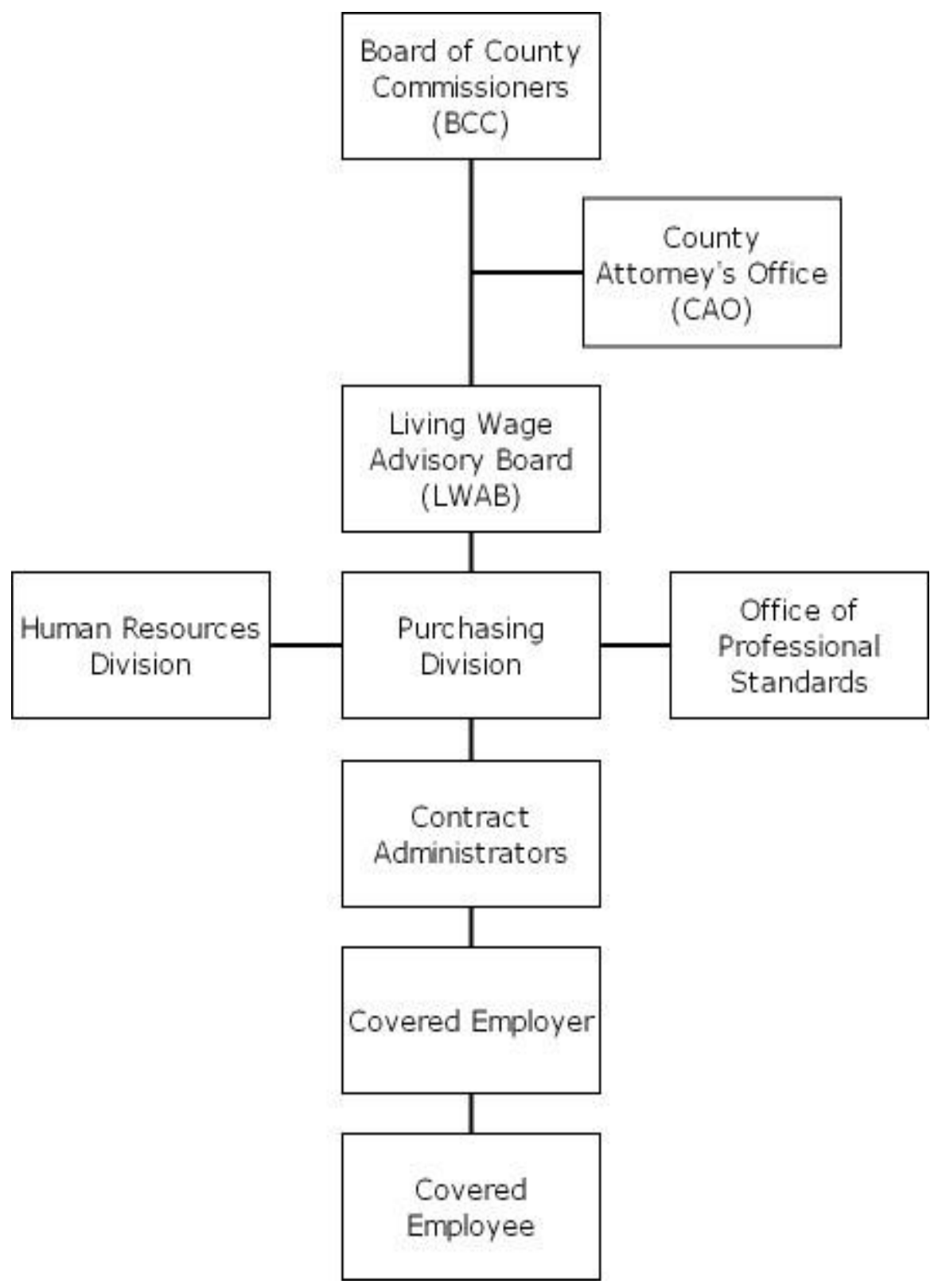

Figure 4 - Broward County Living Wage Implementation Organizational Model

Figure 4 illustrates the implementation process in Broward County. The following outlines the roles and responsibilities of each actor and the execution of the overall process.

- Board of County Commissioners $(B C C)$ - the BCC represents the legislative arm of the LWO, is responsible for passing the ordinance initially, and possesses the 
authority to amend it. The BCC is also accountable for providing sufficient resources to all County departments through budgetary approvals and resolutions.

- County Attorney's Office (CAO) - The CAO handles all legal matters related to the LWO. It is responsible for drafting the language contained in the ordinance, as well as, any other amendments to it. The $\mathrm{CAO}$ also provides legal opinions on the applicability of covered services to the BCC, Purchasing Division, and the Living Wage Advisory Board.

- Living Wage Advisory Board (LWAB) - The LWO created the LWAB with the responsibility of overseeing the County's implementation of the ordinance. The Board consists of nine members appointed by each of the county commissioners and serve as BCC representatives that eventually report to the BCC. The LWAB meets once a month to review reports by other County departments regarding the LWO, address any pressing matters concerning the implementation process, and monitor the ordinance's overall effectiveness and efficiency. The LWAB is also able to advise staff departments and make recommendations regarding the implementation policy.

- Purchasing Division - The Purchasing Division manages the implementation of the living wage contract requirements by including the LWO provision where applicable in County service contracts. It also provides orientation, training, and policy updates to agencies and covered employers. For example, Purchasing provides voluntary pre-bid conferences for all contractors to inform them of the LWO provisions. It also determines and publishes the annual indexing of the living wage rate, which it then notifies all parties involved. Purchasing serves as 
Staff Liaison and Coordinator to the LWAB, provides monthly and/or quarterly staff reports to the Advisory Board, and works with other departments to address LWO matters. Lastly, it coordinates with contract administrators to monitor covered employer audits and compliance issues.

- Human Resources Division - This unit oversees that all County employees earn at least the living wage. It also reports to the LWAB monthly on its status and any noncompliance issues.

- Office of Professional Standards (OPS) - OPS also reports to the LWAB ${ }^{5}$. This unit investigates covered employee complaints relating to any matters of living wage noncompliance. It also takes final action in penalizing employers who do not comply with the LWO if the appointed contract administrator cannot first resolve the issue.

- Contract Administrators - Contract administrators oversee the compliance aspect of the LWO to about 70 applicable service contracts. They perform site visits, payroll audits, and verify proper displays of LWO signage in addition to resolving any issues of noncompliance and report their findings to the Purchasing Division. They also attend pre-bid and contract start-up meetings organized by Purchasing to help inform covered employers of the County's expectations of them and their contractual responsibilities in regards to the LWO.

- Covered Employers - These are contractors awarded service contract(s) by Broward County applicable to the LWO. As a result, aside from paying all

\footnotetext{
${ }^{5}$ OPS used to report to the LWAB on a monthly basis, however, this office recently became part of the Office of Equal Opportunity. It still performs the same functions as before but does so now as a division of this office.
} 
employees at least the living wage rate, they must post signage informing employees about the ordinance, as well as provide contract administrators with payroll information every six months to show their compliance under the LWO.

- Covered Employees - These are individuals working for the covered employers who are the direct recipients of the living wage. In the case that the employee does not receive the living wage that he/she is entitled to, they can file a complaint with the employer, contract administrator, and/or OPS to correct the matter.

Overall, the central focus of the implementation process is on the Purchasing Division and the LWAB. The BCC and CAO are only involved when called upon. The remaining staff departments dedicate time monthly to attend the LWAB meetings and comply with any recommendations made by the Advisory Board. Beyond that, contract administrators deal with covered employers and their employees as need be. Their interaction consists mostly on their six-month payroll audits that the Purchasing Division reviews and approves.

\section{Broward County Living Wage Advisory Board}

This section focuses on assessing Broward County's implementation effort from the LWAB's perspective. Specifically, how the Advisory Board perceives to execute the ordinance successfully, as well as the current challenges hampering the County's progress.

To define what implementing the living wage ordinance successfully means to LWAB members, or at least the essential factors needed, each member provided varied responses while identifying common themes. A response by three of the five members 
interviewed was that there needed to be public awareness promoting what the ordinance guarantees, its application, and how the administrative process works. (Anonymous, personal communications, February 2; February 10; March 1, 2006) Overall, every LWAB member interviewed believed that the County needed to promote the living wage more and work towards expanding it. In addition, they recommended that the County should be more aggressive in enforcing the ordinance by systematically monitoring how contractors pay their employees, provide them with helpful information about the ordinance, and enforce more accurate reporting of employee records. (Anonymous, personal communications, February 2; February 10; February 22; March 1; March 28, 2006)

However, only one LWAB member mentioned that there are two additional critical factors needed to attain better enforcement, expand living wage coverage, and generate greater awareness. First, there needs to be more support from the Board of County Commissioners (BCC). The member states, "I think they direct staff and it seems to me that [County] staff needs a spirited commitment to not just be doing a job, but to make sure that all [of the County's] vigor and enthusiasm is behind the implementation." (Anonymous, personal communication, February 10, 2006) The LWAB member suggested that political influence on this issue flows mainly from top to bottom within the County government and explained that the BCC must provide support by allocating sufficient resources to departments needing sufficient personnel to monitor and enforce the ordinance. This member also recommended that the County develop clearer policy directives and outcomes measuring the ordinance's outcome. Such support by the BCC would help to set the example and develop an organizational culture where the living 
wage would be an administrative priority. (Anonymous, personal communication, February 10, 2006)

Two LWAB members mentioned that the LWO needs an avid grassroots movement that could direct public influence towards convincing the $\mathrm{BCC}$ to make the living wage a greater necessity. $\mathrm{BCC}$ members would prioritize the living wage more if there were more supportive public displays for the LWO. (Anonymous, personal communication, February 2; February 10, 2006) This member suggested that community groups must get involved to contact workers, businesses, advocates, and public officials to develop a structured network committed to having a presence at the County's monthly living wage meetings and living wage lawmaking opportunities. To accomplish this, a communitydriven movement would ensure that County administrators remain accountable to the public and committed to implementing the living wage while developing additional strategies to improve its effectiveness and broaden its scope. However, maintaining such a level of interest is admittedly a daunting task since people tend to lose interest with time especially when they assume that the living wage issue is resolved with the BCC passing the ordinance. (Anonymous, personal communication, February 10, 2006)

While the factors mentioned could help to strengthen the effectiveness of the ordinance, each LWAB member believed that there are several pressing challenges that could limit the long-term effect of the County's implementation effort and the ordinance's impact. When asked if Broward County was successfully implementing their living wage ordinance, the common response by Board members was negative. No member was able to say that the County's progress has been effective. (Anonymous, personal communications, February 2; February 10; February 22; March 1; March 28, 
2006) Two members admitted to being unable to make a clear determination because there is no information outlining the ordinance's effect on workers or the local economy. (Anonymous, personal communications, February 2 and February 22, 2006) Each member emphasized the fact that research is needed to evaluate the effect the living wage is actually having. (Anonymous, personal communications, February 2; February 10; February 22; March 1; March 28, 2006)

There were also concerns as to the ordinance's limitation in coverage. "First of all, I can tell you that I wouldn't define ours as successful," one member mentioned in regards to the number of living wage contracts the County currently manages ${ }^{6}$. “...We hope to make significant changes as opposed to helping one person at a time." (Anonymous, personal communication, February 2, 2006) To a certain extent, this member believed that the County is to blame for ineffectiveness because of its lack of commitment to make the living wage a high priority. Three LWAB members agreed with this idea and feel that there is not enough administrative support provided to improve the implementation process. (Anonymous, personal communications, February 2; February 10; February 22, 2006) They admitted that County administrators are purposely slow in responding to LWAB requests. Members also did not single any person or department as being solely responsible for the state of the ordinance's implementation; however, four LWAB members mentioned that Purchasing has given the Board misleading and/or incomplete information in response to several of their requests and the $\mathrm{BCC}$ was not as committed as

\footnotetext{
${ }^{6}$ Broward County had 37 living wage contracts at the time of this interview. The County had 69 living wage contracts as of October 2007.
} 
it should be in overseeing the implementation. (Anonymous, personal communications, February 2; February 22; March 1; March 28, 2006)

It is the author's opinion that as a result, poor communication has lead to a tense relationship between some of the LWAB members and County administrative staff to the point where three Board members admitted to not trusting the County administration. (Anonymous, personal communications, February 2; February 22; March 1, 2006) These members get the sense at times from Purchasing and other County departments that their requests add to what is already an administrative burden for them and feel as if they are imposing on them, or at least it is the impression they get from the County. There is suspicion among three members that County personnel are deliberately not providing them with accurate information partly because departments are choosing to preserve the status quo in the County and they do not want to increase their workloads by implementing enforcement that is more stringent and monitoring practices. (Anonymous, personal communications, February 2; February 22; March 1, 2006) Each Board member did not blame County departments immediately for this, but cited the fact that the BCC was not as supportive as it should be and administrators accomplish the least expected of them. (Anonymous, personal communications, February 2; February 10; February 22; March 1; March 28, 2006)

Four LWAB members discussed that a lack of transparency related to certain administrative policies affects the ordinance's effectiveness and managed to frustrate them. A general concern by these members was that the language in the ordinance was not clear, which allowed for the ordinance's implementation and enforcement to be open to interpretation. (Anonymous, personal communications, February 2; February 22; 
March 1; March 28, 2006) This issue created loopholes in the legislation that two members believed contractors are exploiting while County personnel did little to resolve it $^{7}$. (Anonymous, personal communications, February 2 and February 22, 2006) Each Board member believed that County administrators needed to be more straightforward in their policies and practices related to the living wage while being more aggressive in its monitoring efforts. (Anonymous, personal communications, February 2; February 22; March 1; March 28, 2006)

Leadership within the LWAB also came into question. While every member praised the commitment of the Chair and other members, there was some criticism as to the LWAB's focus and direction. As one member stated, "I will say that [the Chair] is passionate about this and that's one thing I really do like about her. There are just times when I just walk out of the meeting and wonder what did we accomplish and I hate feeling that way." (Anonymous, personal communication, March 1, 2006) Another member suspected that the LWAB leadership might be overwhelmed with trying to oversee the current ordinance, expanding its scope, and dealing with County administrators at the same time. (Anonymous, personal communication, February 10, 2006) Still, it is the author's opinion that it appears the LWAB is trying to do more that it actually can. There seems to be confusion as to what the primary objectives are and how to approach them. This results in each member working on separate projects and rarely taking further action. Part of the reason perhaps is the poor attendance leading to

\footnotetext{
${ }^{7}$ For instance, part of the covered services in the LWO regarding "routine maintenance services" refers to custodial, cleaning, repair, and other services. (Broward County Living Wage Ordinance 2002-45, 2002) What the ordinance does not specify is what it actually means by "routine." Many of the LWAB members brought up this concern that there are certain clauses in the ordinance not specific as to its coverage and scope and could be providing vendors with opportunities to circumvent the ordinance.
} 
cancelled meetings. As one member mentioned, "We can keep storing numbers but we still don't know what our objective is. We get all this information but it's just information without knowing what to do with it. No one knows how to use these numbers. It's just very frustrating." (Anonymous, personal communication, March 1, 2006)

Even as members admitted that there is room for improvement on their part, they each agreed that their biggest obstacle was dealing with the County bureaucracy. They felt that the County tended to suppress any momentum the Board had to improve the living wage. LWAB members believed that the County takes too long to react to suggestions or requests by the Board. (Anonymous, personal communications, February 2; February 10; February 22; March 1; March 28, 2006) Three LWAB members suspected that the County is purposely hampers the progress of the living wage and/or the Board itself. (Anonymous, personal communication, February 2; February 22; March 1, 2006) These members believed that this was politically motivated where a conflict for support existed among County administrators. As these LWAB members mentioned, the County was publicly in support of the living wage, however, there was mixed support internally that prevented the LWO to progress as the LWAB expected in general. (Anonymous, personal communications, February 2; February 22; March 1, 2006) Overall, each LWAB member believed that some County administrators do not support the living wage, as they would expect. (Anonymous, personal communications, February 2; February 10; February 22; March 1; March 28, 2006)

The BCC's hesitation has been a source of aggravation for the LWAB members interviewed as it also attempted to expand the scope and coverage of the living wage. 
(Anonymous, personal communications, February 2; February 10; February 22, 2006)

One factor that has lent to the BCC's wavering was an article by the South Florida SunSentinel published on March 12, 2006, questioning the progress and cost of the County's implementation efforts. The article estimated that the County had done a poor job in monitoring the ordinance while costing it almost $\$ 30$ million at the same time. (Wyman, 2006) In response to the article, the County worked to develop a report refuting the article's facts. County administrators and the LWAB believe that the estimate is highly inaccurate and overestimated. Still, administrators were not able to determine the cost or impact of the living wage on the County by the time of this writing.

Bargaining and negotiations managed to play a significant role in the implementation process. Ironically, what helped to get the living wage ordinance passed is what might be impeding its success given that some administrators are questioning its purpose and effectiveness. One member agreed with this idea. (Anonymous, personal communication, February 22, 2006) "We had to make a lot of compromises to get it passed and you find yourself settling for incremental change, which you can tell yourself that it's better than nothing." (Anonymous, personal communications, February 2, 2006) Four LWAB members mentioned that their efforts continue in hopes of expanding the LWO's scope and increasing the wage rates aside from improving on its enforcement. They admitted that the policy appears diluted in comparison with the legislation they envisioned when campaigning for its passage. Overall, any attempts to improve the ordinance faced certain conflict with the County. (Anonymous, personal communications, February 2; February 22; March 1; March 28, 2006) 
Internally within the Board, there seemed to be some division as to supporting the living wage ordinance. Individuals from "the other side," as two Board members label them, applied an opposing view toward expanding the ordinance's scope. (Anonymous, personal communications, February 2 and February 22, 2006) County Commissioners who voted against the living wage, coincidently, appointed these members. These Board members did not respond to requests to take part in this study. The general assumption by three LWAB members that those from "the other side" were only there to interfere with the ordinance's implementation by either voting against Board proposals or making continuous requests for additional information and analysis to question the current policy in an attempt to delay the Board's progress. (Anonymous, personal communications, February 2; February 22; March 28, 2006)

\section{Broward County Administrative Personnel}

This section focuses on assessing Broward County's implementation effort from the perspectives of department directors and other administrators directly involved with the LWO, including contract administrators. The focus is on their accomplishments and challenges to implementing the ordinance, as well as, its relationship with the LWAB and with other County departments.

County administrators from each department mentioned that there are several challenges hampering the progress of the LWO's implementation. First, the language in the ordinance is vague at times failed to specify clearly which services apply to the living wage. (Anonymous, personal communications, July 14; July 17; August 20, 2006) While it might be a challenge for the Purchasing Division to act, the County Attorney can offer support through his legal opinions as it related to the legislative intent of the ordinance 
and the contract's scope of services to set precedence. Over time, as more of these cases are resolved, the issue will resolve itself. Still one administrator in the County Attorney's Office agreed with statements made by LWAB members and several County administrators that the ordinance was vague at times and can be open to interpretation. (Anonymous, personal communication, August 20, 2006)

Another concern was the accuracy of the information collected. A Purchasing administrator stated that there was too much faith placed on contract administrators without the County conducting a comprehensive audit of their procedures. As the respondent mentioned, "the fact is that we have no way of knowing whether the information that we are getting is accurate. We are leaving it to the contract administrators to go out into the field, do their audits, and report to us. But we don't do any audits of the contract administrators. I know that for sure." (Anonymous, personal communication, July 13, 2006) In fact, the Broward County Auditor uncovered in 2006 that the contract administrators were treating vendors inconsistently and discovered several instances of contract noncompliance. Of the ten contracts examined, the Broward County Auditor found three incidents of noncompliance where contractors did not provide the required documentation (copies of employee paychecks and payroll records) to the County for proof of compliance. (Broward County Office of the County Auditor, 2006) It is the author's opinion that while this does not necessarily mean that Broward's compliance rate is $70 \%$, it does raise the question on the accuracy and diligence of the contract administrators and Purchasing's efforts to monitor their practices. 
Even as the County's overall implementation policy is "reasonable" according to the County Auditor, monitoring and enforcement of the LWO needed improvement ${ }^{8}$. (Broward County Office of the County Auditor, 2006) In addition, each person interviewed in Broward County failed to recall any incidents of noncompliance. The lack of accurate information can be detrimental to the success of the LWO's implementation for several reasons. First, there were incidents of noncompliance occurring and not properly channeled throughout the County. Second, the lack of clarity regarding roles and responsibilities exposed inconsistencies in monitoring and enforcement. (Anonymous, personal communication, September 29, 2006) For example, with the contract administrators detailing their methods of enforcement, it is the author's opinion that they approaches differed from each other. One contract administrator was aggressive going beyond what the Purchasing Division required to ensure that contractors were complying with the LWO. (Anonymous, personal communication, September 29, 2006) The other contract administrator performed the minimum to an extent that he took contractors at face value and did not verify if the contractors were actually complying with the ordinance. The latter administrator believed as long as a contractor provided the necessary payroll information in a timely manner and made the administrator aware of the posted signage that it qualified as sufficient living wage monitoring. This contract administrator took no further action to confirm the contractor's claims or if payroll records were accurate. (Anonymous, personal communication, September 29, 2006)

\footnotetext{
${ }^{8}$ It is the author's opinion that is either an oversight on the County's part or administrators chose not to know, but it raises the question. Regardless, the fact that their responses contradict the results from the Broward County Auditor's reports showed that both LWAB members and County administrators were not aware of specific instances of noncompliance. This begs the question whether the County's data collection and analysis efforts are transparent and consistent.
} 
However, the third issue mentioned by senior-level management was that implementing the LWO was an administrative burden for County administrators in addition to dealing with the LWAB. (Anonymous, personal communications, July 14; July 17; August 20, 2006) High expectations from the BCC coupled with their lack of political and financial support caused a strain on some departments. As one administrator states:

"Government keeps preaching that we have to do more with less and they keep pouring more and more on us and expect to do it with even less. Everything cumulatively is seriously impacting our abilities to serve our best to the agencies and get things done. We do need more resources and so far they are not forthcoming. You can only stretch it so thin and still try to do things effectively and we are reaching that point where we are behind and we are not generally as effective as we could be or should be." (Anonymous, personal communication, July 17, 2006)

Some Purchasing personnel were dedicating 15 to 30 percent of their time to the LWO by producing reports for the LWAB, attending meetings, and tracking data while still having to attend to other County service contracts they managed prior to the ordinance going into effect. (Anonymous, personal communication, July 14, 2006) Moreover, department directors felt that the $\mathrm{BCC}$ imposed the LWO responsibilities on them. (Anonymous, personal communications, July 14; July 17; August 20, 2006) The BCC never asked if they wanted or were capable of taking on the responsibility and felt that criticisms by the LWAB and BCC were unwarranted at times because their departments were at capacity to begin with. (Anonymous, personal communications, July 14; July 17; August 20, 2006) One administrator related the LWO as a "stepchild" that has been forced onto departments to manage. (Anonymous, personal communication, July 14, 2006) 
The fact that implementation responsibilities fell on Purchasing and other departments without adequate administrative support has left several county administrators with a negative view of the LWO. (Anonymous, personal communication, July 14; July 17; August 20, 2006) As a result, senior-level administrators admitted that they would not try purposely to sabotage the LWO implementation, but one should not expect them to prioritize it over their other responsibilities unless directly ordered to do so by the BCC. However, the LWO was not a high priority for the BCC and some administrators attempted to reflect that lack of commitment in their own LWO implementation efforts. (Anonymous, personal communication, July 14; August 20, 2006)

This reaction by department directors attributed to a tense relationship with the LWAB. As mentioned, Advisory Board members expressed some frustration as to the County's level of commitment to implement the LWO. While senior-level County personnel credited the LWAB for taking the time to analyze the implementation process closely, they stated that some of the criticism by the Board is misplaced. They feel that the LWAB underestimated what the County does to support the LWO. (Anonymous, personal communications, July 14; July 17; August 20, 2006) Purchasing administrators understood the LWAB members consisted of advocates for the LWO; however, the County is limited in its level of support as a public entity. (Anonymous, personal communication, July 14 and August 20, 2006) As one Purchasing administrator stated, "I think the Advisory Board needs to understand that the ordinance reads the way that it does because it's what the $[\mathrm{BCC}]$ agreed to. Advocates for a model [LWO] find the 
County's ordinance to be too limited." (Anonymous, personal communication, August 20, 2006)

Two department directors believed that the LWAB's frustration was a sign of how disconnected they were with the administrative process and regulations in place. (Anonymous, personal communications, July 17 and August 20, 2006) Nevertheless, meetings in late 2007 with County administrators and several of the LWAB members helped to develop a better understanding between both sides even though conflicts and tension remained. (Anonymous, personal communication, October 7, 2007) The author believes that this situation illustrated the challenge certain County administrators faced trying to balance their administrative duties along with their personal opposition to the living wage. As one Purchasing administrator stated, his job is strictly to execute the ordinance as specified by the $\mathrm{BCC}$ and not advocate for or against it. (Anonymous, personal communication, July 14, 2006) Ironically, this attempt to be bureaucratically neutral manages to attract criticism from BCC members and the LWAB for not advocating in favor of the LWO. (Anonymous, personal communication, July 14, 2006)

Several Purchasing administrators expressed concern that the increasing number of living wage contracts will be a problem for the County. (Anonymous, personal communications, July 14; July 17; August 20, 2006) Prior to the LWO became effective, many contractors renewed their contracts and grandfathered into the previous policy that excluded them from paying the living wage. These contracts are renewable and the County has seen the number of living wage contracts nearly triple since 2005. This is problematic since the County was nearly at its capacity to effectively monitor and enforce every contract. (Anonymous, personal communication, July 14, 2006) Additional 
contracts meant more of a strain on Purchasing and other departments. This would only add to the frustration each department has to deal with and cause them to be less effective. (Anonymous, personal communications, July 17 and August 20, 2006) However, Broward took steps in 2007 to examine the living wage's impact from an economic and administrative perspective. However, the results of that study were not available at the time of this writing.

\section{Summary of Findings}

Interviews revealed several themes highlighting the accomplishments and shortcomings of the LWO's implementation in Broward County. This section outlines these themes and provides suggestions on how to improve the implementation policy.

First, Broward's experience related to the implementation literature. As mentioned, policy conflict and the lack of understanding of roles and responsibilities are factors in the outcomes of an implementation policy. Broward County demonstrated that both were to some extent accountable for frustration present between the County's administration and LWAB. A conflict on how to implement the policy was evident in what the LWAB tried to achieve and what the County actually accomplished. As for the contractors, according to a Purchasing administrator, some were openly supportive with the LWO regulations while others complained of having to comply with the ordinance when they were already paying above the living wage before the LWO went into effect. (Anonymous, personal communication, July 14, 2006) For example, elevator technicians earn well above the living wage and did so before Broward adopted the ordinance. Nevertheless, repairing elevators is an applicable service according to the living wage. The County required vendors to provide proof of compliance regardless of the 
circumstance and believed it is senseless work to prove they were in compliance. (Anonymous, personal communication, July 14, 2006)

Policy ambiguity was another issue affecting how the County monitored and enforced the LWO. While the Purchasing Division served as the central point for this action, it expected the contract administrators to manage the vendors they are responsible for at their own discretion. The Purchasing Division simply required that they contact the vendors every six months to verify that they were complying with the ordinance. However, interviews with contract administrators and Purchasing administrators showed that the level of enforcement was inconsistent and limited. (Anonymous, personal communication, September 29, 2006) This finding supported claims by some LWAB members and senior-level County administrators that monitoring and enforcement efforts were sketchy at best. (Anonymous, personal communication, February 2; February 22; July 14; July 17, 2006)

For example, one contract administrator randomly checked payrolls throughout the entire six-month period while another reviewed just the current payroll. The first contract administrator also networked with building managers throughout the County to help in monitoring contractors and their employees, while the other checked with contractors every six months. In the latter contract administrator's defense, that person believed that the County did not have the authority to request private company records even though the ordinance does permit Broward to do so when needed. (Anonymous, personal communication, September 29, 2006) The LWO states that the County can review all 
records as long as it relates to the living wage and it is for monitoring compliance ${ }^{9}$.

(Broward County Living Wage Ordinance 2002-45, 2002)

Moreover, some contract administrators preferred not be as aggressive and limited enforcement so as not to damage their working relationships with other departments. In fact, one contract administrator admitted that the County should not pressure its vendors to comply with the ordinance. He believed that imposing living wage regulations on contractors would eventually dissuade that company from doing future business with the County. As that person stated, "I'm not sure the law gives anyone in the government the right to do a total payroll audit on a company." (Anonymous, personal communication, September 29, 2006) The fact is that the County states the LWO's provisions when it advertises its bids in addition to explaining it to the vendors at the pre-bid meetings. Moreover, contrary to this person's statement, the County can perform total payroll audits based on the terms and conditions of the contract bid. These vendors appear to understand what the expectations are; however, it is the County's responsibility to uphold the ordinance. It is the author's opinion that the contract administrator was incorrect in his assumption and this was an example of how inaccurate information affects policy implementation ${ }^{10}$.

While the ordinance did not specify how the County's organizational structure would apply to the implementation beside the creation of the LWAB, it did make reference that

\footnotetext{
${ }^{9}$ It is the author's opinion that the lack of communication appeared to cause a misunderstanding and inconsistent monitoring of the LWO. The fact that contractors comply every six months by presenting copies of their most recent payrolls should not be adequate monitoring given that there is minor supervision at best conducted in the meantime. A possible solution would be to implement random site visits or at least more frequent payroll reviews.

${ }^{10}$ It is the author's opinion that had County employees been properly educated on the living wage and their roles and responsibilities, this contract administrator perhaps might have been more diligent in monitoring and enforcing the LWO.
} 
all LWO-related provisions were applicable to the procurement portions of the contract. (Broward County Living Wage Ordinance 2002-45, 2002) By default, this would assume that the Purchasing Division would be responsible for its implementation. While this was hardly a surprise to anyone, seeing as Purchasing worked with the BCC to develop the ordinance in the first place, there was some concern expressed by Procurement senior management and a contract administrator that the department was understaffed to monitor and enforce the ordinance effectively. (Anonymous, personal communications, July 14; July 17; August 20; September 29, 2006)

Two senior-level administrators suggested that other departments might be better suited to handle the monitoring and enforcement responsibilities. The Office of Professional Standards (OPS), on the other hand, responded as a final measure of enforcement. Some administrators believed that OPS would be better prepared to handle the overall monitoring effort and that it should be their responsibility to coordinate with contract administrators, as they were all trying implement the same enforcement policy. (Anonymous, personal communications, July 14; July 17; August 21, 2006) In this regard, Purchasing served as the main actor doing work that others could be doing themselves. This only complicated Purchasing's situation by trying to balance the responsibilities it had before and after Broward adopted the $\mathrm{LWO}^{11}$. (Anonymous, personal communications, July 14 and July 17, 2006)

The literature review suggests that organizational culture can influence both the administrative and political aspects of the implementation policy. This can be

\footnotetext{
${ }^{11}$ In the author's opinion, for the sake of making the entire process more efficient and effective, the County should rethink how it delegates responsibilities and consider whether some departments would be more prepared to handle certain LWO issues at a better capacity.
} 
determined by examining the administrative support offered to the implementation process. First, the BCC had been reluctant in recent years to provide its departments with sufficient resources to effectively monitor and enforce the ordinance. The Purchasing Division made several requests in their annual budgets for more personnel, citing the fact that the increasing number of contracts caused the department to falter in its attempt to monitor the ordinance and manage their other responsibilities only for the $\mathrm{BCC}$ to deny its requests every time. (Anonymous, personal communication, July 17, 2006) This was both an organizational culture and capacity issue. From the capacity standpoint, there were not enough personnel to track the increasing number of contracts. Two department directors stated that the $\mathrm{BCC}$ normally denies any attempts to allocate more resources because of conflicting interests amongst BCC members. (Anonymous, personal communications, July 17 and August 20, 2006)

Morale within the LWAB was also low as demonstrated by the challenge to reach quorum for its monthly meetings. The LWAB only met seven times in 2006 (the Advisory Board breaks two months in the summer). It is the author's opinion that this sends a message to County administrators about the LWAB's overall commitment. What made this situation more trying was that County administrators dedicated their time to prepare for these monthly meetings without knowing if they were to take place or not. From the County's perspective, senior-level administrators felt that they wasted time and effort in preparing for meetings that normally failed to take place. (Anonymous, personal communications, July 14; July 17; August 20, 2006) Similarly, one LWAB member was frustrated at the poor attendance since members sacrifice their time to attend the meetings. (Anonymous, personal communications, March 1, 2006) Overall, poor 
attendance caused tension in the LWAB's relationship with the County; however, the LWAB discussed this issue in November 2006 to stress the importance of consistent attendance and the Board had since improved on its attendance record. In fact, since 2007, three consecutive absences or four throughout the calendar year was sufficient to remove LWAB members from the Board for poor attendance. (Anonymous, personal communication, October 7, 2007)

However, three LWAB claimed that County administrators, specifically those in Purchasing, do not promote the ordinance, as the Board would prefer. (Anonymous, personal communications, February 2; February 22; March 28, 2006) Some administrators admitted that they were in a precarious position since they address the LWAB's concerns, however, as a member of public organization, county officials serving as outspoken living wage supporters would be a conflict of interest on their part. As one Purchasing administrator explained,

"The Purchasing Division and the County cannot be advocates as much as our personal conversations off the record with some of the board members would like us to be advocates for the living wage. We're not advocates, we're people who are staff-functioned to the county administrators and commissioners. We abide by whatever policies and procedures and laws that they have set in place. We have to take the middle ground by keeping in mind that we also have to be the best political servants and civil servants for the taxpayers' money and there's a lot of cost involved in administering this ordinance." (Anonymous, personal communications, July 17, 2006)

What drew some tension from County administrators is that several LWAB members seemed to overlook the fact that County personnel cannot be advocates of the living wage to the extent LWAB members can. (Anonymous, personal communications, July 14; July 17; August 20, 2006) As a result, the distrust several LWAB members had for some 
County administrators' generated from what these Advisory Board members considered lukewarm commitment to the living wage. (Anonymous, personal communications, February 2; February 22; March 28, 2006)

The situation in Broward County supported Luce's (2004) argument that there is a drastic reduction in interest upon adopting a living wage. Organizations, like ACORN, managed to assist local groups to organize the campaign that resulted in the ordinance, but quickly moved on once Broward adopted its LWO. (Anonymous, personal communication, February 2, 2006) However, County administrators believed that the grassroots presence remained given that the LWAB consisted mostly of those local leaders who fought to get the LWO passed in the first place. (Anonymous, personal communications, July 14 and July 17, 2006) To date, the LWAB members remained as the only advocates pushing to expand the scope of the LWO and increase its effectiveness. (Anonymous, personal communication, July 13, 2006) However, interest from Broward's resident and business communities was almost nonexistent. Four LWAB members believed that this was a concern because many do not know the LWO even exists or that they can contribute towards the effort of expanding the ordinance. (Anonymous, personal communications, February 2; February 10; February 22; March 1, 2006) A department director mentioned that if the living wage had local support to influence the $\mathrm{BCC}$ of its importance, there would be a stronger commitment by the County to implement the ordinance, but there hardly seemed to be any interest at the time. (Anonymous, personal communication, July 17, 2006)

It is the author's opinion that the overall result was a ratified ordinance supported through insufficient resources, lacking clear roles and responsibilities, and an 
organizational culture that was conflicted. Most County administrators viewed the LWO as more of a nuisance than anything else. Implementing the LWO has become such a burden to most departments, such as Purchasing and Human Resources that it was beginning to affect the other responsibilities they tend to as well. Without additional support that only the $\mathrm{BCC}$ can provide and the increasing number of contracts, one can expect the monitoring and enforcement of the living wage to become less effective over time with some interviewees suggesting that it will affect non-LWO responsibilities. As a result, employees felt caught between uncertain aims and other priorities, resulting in inconsistent and infrequent monitoring - a necessary action of the ordinance. 


\section{CHAPTER V}

\section{MIAMI-DADE COUNTY, FLORIDA}

This chapter presents the results from interviews conducted between January and July 2006 with the Miami-Dade County Living Wage Commission (LWC) and County personnel directly involved in the implementation of the living wage ordinance (LWO). Similar to the previous chapter, this chapter divides into four sections. To begin with, this chapter provides a description of Miami-Dade's living wage implementation process, in addition to explaining the roles each actor performed. The second section offers an assessment of the LWC members' perspective to the implementation's progress, objectives, and challenges while the third section focuses on Miami-Dade County's administrative personnel experiences. This chapter concludes by presenting a general assessment of the interview findings. It will also focus defining and identifying a successful living wage implementation and identify the administrative and political factors involved, in addition to the overall strengths and weakness of the Miami-Dade policy and procedures.

\section{Miami-Dade County's Living Wage Ordinance}

This section offers a description of the living wage implementation approach in Miami-Dade County. It also explains the provisions contained in the ordinance, as well as the involvement of each actor throughout the implementation process.

The Miami-Dade Board of County Commissioners passed its living wage ordinance by a unanimous 12-0 vote on May 11, 1999 and placed it into effect on August 4, 2000. (Miami-Dade County Ordinance 99-45, 1999) The Miami-Dade ordinance covers the same services as Broward by designating contracts with a total value over $\$ 100,000$ 
applicable to the living wage. All County employees earn at least the living wage as well. The County indexes the living wage for inflation each year based on the Miami PMSA Consumer Price Index. As of October 2007, the living wage rate was $\$ 10.27 /$ hour with an additional $\$ 1.49 /$ hour dedicated to employee health benefits or $\$ 11.76 /$ hour without benefits. (Department of Business Development, 2006) Miami-Dade County also had 221 applicable contracts with approximately several thousand workers on these contracts earning the living wage or higher ${ }^{12}$.

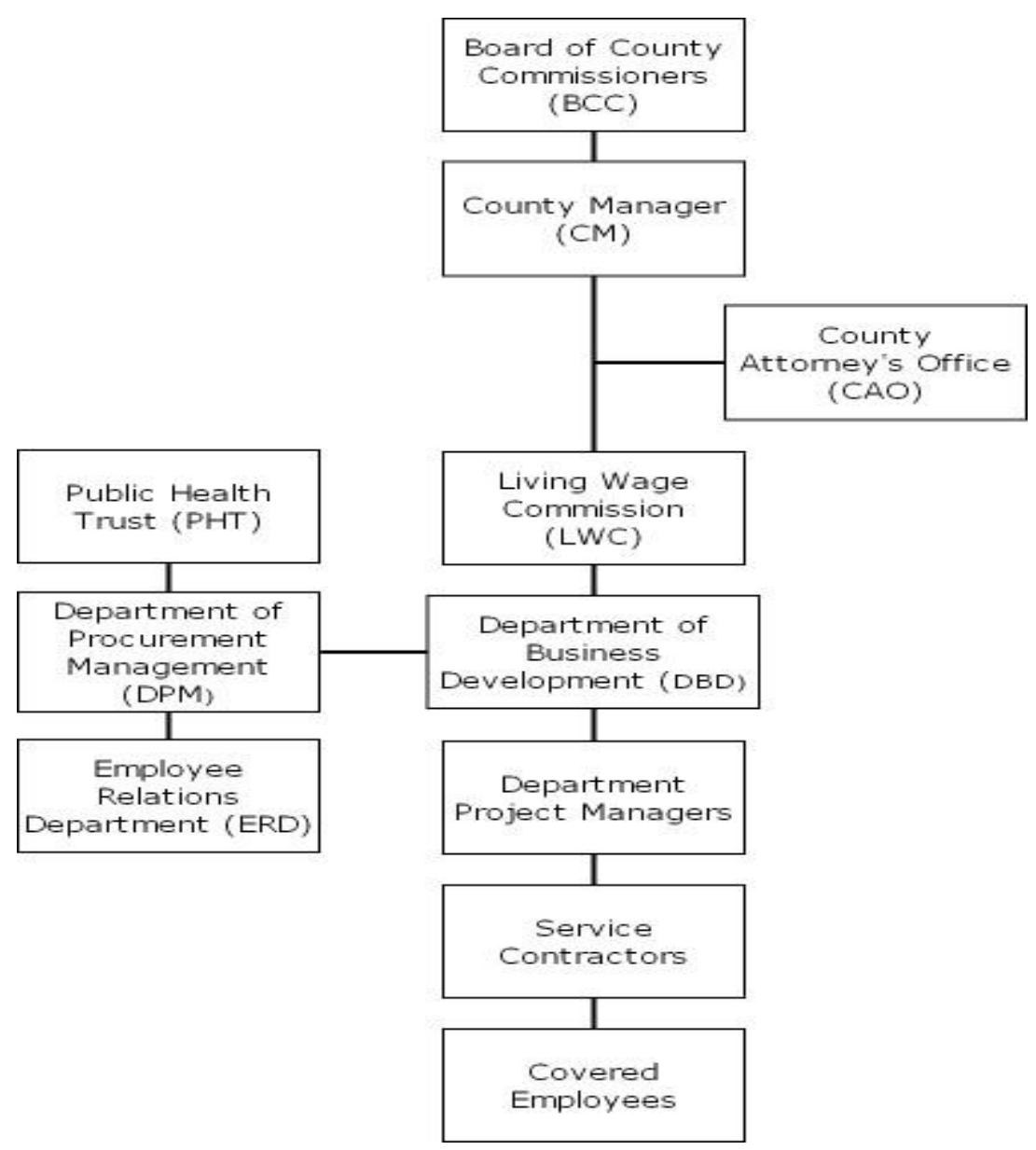

Figure 5 - Miami-Dade County Living Wage Implementation Organizational Model

\footnotetext{
${ }^{12}$ Even though an accurate worker total was not available, a representative from DBD/DPM stated that there are 4,000 to 5,000 workers currently earning living wages under the ordinance. (Anonymous, personal communication, October 9, 2007)
} 
Figure 5 illustrates how Miami-Dade County executed its LWO. Miami-Dade's organizational structure reflected that of Broward's. Keep in mind that in drafting their LWO, Broward approached Miami-Dade for assistance and tried to mirror Miami-Dade's ordinance as much as possible. (Anonymous, personal communication, July 17, 2006) The following explains the fit of each actor to the process and how the County executed its policy implementation: (Miami-Dade County Administrative Order 3-30, 2000)

- Board of County Commissioners (BCC) - As in Broward, the BCC is responsible for ratifying all living wage legislation including any amendments to the ordinance. The Board is also accountable for providing sufficient resources to all County departments through budgetary approvals and resolutions.

- County Manager's Office (CMO) - According to Administrative Order 3-30 (AO), the $\mathrm{CMO}$ is responsible for the overall implementation of the ordinance. This includes monitoring and enforcement. However, the AO grants the CMO authority to pass the implementation responsibilities to other departments, which it did initially to the Departments of Procurement Management and Business Development. These departments manage to implement the ordinance on their own, but they ultimately need final approval from the CMO for any policy changes or enforcing significant penalties on noncompliant vendors.

- County Attorney's Office (CAO) - Similar to Broward, the CAO handles all legal matters related to the LWO. It is responsible for drafting the language contained in the ordinance, as well as any other amendments to it. The $\mathrm{CAO}$ also provides legal opinions on the applicability of covered services to County departments and the Living Wage Commission. 
- Living Wage Commission (LWC) - Miami-Dade has a Living Wage Commission that serves the same role as Broward's LWAB. It is responsible for overseeing the County's implementation of the ordinance and reviewing its effectiveness. The LWC consists of fifteen members appointed by each of the county commissioners and mayor. The LWC meets monthly to review status reports by other County departments while discussing any pressing matters concerning the implementation process. The $\mathrm{AO}$ also states that departments like Procurement and Business Development are to provide staff support to handle any requests by the LWC. (Miami-Dade County Administrative Order 3-30, 2000)

- Department of Business Development (DBD) - As authorized by the CMO, DBD was mainly responsible for overseeing the LWO's compliance. It was accountable for the ordinance's monitoring and enforcement. DBD worked closely with the LWC to address any compliance issues and coordinated with department project managers to monitor compliance. Until 2005, DBD shared these responsibilities with the Department of Procurement Management; however, the County Manager decided to centralize implementation responsibilities under this department.

- Department of Procurement Management (DPM) - DPM is responsible with determining whether contracts are applicable under the LWO and applies the provision to the appropriate contracts. It also evaluates the health benefits each service contractor provides to allow contractors to pay the low range of the living wage rate and determines whether the health policy is acceptable by Florida standards. 
- Employee Relations Department (ERD) - The ERD is responsible for ensuring that all County employees earn the living wage. It reports monthly to the LWC on its progress.

- Public Health Trust (PHT) - The PHT is responsible for ensuring that all applicable employees in Jackson Memorial Hospital earn the living wage. It reports monthly to the LWC on its progress.

- Department Project Managers - According to the AO, each County department is responsible for monitoring and enforcing the living wage in their contracts. Each department must designate a contract coordinator responsible for monitoring and enforcement in addition to working with DBD.

- Service Contractors - In addition to regular vendors who receive a contract to provide a service for the County, the ordinance includes the General Aeronautical Service Permittees (GASP) situated at Miami International Airport. These GASPs provide aeronautical ground services to smaller airline carriers that cannot offer the services on their own (ticketing, cargo handling, etc.). Currently, there are six GASPs at MIA. All services provided by the GASPs require a living wage unless the County waives the service. The responsibilities service contractors must comply with are the same as those mentioned in Broward.

- Covered Employees - As in Broward's case, covered employees work for the service contractors and are the direct recipients of the living wage and its benefits.

Similar to Broward County, Miami-Dade County's BCC and CAO only participate when required to, however, certain commissioners are supportive of the LWO and actively monitor its progress. The CMO must give final approval to all major policy 
decisions. Unlike Broward, the service contractors participate regularly in LWC meetings along with the covered employers, who on occasion have filed complaints on their employers for noncompliance. Overall, DBD's compliance officers took it upon themselves to supervise almost the entire implementation process. The LWC, along with DBD, were strongly committed to ensuring not only that service contractors complied with the ordinance, but that all relevant County departments contributed effectively to the goal as well.

\section{Miami-Dade County Living Wage Commission}

This section concentrates on assessing Miami-Dade County's implementation effort based on the perspectives of the LWC's members. The focus is on the Commission's definition for a successful implementation of the living wage, its evaluation of the County's progress in executing the ordinance, and the pressing issues involved with the process.

The author asked each LWC member how he or she defined what a successfully implemented living wage meant to identify the critical factors needed to achieve such success. The consensus by the majority of the LWC members stated that a successfully implemented living wage ordinance is one where all applicable contractors comply by providing their employees the standing living wage pay rate as well as practical healthcare options. (Anonymous, personal communications, February 1; February 3; February 10; February 15; March 2; March 17, 2006) Members mentioned that in addition to having employees improve their qualities of life through higher wages, it was the County's intention to emphasize healthcare provisions in the ordinance. The intended outcome was to alleviate Jackson Memorial Hospital from the burden of having to treat 
so many uninsured individuals. The health benefits guaranteed by the ordinance gave those individuals options for medical care. (Anonymous, personal communication, February 1, 2006)

As to the critical factors necessary to implement a living wage, every LWC member agreed that communication is perhaps the most important factor. As one member explained, "ideally, it would be free-flowing information from the top to the bottom, vertically, laterally, between the departments, County Commission, as well as the public, businesses, and vendors.” (Anonymous, personal communication, March 17, 2006) Members believed that communication was important to support various channels of information that could link each stakeholder to work objectives and regulations cohesively. Each member understood their roles not only as advisors to the commissioners that appointed them, but to the County Manager as well. They also acknowledged their responsibility to hear concerns from contractors, employees, and other groups at LWC meetings and address them with County administrators and the BCC. LWC members also stated that County administrators support the open communication process. The members admitted that this was a significant advantage to implementing the ordinance effectively. (Anonymous, personal communications, February 1; February 15; March 17, 2006) However, communication was also important in regards to employee complaints, as the County relied on these workers to notify the County of non-compliance issues. (Anonymous, personal communication, February 1, 2006) It was also important as it applied to grassroots organizations because they focused primarily on awareness campaigns to expand the ordinance while ensuring that the County remained accountable for its monitoring and enforcement measures. 
(Anonymous, personal communications, February 3; March 2, 2006) Conversely, the lack of communication/information posed a challenge to monitoring, evaluating, and enforcing the ordinance.

In addition to communication, members also mentioned other important factors needed to implement a living wage. From an administrative standpoint, three LWC members believed that centralizing the process is important. (Anonymous, personal communications, February 1; February 10; March 17, 2006) This meant that the County should have a central point where one department or agency should be responsible for collecting and analyzing information, as well as enforcing the ordinance. Upon creating the ordinance, the County Manager assigned living wage responsibilities to both DPM and DBD. It was not until 2005 that DBD became directly responsible for assisting the LWC to monitor and enforce the ordinance. As a LWC member mentioned, this move helped to make the process more efficient:

"In prior year's reports, we were not getting the attention and the resources from the Department of Procurement where the living wage administratively sat. Then a year ago, when it was moved to the Department of Business Development which is now responsible for enforcement, interpretation, etc. The working relationship with DBD has been phenomenal." (Anonymous, personal communication, February 1, 2006)

The language in the ordinance also needs to be as clear as can be to prevent the possibilities of any loopholes. LWC members understood that new situations tend to arise where the ordinance's applicability might not be specific enough to address them. However, members believed a commitment by the BCC and departments was important to remain aggressive and proactive in enhancing and expanding the efforts towards contract compliance. To accomplish this, five LWC members believed that the County 
must support an organizational culture conducive to effective living wage monitoring and enforcement. (Anonymous, personal communications, February 2; February 3; February 10; March 2; March 17, 2006) Four LWC members believed that DBD would need sufficient resources ensuring that there were enough personnel to monitor contractors and keep them accountable. With so many contracts for the County to supervise, there needs to be enough people to investigate complaints and keep contractors accountable.

(Anonymous, personal communications, February 1; February 10; February 15; March 17, 2006)

From a political perspective, awareness and grassroots organizing helped to persuade County leaders to ratify the living wage. The majority of LWC members stated that with a consistent level of grassroots involvement there would be more support for an awareness campaign to help expand the ordinance's coverage and oversee its current progress. (Anonymous, personal communications, February 2; February 9; February 10; February 15; March 17, 2006) As a way to support this idea, two LWC members took it upon themselves to coordinate meetings with local businesses and residents to inform them of the benefits of expanding a living wage. (Anonymous, personal communications, February 2 and February 3, 2006) In addition to expanding the ordinance's scope, four members believed that there needed to be greater accountability on the part of contractors to comply. (Anonymous, personal communications, February 2; February 10; March 2; March 17, 2006) Members acknowledged the fact that politics plays a large part in the implementation process given the business interests and other political dynamics involved, such as longstanding relationships between businesses and elected officials, which hampers County's efforts to remain stern in administering 
warnings and enforcing penalties consistently. Four LWC members recommended that the $\mathrm{BCC}$ and $\mathrm{CMO}$ commit more resources by hiring additional contract compliance officers. It would allow the County to expand its enforcement efforts and thereby reduce incidents of noncompliance. (Anonymous, personal communications, February 2; February 10; February 15; March 17, 2006)

When asked about challenges related to implementing the ordinance, aside from the County needing additional contract compliance officers, four LWC members believed that the County should improve the accuracy and consistency of information shared amongst stakeholders. While they agreed to having a good relationship with County administrators, they cited information gaps within the County that prevented the ordinance's enforcement. (Anonymous, personal communications, February 1; February 10; February 15; March 17, 2006) This, combined with contractors' efforts to exploit potential loopholes made the implementation process difficult and frustrating.

Miami International Airport (MIA) appeared to be a particular source of frustration for every LWC members. In fact, the County has a history at MIA of failed management practices - its enforcement of the living wage being another example ${ }^{13}$. (Anonymous, personal communications, February 1; February 2; February 10; March 2; March 17, 2006) As to why LWC members believed that contractors did not comply, members offered different reasons. In some cases, contractors made honest mistakes of not

\footnotetext{
${ }^{13}$ For over 10 years, MIA has earned the mark for arguably being the most inefficient and corrupt County department and facility. In 1999, the Miami Herald published a series of articles focusing on airport cost overruns, cronyism, and money laundering. (De Lollis, 1999; Morgan, 2000) The Miami New Times has also published several articles exposing corrupt contracting practices and mismanagement throughout the airport. (DeFede, 1993; DeFede, 1998; Korten, 2005) Since then, MIA has continued to attract negative publicity with its expansion cost overruns, corruption, and bond rating downgrades. Overall, many County administrators and LWC members stated that most of the living wage challenges are located in MIA.
} 
providing payroll verifications or other documentations on time. These situations are usually resolved quickly with a warning by the County. In other cases, contractors attempted to circumvent the system in hopes of not paying the living wage rate altogether. Contractors argued that they were not obligated to comply and ignored it or that it did not pertain to them even though they signed an agreement to abide by the living wage provisions prior to receiving the contract. (Anonymous, personal communication, February 2 and March 2, 2006) Contractors were willing to take the risk and pay employees below the living wage or not provide health benefits and hoping that the County never found out. In some cases, it was actually more cost effective for the contractor to pay the fine than it was to provide employees a living wage given the lax penalties and insufficient monitoring and enforcement. (Anonymous, personal communications, February 2 and March 2, 2006) For example, until 2006, several employers at MIA were taking advantage of a glaring loophole related to the employee probationary periods where employees earned the low range of the living wage while trying to work past their probation to collect health benefits. One LWC member stated the following:

"The big GASPs [General Aeronautical Service Permittees] are making a killing because even though they always provide medical insurance what they did was change their probationary period from three months to six months. And after six months, rather than give them the medical insurance, they fire the employee. So for those six months, since they were going to offer the employee health insurance, they don't pay the living wage without medical insurance, they paid the $\$ 9.81$ /hour." (Anonymous, personal communications, March 2, 2006)

Another LWC member stated, "It's just phenomenal how they spend more time and money fighting it than it would be to just go along with the covered workers... ... they 
feel that it's cheaper to spend millions fighting it than to go ahead and comply." (Anonymous, personal communications, March 17, 2006) ${ }^{14}$

Overall, four LWC members believed that the County did not apply enough pressure on contractors to comply. They understood that DBD did not have the capacity to monitor each contract at MIA consistently. They also believed that the County must enforce penalties more consistently and hold contractors and other County employees accountable for their actions. (Anonymous, personal communications, February 2; February 10; March 2; March 17, 2006) One LWC member believed that the County Manager preferred not to address this matter. By handing the enforcement duties to DBD, it is this department, and not the County Manager, that became publicly responsible for its deficient enforcement policy. This disconnect made the implementation process more difficult and representative of the emerging rift between DBD and other departments regarding to the living wage. Overall, put into the larger scheme of issues and challenges facing the County, the living wage is a low priority. (Anonymous, personal communications, February 10, 2006) The result at MIA, and in some cases beyond the airport, was unfair business practices that potentially spurred a motive for other contractors not to comply. If one contractor saw violations taking place while the County was unaware or slow to respond, then there was the likelihood of others falling into noncompliance as well because of the low risk involved. The LWO also created animosity between workers earning a living wage and those who do not, in

\footnotetext{
${ }^{14}$ The County amended the ordinance to ensure that all probationary periods last 90 days. (Miami-Dade County Ord. 06-67, 2006)
} 
addition to vendors openly complying with the ordinance and those clearly trying to work around it. (Anonymous, personal communications, February 2; March 2, 2006)

Even standard enforcement of the ordinance can be complicated. On several cases, companies failed to pay their employees the living wage, and if caught, the companies threaten the County with massive layoffs because it could not afford the retroactive living wage pay differential and subsequent penalties for noncompliance. The County did not want to be in a position where the public would perceive it as being responsible for large groups of workers quickly becoming unemployed. The County's response was to continue sending notices to the contractor, and in rare cases, executed a stop payment. Regardless, three LWC members admitted that these actions rarely diminished the strong possibility that contractors failed to pay the wages or penalties. (Anonymous, personal communications, February 2; March 2; March 17, 2006) In the meantime, resentment built amongst airline employees performing the same jobs as MIA employees and earning less than the living wage ${ }^{15}$. Smaller companies complied of fear for penalties while large companies could afford to take the risk and exploit the system. Larger companies were also more likely to be repeatedly noncompliant; ironically, the County continued to award them service contracts out of fear of losing their business. (Anonymous, personal communication, March 2, 2006)

In addition, the County had been reluctant to enforce penalties on companies that they had been in business with for many years. As a result, smaller companies believed that companies with a long history with the County receive preferential treatment over

\footnotetext{
${ }^{15}$ Employees who worked directly for airline companies were exempt from the County's living wage provisions.
} 
others and this created an unfair advantage amongst competitors at MIA. As one LWC member involved with MIA business for almost 20 years explained:

"The people at the airport are big lobbyists. Companies that have pretty big contracts make a stink. They call their lobbyist, I'm guessing, but they call their legislators and they call people. Also, some companies have long-term relationships with the County. They've been working for the County for almost 20 years. It's not like this is illegal, but it's just what they do." (Anonymous, personal communication, February 3, 2006)

A telling sign about the LWO in Miami-Dade County is that Miguel Diaz de la Portilla, former County Commissioner and co-sponsor of the LWO, spent most of 2006 as a registered lobbyist speaking against the living wage, arguing that it posed unfair conditions and financial burdens to airport contractors. (Anonymous, personal communication, June 16, 2005)

With so many areas for needed improvement, the ordinance was successful to a certain extent. Nissen and Borum (2006) recently determined that the living wage managed to have a positive influence and improved the quality of life for a number of MIA employees. In addition, support for the living wage remained strong through the years and the County has continued to address matters that could improve the implementation process. Four LWC members acknowledged the fact that having support from senior administrators and the $\mathrm{BCC}$ is a rare blessing that other jurisdictions do not possess. They credited the County's continued efforts, as well as those from individual LWC members to improve the ordinance. (Anonymous, personal communications, February 2; February 9; February 10; March 17, 2006)

Regardless, each LWC member believed that the County could do more to improve the effectiveness of the ordinance. Highlighted in the annual needs assessment report and 
in interviews conducted, LWC members recommended four general solutions to address the pressing LWO challenges: (Miami-Dade County Living Wage Commission, 2005)

- Limited resources - As mentioned, without a sufficient number of compliance officers available there will be cases of noncompliance that will go unnoticed or not adequately enforced. Contractors knew this and were willing to take the chance of not paying the living wage. (Anonymous, personal communications, March 2, 2006) Each member mentioned that the lack of personnel was one of the greatest challenges hampering DBD and its attempt to enforce the ordinance. DBD concurred with this recommendation.

- Stricter penalties and enforcement - Eventually, the County needs to enforce the ordinance to the degree where contractors must pay thousands in penalties for noncompliance and do so publicly. Four LWC members believed that the County was too lenient with contractors and were willing to negotiate to resolve the matter quietly. This process was frustrating when the County awarded these same offenders new contracts only to find them not complying and the County go through the same process again. (Anonymous, personal communications, February 2; February 10; March 2; March 17, 2006) Three LWC members believed that the County should set an example with these security and airline companies. Until then, these companies know that they have an advantage in negotiations because the County will not crack down on noncompliant vendors as aggressively. (Anonymous, personal communications, February 10; March 2; March 17, 2006) 
- Enhance departmental communication and coordination - Without DBD having sufficient resources, added responsibility should fall on project managers and other department directors to be more accountable to monitoring their contracts. This would allow the County to expand its monitoring capabilities whereby contractors might reconsider before not complying and verify that each County department fulfills its responsibilities. This is essential because it helps to simplify the process for DBD.

\section{Miami-Dade County Administrative Personnel}

This section assesses Miami-Dade County's implementation effort from the standpoint of County administrators and contract compliance officers and their process to monitor and enforce the living wage. The process relates similarly to that of Broward's; however, given the fact that Miami-Dade has implemented its ordinance longer and currently manages over 220 living wage contracts, its experience with contractors is broader and more convoluted than Broward's. Miami-Dade deals with more noncompliant contractors than Broward, which has left some administrators and contract compliance officers facing a routinely arduous and exhaustive process that in some cases does not achieve what they believe to be successful results.

The process appears to be simple. Once contractors place the winning bid for a contract, the County invites them to participate in meetings to have the contract process explained. The County takes that opportunity to instruct the contractors on the contract provisions, especially any living wage requirements that they must abide by. If the contractor complies, meaning that it provides living wages and benefits accordingly, posts living wage information for employees, and responds to County audits in a timely 
manner, the process runs smoothly throughout the life of the contract. Overall, the majority of contractors manage to comply; however, there are those who make the entire monitoring and enforcement process difficult for County administrators, especially contract compliance officers. (Anonymous, personal communications, January 29 and April 5, 2006) Table 5-1 provides the frequency of living wage violations since the LWO's passage as reported by the County Manager in March 2008. There have been 97 reported violations. The County's current compliance rate is $91 \%$

Table 5-1: Miami-Dade County Living Wage Violations

\begin{tabular}{|l|c|c|}
\hline \hline Violation & Instances & \% \\
\hline \hline Failed to submit payrolls & 39 & $40 \%$ \\
\hline Underpayment of Employee & 27 & $28 \%$ \\
\hline Failed to respond to payroll audit & 17 & $18 \%$ \\
\hline Cashier's check within bi-weekly period & 7 & $7 \%$ \\
\hline Failure to respond to request for information & 5 & $5 \%$ \\
\hline Submittal of inaccurate payrolls & 2 & $2 \%$ \\
\hline
\end{tabular}

In cases where contractors do not comply, they receive a "notices to cure" citing their alleged noncompliance issues. Contract compliance officers or complaints made by employees and/or other businesses usually help the County discover these instances of noncompliance in addition to random site visits. (Anonymous, personal communications, April 5; April 12; April 14, 2006) The County grants the contractors time to comply and offers assistance to ensure that they eventually do. If the contractors are unsuccessful in becoming compliant, or refuse to do so altogether, the County then issues additional letters and notices before it threatens to stop payment or terminates the contract. The majority of the contract compliance officers credited themselves for helping contractors to become compliant, but also blame the enforcement process for being too lenient and enticing for contractors not to comply. (Anonymous, personal communication, January 
29; April 5; April 12, 2006) The County's intention was to reach some resolution with the contractors; however, two contract compliance officers and a senior-level DBD administrator, along with the majority of LWAB members, believed that these actions represented temporary fixes and do not persuade contractors not to violate the ordinance again. (Anonymous, personal communications, February 2; March 2; March 17; April 12; April 14, 2006)

When asked about effectively implementing the living wage, County administrators provided not only a definition, but also certain factors needed to achieve the expected level of accomplishment. In describing the concept, two DBD senior management administrators and four contract compliance officers defined the implementation of a living wage as the rate of compliance by contractors to provide the required wage, benefits, and information to employees as specified by the terms of the ordinance. (Anonymous, personal communications, January 29; April 5; April 12; April 14; July 10, 2006)

To achieve a successful compliance rate, they recommended that the following factors are required. First, there needs to be hands-on research by the County to understand how the living wage affects contractors and employees. Direct communication with those involved would provide a first-hand account as to why certain challenges emerge and how County measures affect the implementation outcome. It is this face-to-face interaction and the word-of-mouth networking that aids the County in identifying violations. (Anonymous, personal communication, January 29, 2006) Second, policies need to be clear. Inconsistencies or ambiguities in the ordinance have caused a gap allowing contractors to exploit loopholes, and County administrators are 
unable to determine the extent to which they should act accordingly. Three contract compliance officers mentioned that they were afraid that they might overstep their legal bounds to enforce the ordinance. (Anonymous, personal communication, April 5 and April 14, 2006) Lastly, perhaps most importantly, the County should have the necessary resources available to enforce the ordinance effectively. DBD and DPM administrators and compliance officers believed that there are simply not enough officers available to review each contract in a timely manner to ensure that all contractors comply with the ordinance. Without the necessary staffing, they admitted that contractors were less likely to comply unless County compliance officers placed persistent and visible pressure upon them. (Anonymous, personal communications, January 29; April 5; April 12; April 14; July 10, 2006)

In regards to implementation challenges, DBD senior-level managers and contract compliance officers cited several factors that are currently impeding the process. What is interesting to mention is that the factors identified by these County administrators mirrored closely to those discussed by the majority of the LWC members. The first factor mentioned is the reasons contractors fail to comply with the ordinance's provisions. Whether knowingly or not, some contractors provide inaccurate information, if any at all, fail to pay the living wage rate, provide benefits insufficient to meet requirements, and/or misinform their employees. (Anonymous, personal communications, January 29; April 5; April 12; April 14; July 10, 2006) Contractors have a reputation for being uncooperative, verbally aggressive to County employees, and examine every possible way to avoid paying the living wage. (Anonymous, personal communication, January 29, 2006) When contract compliance officers made an effort to 
notify and explain to contractors that they must comply, contractors notify senior administrators in the County to work around the process. Two contract compliance officers and a senior-level DBD administrator admitted they felt the political pressure from superiors or other departments in certain cases to provide added leniency to certain contractors given how long they have done business with the County. (Anonymous, personal communications, April 5 and April 12, 2006)

Every contract compliance officer mentioned that, in some cases, contractors admitted to not having a clear understanding of what the ordinance's provisions actually were or meant. Their lack of awareness was attributable to several reasons. First, contract compliance officers believed that contractors were more interested in the contract amount awarded or were in too much of a hurry to attain the contract than focus on the living wage clauses in their contracts. They simply ignored the requirements and/or argued that they did not pertain to contracted services even though in signing their contracts they agreed to understand and comply with the ordinance. (Anonymous, personal communication, April 12, 2006) Subcontractors also made the incorrect assumption that the services they were providing not amounting to $\$ 100,000$ would exempt them from paying living wages. If the overall contract is valued over $\$ 100,000$ then everyone under the umbrella of the contract is responsible for complying with the ordinance. Contractors tended to argue that they were unaware of this provision; however, the County discussed the details of each contract at the pre-bid meetings. (Anonymous, personal communications, April 5 and 12, 2006)

Further, two contract compliance officers mentioned that the project managers in other departments utilizing the contracted services appeared to be misleading the 
contractors and/or were not acting diligently to ensure the contractors are well informed.

(Anonymous, personal communications, April 5 and April 12, 2006) Even though DBD did have contract compliance officers that monitor compliance, DBD believed it was primarily the project managers in the County departments outsourcing the service who were directly responsible for every aspect of the contract. As one contract compliance officer mentioned, the problem appeared to be that project managers believed keeping the contractors satisfied was more important than complying with the living wage:

"They really need to help us do our job because they might know that the living wage might apply to something, but all they are interested in is who they contract and that they are getting the service they are paying for. They really have no interest, they really don't show any interest in that they care about the person that is not being paid the living wage because as long they are getting the services they are paying for, their job is done. What they need to understand is that if there is an ordinance enforcing a living wage, they don't have to do our job but they should encourage these venders to do the right thing." (Anonymous, personal communication, April 12, 2006)

Even though this contract compliance officer believed project managers are responsible for what is occurring, two other contract compliance officers mentioned there was a lack of effort on the part of each department as well exacerbating the situation. (Anonymous, personal communications, April 12 and April 14, 2006) Having other County departments commit themselves to providing clear and accurate information while holding their contractors accountable would help to curtail the rate of noncompliance hindering the implementation process.

It is the author's opinion that there appeared to be a communication gap both internally and externally in the process. Internally, this was evident through the inaccurate information shared between DBD, project managers, and their contracted 
vendors. DBD wanted project managers to provide more accurate information regarding their contractors; however, the project managers were more concerned with ensuring contractors performed their contracted service than living wage compliance. Two contract compliance officers mentioned that the lack of commitment by the project managers had been a source of frustration to DBD administrators. Externally, contractors were difficult to deal with because they were not open or truthful about their disclosures. (Anonymous, personal communications, April 5 and April 12, 2006) Employees also chose not to speak to County officials out of fear that they might lose their jobs. A contract compliance officer mentioned that this was a critical challenge because the County relied mainly on contracted employee confidential admissions to remain aware of living wage noncompliance issues. (Anonymous, personal communication, April 14, 2006) In addition, what made communicating with contractors challenging was the fact that certain contracted jobs occurred in different locations making it difficult to track down contractors at times. For example, landscapers manage to perform services throughout the entire county. Contractors forced contract compliance officers to track down some contractors to meet with them when they were not present at the time and location provided to the County. (Anonymous, personal communication, April 5, 2006)

The majority of the contract compliance officers and a DBD manager believed that the process itself was a challenge because either penalties or enforcement was either too lenient and/or time-consuming. (Anonymous, personal communications, January 29; April 5; April 12; April 14; July 10, 2006) As one contract compliance officer mentioned, "For sure, we are way too lenient. I've been here for four years and I don't think that I have ever seen anybody get the hammer. He might get a slap on the hand, but 
that is way too lenient." (Anonymous, personal communication, April 12, 2006)

Consider how the enforcement process occurred: (Anonymous, personal communication, April 5, 2006)

- Upon discovering a violation, the County sends a "notice to cure" for the contractor to address the issue. The contractor has 30 days to respond.

- Contractors tend to provide the wrong information or incomplete documents. The County notifies the contractors and offers an additional two weeks for them to provide the correct information.

- If there is no response in 30 days of the "notice to cure," the County calls the contractor directly as a courtesy.

- Contractors at this point can be given additional time (2 weeks for payroll information due, 30 days for wages due).

- If there is still no progress (at least 60 days from the initial "notice to cure"), the County sends an official violation letter to the contractor instructing them to comply within 30 days or the County takes further actions.

- The County then reserves the right to stop payment on the contract and/or terminate it completely if the contractor does not comply.

Overall, the process can take up to 180 days ${ }^{16}$. Contractors can continuously delay the process by providing inaccurate information that requires them more time to correct. A contract compliance officer admitted that contractors know this and use this to their advantage. (Anonymous, personal communication, April 12, 2006) In the meantime, the

\footnotetext{
${ }^{16}$ As of January 2006, DBD took an average of 67 days to resolve a living wage violation successfully. (Miami-Dade County Department of Business Development, 2006)
} 
more the contractors delayed the process, the more they save by failing to pay the living wage. Even though the contractor was expected to pay all back wages, the County would rather negotiate a settlement rather than terminate the contract and be held responsible for having workers lose their jobs. (Anonymous, personal communication, April 12, 2006) Moreover, the County department responsible for outsourcing the service must then find a new contractor to replace the previous one. As another contract compliance officer explained, the County felt conflicted because of the contractors' entitlement to due process when appealing County decisions and simply terminating the contract would negatively affect too many individuals. (Anonymous, personal communication, April 14, 2006) Ironically, these same contractors repeatedly violating the ordinance managed to renew or attain additional contracts. BCC members rarely questioned the issue, if at all, because of the longstanding relationships some contractors had with the County and/or certain elected officials. It was at this point in the process that half of the contract compliance officers became disillusioned and felt that the ordinance was ineffective. (Anonymous, personal communication, April 12, 2006)

Lastly, three contract compliance officers believed that the amount of resources dedicated towards enforcing the living wage was not sufficient to meet the demands of monitoring and enforcement. (Anonymous, personal communications, April 5 and April 12, 2006) To begin with, contract compliance officers had a substantial amount of work related to each contractor. Through site visits, certifying and auditing payrolls, and addressing complaints, the average amount of time it would take one contract compliance officer was approximately three days to conduct these actions for each contractor. (Anonymous, personal communications, April 5 and April 12, 2006) This assumed that 
the contractor was cooperating. Site visits were challenging in some cases since MiamiDade County was one of the largest counties in the country geographically and compliance officers would have to travel over an hour each way to assess contractors. In some cases, contractors were not even at the location(s) they specified. In certifying and auditing payrolls, contractors were capable of providing incorrect or inadequate information that resulted in a lengthy battle to disclose the correct information. Complaints also took considerable time depending on the complexity of the situation. Once a compliance officer was aware of a violation, the investigation itself could take several days or weeks before reaching a conclusion. (Anonymous, personal communication, April 5, 2006) In the meantime, DBD overlooked other contractors because there was not enough time or labor to handle every issue.

Contract compliance officers believed that contractors used the County's limited resources to their advantage. (Anonymous, personal communication, April 5 and April 14, 2006) They learned the routines by each compliance officer and knew that once an assessment was completed, County officials would not be back for several months, if not longer. Those that provided services far from County Hall in cities like Homestead and Florida City also used the distance to their benefit for the same reasons. For contractors like landscapers, contract compliance officers normally had to call ahead to make sure they were able to perform their assessment and not waste time if they drove great distances to find no one available. (Anonymous, personal communications, April 5 and April 14, 2006) This eliminated the element of surprise random visits would have and gave contractors enough time to make their work areas appear compliant. With four dedicated contract compliance officers and approximately 220 contracts, the 
opportunities easily presented themselves where contractors could violate the ordinance without the County being aware. (Anonymous, personal communication, April 5, 2006)

As a result, because contract compliance officers were overworked and faced the difficult challenges of monitoring the living wage, one officer admitted that there was low morale amongst the group. Another officer described it as "All of us are frustrated because you try to do your best job and you're already starting out crippled."

(Anonymous, personal communication, April 5, 2006) Turnover appeared to be an issue for two reasons. First, the County trained contract compliance officers extensively and they eventually became well experienced, which made them attractive to other County departments to recruit. (Anonymous, personal communication, April 14, 2006) Second, some believed the best solution was to change jobs and leave the responsibilities to someone else. There was too much of a work backlog and not enough support to address the matter. As one contract compliance officer mentioned, “...it takes so much time to get results that you feel like you're working but not accomplishing anything." (Anonymous, personal communication, April 12, 2006) The impression by senior management was that morale was not an issue and while compliance officers might be overworked, it was not necessarily due to a shortage of officers, but simply the demanding nature of the work. (Anonymous, personal communication, April 14, 2006) Regardless, every contract compliance officer interviewed agreed that with additional officers it would relieve part of the workload from the current officers and prevent the current officers from being overwhelmed. Additional compliance officers would help the County's enforcement efforts as well to review more contractors at the same time. 
(Anonymous, personal communications, January 29; April 5; April 12; April 14; July 10, 2006)

Those interviewed cited some positives that have supported the ordinance. Since its inception, the ordinance received support from County staff, particularly from the BCC. BCC support through the years has helped to strengthen the ordinance by amending it to clarify and broaden its scope. (Anonymous, personal communication, April 12, 2006) In addition, an organizational culture continued to emerge where more departments were becoming aware of the ordinance and willing to do their part to comply and support the legislation. (Anonymous, personal communication, April 5, 2006) DBD's senior management also acknowledged that the County's contract compliance officers were hard working and dedicated to enforcing the ordinance and commended their efforts for doing their part. (Anonymous, personal communication, April 14, 2006) DBD also credited the LWC for doing an excellent job in overseeing the execution of the ordinance and working with other departments to assist and coordinate in the implementation effort while addressing the concerns of the contractors and employees. (Anonymous, personal communication, July 10, 2006) However, that lack of sufficient compliance officers and lenient penalties showed that the County was limited and some contractors used that to their advantage. (Anonymous, personal communication, April 14, 2006)

\section{Summary of Findings}

Similar to Broward's case, several themes emerged based on the interviews conducted. This section highlights these themes as it related to this study in addition to outlining the accomplishments and deficiencies of Miami-Dade County's execution of 
the living wage. In light of those areas for improvement, this section also provides recommendations for improving the County's implementation efforts.

It is the author's opinion that Miami-Dade County demonstrated that both administrative and political factors affected the level of success in implementing the living wage. As a positive influence, the administrative efforts by the County to amend the ordinance and dedicate staff to monitor and enforce the living wage have helped to keep most contractors in compliance. On the other hand, there still appeared to be instances where the ordinance was open to interpretation. Contract managers were not providing contractors or DBD with sufficient information. Contractors took advantage of longstanding relationships with influential administrators throughout the County bureaucracy to evade living wage restrictions, in addition to, forcing County officials to negotiate pending penalties by placing their employees' jobs at stake. Larger companies used their size as a bargaining ploy essentially having their employees as collateral to negotiate or avoid having to pay any penalties and/or repay back wages at some point ${ }^{17}$. (Anonymous, personal communications, February 1; March 17; April 5; April 12, 2006) Overall, senior-level DBD and DPM administrators and BCC members can investigate and address this matter, however, the County feared it could potentially lose business. In the meantime, contractors lobbied County administrators to endorse a more businessfriendly approach to the living wage supporting fewer restrictions on wages and health benefits. (Anonymous, personal communications, February 1; February 10; March 17, 2006)

\footnotetext{
${ }^{17}$ However, since the County implemented the LWO, it has not recovered all the lost wages contractors failed to pay. Miami-Dade's County Manager reported in March 2008 that the County has successfully collected $\$ 180,935.65$ in back wages out of a total $\$ 285,633.02$. In addition, since they began to uphold the penalties in 2007, the County collected \$15,472.10 in sanctions. (Miami-Dade County Manager, 2008)
} 
First, every LWC member stated that the ordinance's language was not clear. (Anonymous, personal communications, February 1; February 3; February 10; February 15; March 2; March 17, 2006) Because of the ambiguity in the policy, there were concerns related to acceptable levels of quality over healthcare and how the County interpreted and enforced the ordinance. DBD questioned the employee probationary periods and the type of care provided by the health plans offered as being impractical and/or the reason for early terminations of some employees. It was unclear whether particular services were applicable or not. As a contract compliance officer explained, some "routine" services needed clarification, if only for the purpose of the County to know exactly what it should be enforcing. (Anonymous, personal communication, April 5 , 2006) Since the ordinance fell short of clearly outlining responsibilities, potential penalties, and specific criteria for living wage eligibility (in addition to a communication gap existing between County administrators and contractors), it is the author's opinion that it only supported the possibility that the implementation process could be highly politicized with equals being treated unequally, ineffective, and potentially biased.

As a result of the ambiguities in the policy, DBD was at odds with other departments since not only was it responsible for ensuring that contractors complied with the ordinance but that County departments fulfill their responsibilities throughout the process as well. Two LWC members believed that either most departments did not take the living wage ordinance seriously or that implementing the LWO was mainly DBD's responsibility. (Anonymous, personal communications, February 1 and February 10, 2006) Even though DBD was dedicated to being hands-on with contractors, it needed the help from the contracting agents in other departments to supervise every contract with 
limited resources. Two contract compliance officers recommended that DBD be more assertive in informing contractors and the contracting agents in every department of what the living wage is, how it pertains to them, and the consequences involved in cases of noncompliance. (Anonymous, personal communications, April 5 and April 12, 2006)

Miami-Dade County has made strides to strengthen its organizational structure. A glaring flaw in its original arrangement was to have DPM and DBD coordinate the implementation of the living wage together. Since placing the administrative responsibilities on DBD almost entirely, both LWC members and County administrators acknowledged an improvement in organization and compliance rates. (Anonymous, personal communications, February 1; February 10; March 17; April 5, 2006) Still, some departments saw the living wage as an inconvenience and just another issue for concern. Project managers in each department needed to cooperate more with DBD to inform and monitor contractors. Unfortunately, as noted by the contract compliance officers, these departments were more concerned with hiring a contractor to provide a service and fulfilling their objectives than to work to assist DBD in theirs. (Anonymous, personal communications, April 5 and April 14, 2006) In addition, three LWC members believed that the BCC should act as a more unified front in support of the ordinance rather than have only one or two commissioners speak publicly in favor of it. (Anonymous, personal communications, February 1; February 10; March 17, 2006) DBD administrators stated that the lack of overwhelming support was ultimately tainting the credibility of the County's dedication to support the ordinance and it was evident in the limited resources currently dedicated to the living wage. (Anonymous, personal communications, April 5; April 12; April 14, 2006) 
Several stakeholder groups played significant internal and external roles in the implementation process. First, Miami-Dade County sought to execute, monitor, and enforce the ordinance and ensure a high rate of contract compliance. Within the County, departments aside from DBD and DPM concerned themselves more with addressing their service demands and not prioritizing the living wage as DBD and DPM would expect. Outside the County, noncompliant contractors sought business from the County and attempted not to pay the living wage to earn higher profits. Covered employees served a vital role to inform the County of violations in hopes of receiving the living wage and benefits they were entitled to earn. Interestingly, competing businesses also reported noncompliant vendors to DBD and the LWC. (Anonymous, personal communication, April 5, 2006)

It is the author's opinion that grassroots organizations played a minor role from a post-implementation standpoint (or at least a less visible function than they did to advocate for the living wage), LWC members represented them throughout the implementation process. As mentioned, those LWC members involved with grassroots organizations worked towards expanding awareness of the living wage, advocated for better healthcare provisions, expanding the scope of the ordinance, and advised BCC members on the status of the ordinance's implementation. In addition, the Coalition for a Living Wage (CCLW) also promoted the living wage through its website, newsletter, and meetings. It also represented itself by having members as part of the LWC. Even though politics has a reputation of acting more as a negative factor than a positive one, the grassroots involvement was a clear sign of how politics can positively influence the living wage. This was why Luce (2004) and the majority of LWC members believed that 
there needed to be a strong grassroots representation to ensure the living wage continues to progress. (Anonymous, personal communications, February 1; February 3; February 9; March 17, 2006)

Similar to Broward County, there was a significant drop-off of grassroots participation in promoting the living wage once the Miami-Dade adopted its ordinance in 1999. Although LWC members represented several of those groups that helped to pass the ordinance, their roles evolved to where their focus now ensured that the County remained accountable for effectively implementing the living wage. Luce's (2004) assumption in this case was correct, as grassroots organizations themselves do not have the same presence as they did prior to implementation.

It is the author's opinion that while the County should balance administrative and political influences when implementing the living wage, the resources it has at its disposal to carry out its objectives dictates its effectiveness. Even though, the County's compliance rate is relatively high, the fact that contract compliance officers admit to not having the ability to constantly monitor the contractors begs the question how many other noncompliance cases go unnoticed. Both LWC members and County personnel in this study unanimously agreed that the County should acquire additional compliance officers to effectively monitor and enforce the ordinance. The fact that the County is operating with insufficient resources has attributed to lower compliance rates, overworked personnel, and low employee morale. (Anonymous, personal communications, February 1; March 17; April 5; April 12, 2006) Overall, since 2006, the County's proactive actions resolved several ambiguities in the ordinance as well as instituted stricter sanctions on noncompliant contractors. However, it is the author's opinion, that to sustain a high level 
of compliance, the County should invest in additional compliance officers and coordinate with other departments to improve its enforcement efforts. 


\section{CHAPTER VI}

\section{QUANTITATIVE RESULTS AND ANALYSIS}

This chapter presents the results obtained from the survey administered along with the statistical analysis techniques conducted. First, this chapter provides a discussion of the survey's unit of analysis, sample characteristics, and response rate. The second section describes the statistical methods used to test the study's hypotheses and the results. The methods this study utilized included descriptive statistics, Chi Square, Cronbach's Alpha, and Spearman's Rank Correlation Coefficient (Spearman's rho). The third section discusses the study's hypotheses and their relation to the quantitative and qualitative results. The final section discusses the results generated from the open-ended questions utilized in the survey. The author used SPSS and STATA to conduct the statistical analysis for this study.

\section{Sample Characteristics ${ }^{18}$}

This section presents the demographic information of the jurisdictions that participated in the survey. Along with presenting descriptives on the variables in Table 6-1, Table 6-2 provides the Chi-Square statistics that demonstrate the relationship strengths among variables. The Kurtosis and skewness values in Table 6-1 indicate that each variable's frequency distributions appear skewed and not normally distributed, thus supporting the need for Chi Square analysis. Kurtosis and skewness tests help to verify the normality of each variable's frequency distribution. (Gujarati, 2003) Checking variable responses for normality is essential given the basic statistical assumption that one could easily infer the survey's results to be reflective of a larger population.

\footnotetext{
${ }^{18}$ Appendix C provides the descriptive survey results.
} 
(Gujarati, 2003) While a sample size of at least 19 as shown in Table 6-2 might arguably be too small for Chi Square tests to provide valid results, Howell (2002) states that conservative sample sizes of 20 are acceptable, however, statistical power might come into question. Table 6-1 indicates that the skewness for the variables ranged from -2.87 to 5.27 and Kurtosis ranged from -0.14 to 28.14 . This means that normal distributions hardly existed among the variables. In cases where they existed, the distributions peaked away from the population mean. Ideally, the targets for skewness and Kurtosis are 0 and 3 respectively. (Gujarati, 2003) Overall, these statistics indicate considerable variation in the approaches jurisdictions implement their LWOs.

Table 6-1: Sample Characteristic Kurtosis and Skewness Values

\begin{tabular}{lcccccccc}
\hline \hline \multicolumn{1}{c}{ Variable } & n & Min & Max & Mean & Median & St. Dev. & Skewness & Kurtosis \\
\hline \hline Years LW Implemented & 27 & 2 & 10 & 6.47 & 6 & 1.94 & 0.69 & -0.14 \\
LW Service Contracts & 19 & 2 & 1000 & 160.05 & 50 & 255.02 & 2.49 & 6.46 \\
LW Compliance Rate & 28 & .4 & 1 & .94 & 1 & .14 & -2.87 & 8.51 \\
LW budget & 21 & 0 & 850,000 & 70565.79 & 5000 & 176218.30 & 3.98 & 17.25 \\
FTE Dedicated to LW & 27 & 0 & 30 & 1.84 & 1 & 5.45 & 5.27 & 28.14 \\
\hline
\end{tabular}

For Table 6-2, the purpose of utilizing and presenting the Chi-square statistics is to demonstrate that there is no relationship between the variables. This measure ensured that the larger the difference existing between variables, the stronger the relationship actually was. A weak relationship can be the result of a skewed distribution that can potentially threaten the validity of the survey results and any conclusions to reject, or fail to reject, the null hypotheses. (Singleton, Straits, Straits, and McAllister, 1988)

Table 6-2: Sample Characteristics Chi-Square Values

\begin{tabular}{lccc}
\hline \hline \multicolumn{1}{c}{ Variable } & Chi-Square & df & Asymp. Sig. \\
\hline \hline Years LW Implemented & 20.222 & 4 & .000 \\
LW Service Contracts & 46.667 & 7 & .000 \\
LW Compliance Rate & 16.333 & 1 & .000 \\
LW budget & 30.857 & 10 & .001 \\
FTE Dedicated to LW & 22.667 & 8 & .004 \\
\hline
\end{tabular}


As part of the survey, the author contacted each jurisdiction listed by ACORN on its living wage website (http://www.livingwagecampaign.org) by phone and/or email between June and October 2006. Survey findings revealed that jurisdictions implementing a living wage ranged from one to nine years with the majority (89\%) having done so for at least four years. There were seven jurisdictions (26\%) to report that they have no living wage contracts currently open. Overall, the proportion of living wage contracts to all other service contracts averaged $15 \%$ amongst cities and counties. Three jurisdictions (11\%) reported having a living wage advisory board. Nine jurisdictions (33\%) admitted to dedicating no funding towards living wage implementation while one jurisdiction budgeted $\$ 850,000$. Overall, the average funding jurisdictions invested in the living wage is $8 \%$ of their current budget. The majority of cities and counties (56\%) dedicated at least one FTE to the living wage while five reported that they have none. In regards to their compliance rate, $56 \%$ reported having $100 \%$ contract compliance. This does not mean that they have perfect compliance, but rather that there were no instances of noncompliance reported.

\section{Constructs Reliability Tests}

As discussed throughout this study, a successful living wage implementation strategy has to engage different factors. Specific questions asked in the survey aimed to define and measure these constructs. Ensuring construct validity is important because it confirms that the measures and contexts within the survey are consistent, accurate, and comparable to larger populations. (Shadish, Cook, and Campbell, 2002) 
Chapter 3 explained the importance of validity and reliability. Reliability represents the level of consistency variables are capable of measuring a particular construct. The author utilized Cronbach's Alpha to assess the reliability of the measures incorporated in this study. Cronbach's Alpha is a statistical measure based on the correlations amongst specific variables. In essence, the higher the alpha score, the better it reflects the consistency and reliability that the variables assumed would define a construct. The highest Cronbach's Alpha value one can attain is 1 while values below 0.7 generally are not reliable. (Gujarati, 2003) As shown below, each of the construct groups demonstrated to having Cronbach's Alpha scores of over 0.7.

\section{Policy Ambiguity}

Policy ambiguity relates to unclear language within the ordinance that can contain loopholes where individuals can take advantage and avoid having to comply with the living wage. In addition, a high level of uncertainty would provide a better opportunity for political influences to hamper the implementation process.

Respondents rated on a five-point scale the following statements related to political ambiguity. The aim was to examine the extent which vague language in the ordinance can attract negative political influences and impede the implementation process.

- LWO ordinance language and governing regulations are clear and unambiguous to all stakeholders.

- LWO ordinance "loopholes" contribute to lackluster employer compliance.

- Ambiguity in the LWO policy offers the opportunity for political interference.

- Administrative orders and objectives are clear to those involved in monitoring and enforcing the LWO.

- Contractors/vendors understand what the LWO is and what is required of them.

The author conducted a reliability test to confirm whether these variables as a group are capable of representing the political ambiguity construct. As shown by the results in 
Table 6-3, each variable shows at least borderline acceptable alpha scores thus ensuring that they suffice to represent the construct. Overall, the Cronbach's Alpha score for construct variables as a whole defining political ambiguity was 0.764 .

Table 6-3: Policy Ambiguity Cronbach's Alpha Values

\begin{tabular}{llc}
\hline \hline Variable & $\mathrm{n}$ & Cronbach's Alpha \\
\hline \hline Ordinance Language Clarity & 28 & .692 \\
Ordinance Loopholes & 28 & .680 \\
Ambiguity = Politics & 29 & .637 \\
Clear AO and Objectives & 29 & .733 \\
Vendors Understanding & 29 & .810 \\
\hline \multicolumn{3}{c}{ Policy Conflict }
\end{tabular}

Policy conflict relates to any forces challenging policy implementation because of poorly outlined organizational roles, responsibilities, procedures, etc.

The survey respondent the following questions on the same five-point scale to rate political conflicts:

- Monitoring, and enforcement are met with vendor resistance.

- Vendors are generally at odds over LWO regulations.

- Contractors/vendors are constantly trying to find loopholes to avoid LWO obligations.

- Contractors/vendors fulfill their obligations to inform employees about the LWO.

Overall, in testing for internal consistency reliability as shown in Table 6-4, the

Cronbach's alpha statistics reported that all four have strong relationships and generated a 0.89 overall alpha score thus demonstrating that these variables were reliable to define this construct.

Table 6-4: Policy Conflict Cronbach's Alpha Values

\begin{tabular}{lcc}
\hline \hline Variable & $\mathrm{n}$ & Cronbach's Alpha \\
\hline \hline Vendor Resistance & 28 & .866 \\
Vendor Conflict & 28 & .835 \\
Exploit Loopholes & 28 & .870 \\
Informing Employees & 28 & .866 \\
\hline
\end{tabular}




\section{Stakeholders}

Stakeholders represent workers, labor groups, living wage advocates, and other groups and individuals directly impacted by the implementation of a living wage. Ideally, the higher degree of involvement by these groups would allow the implementation to be more effective, as there would be the possibility for open communication and cooperation.

Respondents were asked to rate the following stakeholder group on a five-point scale ranging from low to high as to their political influence in the implementation process:

- Elected officials

- Contractors

- Grassroots groups (e.g. church, labor, and/or community action groups)

- Bureaucratic politics (e.g. competition amongst government subdivisions)

The following question allowed respondents to rate the extent living wage advisory boards affect the implementation process:

- How active is the advisory board's role in enforcing and/or improving the LWO? Overall, Table 6-5 demonstrates how the variable group defining stakeholder influence earned a 0.828 Cronbach's alpha rating and proved to define this construct reliably.

Table 6-5: Stakeholder Influence Cronbach's Alpha Values

\begin{tabular}{lcc}
\hline \hline Variable & $\mathrm{n}$ & Cronbach's Alpha \\
\hline \hline Elected Officials & 29 & .817 \\
Contractors & 29 & .804 \\
Grassroots & 29 & .762 \\
Bureaucratic Politics & 29 & .752 \\
LWAB Activity & 20 & .817 \\
\hline
\end{tabular}

Organizational Culture

For the purpose of this study, organizational culture represents the level of acceptance and commitment to which each jurisdiction implements the living wage. 
There are two components of organizational culture measured in this survey. First, information as to its accuracy and timeliness and the effect it potentially has on the implementation policy. This is a critical factor given that how organizations communicate and utilize their information can determine the success of implementing a policy. As shown in the case of Broward County, information gaps managed to complicate their process and lead to inaccurate assessments of the LWO's effectiveness. Second, the level of monitoring and enforcement demonstrates how committed a jurisdiction is to actually implementing the living wage. This involves the time and efforts as demonstrated by Miami-Dade County to hold contractors accountable for providing living wages to employees. In addition, the organizational culture can lead to political influences impeding the administrative process from ensuring compliance.

The survey asked respondents on a five-point scale how much they agreed or disagreed with the statements provided below. The goal was to measure the value, access, use of information, and the quality of the communication channels in place.

- We strive to improve the LWO based on past mistakes and current trends.

- Information on program results is easily accessible and shared openly with ALL stakeholders.

- We have sufficient data to monitor the effectiveness of our implementation of the LWO.

- Policymaking reflects input provided by all stakeholders. (e.g. elected officials, administrators, vendors, and grassroots groups)

In regards to monitoring and enforcement, respondents were asked on the same scale to rate their level of agreement on the following statements. The aim measured how jurisdictions prioritize their monitoring and enforcement efforts in addition to penalizing noncompliant vendors. These statements also weighed the political influence, if any, on monitoring and enforcement practices. 
- Elected officials generally act quickly to resolve loopholes in the ordinance.

- Enforcement of contract compliance is consistent regardless of the vendor.

- We apply more stringent standards against repeat offenders.

- Penalties for LWO noncompliance are fair with the gravity of the violation.

- Upon being reported, violations are investigated in a timely manner.

- Penalties are applied in a timely manner after adjudication.

Table 6-6 demonstrates how the individual Cronbach's alpha scores and the overall .9036 score verifies that information access, open communication, sufficient data, and efforts to continuously improve their practices are strong indicators defining the information component of the organization's culture. Table 6-7 provides similar results for the monitoring and enforcement component of the organization's culture. Overall, the variables for these groups demonstrated a strong internal consistency indicating that each variable is a reliable indicator for defining the monitoring and enforcement aspect of an organization's culture. The Cronbach's alpha values were .904 and .944 for the information and monitoring/enforcement components respectively.

Table 6-6: Org. Culture (Information) Cronbach's Alpha Values

\begin{tabular}{lcc}
\hline \hline Variable & $\mathrm{n}$ & Cronbach's Alpha \\
\hline \hline Efforts to Improve LW & 28 & .889 \\
Information Access & 28 & .890 \\
Sufficient Data & 28 & .889 \\
Stakeholder Input & 29 & .835 \\
\hline
\end{tabular}

Table 6-7: Org. Culture (Monitoring and Enforcement) Cronbach's Alpha Values

\begin{tabular}{lcc}
\hline \hline Variable & $\mathrm{n}$ & Cronbach's Alpha \\
\hline \hline Resolving Loopholes & 27 & .934 \\
Consistent Enforcement & 29 & .931 \\
Penalties for Repeat Offenders & 27 & .933 \\
Proportionate Penalties & 29 & .931 \\
Timely Investigations & 29 & .931 \\
Timely Penalties & 26 & .946 \\
\hline
\end{tabular}




\section{Organizational Capacity}

The insufficient resources limiting the success of a living wage implementation policy define organizational capacity. As shown in both Miami-Dade and Broward County cases, insufficient funding and personnel hindered county departments from evaluating, monitoring, and enforcing the ordinance. Luce (2004) mentioned one needs adequate funding and personnel to implement a living wage in an effective way.

The following statements helped respondents confirm the level of staffing and funding their jurisdictions invested into implementing the living wage. The survey asked respondents to rate on a five-point scale their level of agreement on the following:

- We are understaffed and cannot implement the ordinance effectively.

- The LWO receives sufficient funding for successful implementation.

Both managed to generate a high Cronbach's alpha confirming a strong internal consistency to define organizational capacity. However, given that there are only two variables, STATA is only able to provide the average inter-item covariance and scale reliability coefficient for both together (.883). Table 6-8 reflects these results.

Table 6-8: Organizational Capacity Cronbach's Alpha Values

\begin{tabular}{lcc}
\hline \hline Variable & $\mathrm{n}$ & Cronbach's Alpha \\
\hline \hline Understaffing & 28 & .883 \\
Sufficient Funding & 29 & .883 \\
\hline
\end{tabular}

\section{Organizational Politics}

Organizational politics represent the dynamic relationships amongst the parties involved and how their roles affect the implementation process. In some cases, organizational politics has been a positive influence by helping advance living wages 
throughout the country. However, it also caused several challenges to how its implementation as seen in the cases of Broward and Miami-Dade Counties.

Luce (2004) mentions that there is a trend where jurisdictions pass living wage ordinances yet fail to effectively plan for its implementation. The survey provided statements to respondents to evaluate the validity of this claim and determine the extent politics affect the implementation process. Based on a five-point scale, respondents rated their level of agreement on the following:

- Elected officials support the passage of the LWO, but not its implementation.

- Political influence limits the overall effectiveness of LWO implementation.

Since there are only two variables defining this construct, STATA provided only the average inter-item covariance and scale reliability value of .999 .

Table 6-9: Organizational Politics Cronbach's Alpha Values

\begin{tabular}{lcc}
\hline \hline Variable & $\mathrm{n}$ & Cronbach's Alpha \\
\hline \hline Elected Official Support & 28 & .999 \\
Political Influence & 28 & .999 \\
\hline
\end{tabular}

Hypothesis Testing

The purpose for testing reliability was to ensure that the measures operationalized to define the constructs were capable of doing so. Given the reliability test results, the next step was to measure how these constructs (independent variables) correlated with the contract compliance rate (dependent variable). Table 6-10 lists this study's hypotheses.

Table 6-10: List of Null Hypotheses

\section{Hypothesis}

$\mathrm{H}_{1} \quad$ Policy ambiguity has no effect on the compliance rate of a living wage contract.

$\mathrm{H}_{2} \quad$ Policy conflict has no effect on the compliance rate of a living wage contract.

$\mathrm{H}_{3} \quad$ Stakeholders have no effect on the compliance rate of a living wage contract.

$\mathrm{H}_{4}$ An organizational culture promoting information sharing has no effect on the compliance rate of a living wage contract. 
Table 6-10 (continued): List of Null Hypotheses

Hypothesis

$\mathrm{H}_{5} \quad$ An organizational culture emphasizing monitoring and enforcement has no effect on the compliance rate of a living wage contract.

$\mathrm{H}_{6} \quad$ Inadequate organizational capacity has no effect on the compliance rate of a living wage contract.

$\mathrm{H}_{7} \quad$ Organizational politics has no effect on the compliance rate of a living wage contract.

To test these hypotheses, the author utilized Spearman's rho (or Spearman's rank

correlation coefficient) to measure the correlation between the construct groups and the rate of compliance. Spearman's rho is nearly identical to Pearson's Correlation,

however, Spearman's rho substitutes raw scores with ranks to measure the linear

relationships between two variables. (Howell, 2002) The correlation coefficient ranges

from -1 to 1 . The direction and magnitude measured the strength of the relation as well as its positive or negative correlation.

To measure the relationships between the construct groups to the dependent variable, the author totaled the responses from the independent variables defining each construct group to create a separate variable for each construct. Table 6-11 presents the results. Each represents the bivariate correlation values of the aggregated construct variable as it related to the compliance rates provided by each responding jurisdiction.

Table 6-11: Spearman's rho Values by Construct Group

\begin{tabular}{|c|c|c|c|}
\hline & $\mathrm{n}$ & Sig. (2-tailed) & $\begin{array}{l}\text { Correlation } \\
\text { Coefficient }\end{array}$ \\
\hline Policy Ambiguity & 22 & 0.008 & $-0.550 * *$ \\
\hline Policy Conflict & 23 & 0.121 & -0.333 \\
\hline Stakeholders & 15 & 0.631 & 0.135 \\
\hline Org. Culture (Information) & 21 & 0.084 & 0.386 \\
\hline Org. Culture (Monitoring \& Enforcement) & 20 & 0.048 & $0.448 *$ \\
\hline Org. Capacity & 23 & 0.027 & $-0.460 *$ \\
\hline Org. Politics & 23 & 0.015 & $-0.501 *$ \\
\hline $\begin{array}{l}* \text { Correlation is significant at the } 0.05 \text { level (2-tailed) } \\
* * \text { Correlation is significant at the } 0.01 \text { level }(2 \text {-taile }\end{array}$ & & & \\
\hline
\end{tabular}


Hypothesis $\mathrm{H}_{1}$ examined the effects policy ambiguity has on living wage implementation and contract compliance rates. Specifically, the hypothesis is that policy ambiguity would have a negative effect on the compliance rate. As shown in Table 6-11, policy ambiguity demonstrates having a significant negative effect.

In both case studies, the majority of living wage advisory board members and senior and mid-level county administrators admitted that the ordinance language and their stated policies and practices require corrections and/or amendments. In some instances, some contract compliance officers in Miami-Dade admitted to either not being sure of what actions to take or that loopholes put them in a precarious situation of possibly overstepping their bounds to monitor and/or enforce. (Anonymous, personal communication, February 2; February 10; April 5; July 14, 2006) Contract compliance officers in Miami-Dade believe that processes need to be more transparent as there are contractors claiming to be unaware of the living wage and its requirements. Overall, because of the lack of clarity, it makes their jobs more frustrating. (Anonymous, personal communication, April 5 and April 14, 2006)

Hypothesis $\mathrm{H}_{2}$ examined the effects policy conflicts have on living wage implementation and contract compliance rates. Specifically, the hypothesis is that policy conflict would have a negative effect on the compliance rate. As shown in Table 6-11, this construct was unable to yield a significant result.

Consequently, although this construct emerged as an important role in the case studies, it failed to reject the null hypothesis. It should be noted that by utilizing Spearman's rho on the individual variables defining this construct, contractors not 
informing their employees of their living wage entitlements is a significant negative factor affecting the contract compliance rate $\left(r_{s}=-0.452 ; p=0.03\right)$. Conflicts on how to implement the ordinance can cause some friction as it did in both Miami-Dade and Broward Counties. (Anonymous, personal communication, March 17 and July 14, 2006) Challenges also stem from the lack of information shared between administrators. (Anonymous, personal communication, April 5 and July 14, 2006) In Broward's case, conflict as to the extent contract administrators believe they should monitor contractors led to inaccuracies in its enforcement and compliance projections. (Anonymous, personal communication, September 29, 2006)

Hypothesis $\mathrm{H}_{3}$ examined the effects stakeholders have on living wage implementation and contract compliance rates. Specifically, the hypothesis is that stakeholders in general would have a positive effect on the compliance rate. As shown in Table 6-11, this construct was unable to yield a significant result.

To a certain extent, this result is not surprising given that the stakeholders identified (elected officials, contractors, grassroots organizations, and government administrators) have conflicting goals that impede the overall progress of the ordinance. As Luce (2004) mentioned, the lack of grassroots involvement during the implementation process caused some LWOs to fail or lose its significance. In fact, $67 \%$ of all jurisdictions surveyed noted a decrease in the grassroots involvement once the living wage became law.

Hypothesis $\mathrm{H}_{4}$ examined the effects an organizational culture promoting information sharing has on living wage implementation and contract compliance rates. Specifically, the hypothesis is that information sharing would have a positive effect on the compliance rate. As shown in Table 6-11, this construct was unable to yield a significant result. 
While the construct failed to reject the null hypothesis, there were two variables within the construct group that demonstrated significant correlations to the compliance rate. Information access proved to be a positive factor $\left(\mathrm{r}_{\mathrm{s}}=0.428 ; \mathrm{p}=0.042\right)$ as well as shared input by all stakeholders $\left(\mathrm{r}_{\mathrm{s}}=0.464 ; \mathrm{p}=0.022\right)$. Stakeholder input has shown, especially in Miami-Dade County, to be beneficial to improving the implementation process of the LWO. Living Wage Commission meetings offer opportunities to have vendors and County departments share ideas, complaints, and so forth. These open forums lead the County to amend the ordinance in several instances and update its policies and procedures. Broward County's meetings are similar in form; however, external stakeholders have yet to play a significant role in advancing the ordinance.

Hypothesis $\mathrm{H}_{5}$ examined the effects an organizational culture emphasizing monitoring and enforcement as part of its policies and procedures has on living wage implementation and contract compliance rates. Specifically, the hypothesis is that a commitment to monitoring and enforcement would have a positive effect on the compliance rate. As shown in Table 6-11, organizational culture emphasizing monitoring and enforcement shows to have a significant positive effect.

The case studies pointed to elements of this construct. First is the commitment by each county to monitor contracts and to penalize violations to the ordinance properly. Second, the effect lax penalties have to ensure proper compliance. While the upper management in both counties believes monitoring and enforcement is a top priority, it seems to dissipate as one examines the lower administrative levels of the jurisdictions, specifically to the level of the contract administrators. In Miami-Dade, LWC members believed that jurisdictions must execute more stringent penalties to reduce the likelihood 
of contract noncompliance. Overall, a structured penalty scale based on the severity of the offense and contractor's record of accomplishment would help enforce any ordinance violations. (Anonymous, personal communication, February 2 and February 10, 2006)

Hypothesis $\mathrm{H}_{6}$ examined the effects organizational capacity has on living wage implementation and contract compliance rates. Specifically, the hypothesis is that organizational capacity would have a negative effect on the compliance rate. As shown in Table 6-11, organizational capacity shows to have a significant negative effect.

In both case studies, Miami-Dade contract compliance officers and Broward Purchasing administrators admit to being overworked and understaffed. (Anonymous, personal communication, April 5 and July 13, 2006) While much effort goes to passing the ordinance, it does not reflect the support to implement it effectively. Follow-up emails to the surveyed jurisdictions reflected this sentiment. Department directors in both counties stated that organizational capacity is the most important factor needing consideration but is unlikely to receive it. (Anonymous, personal communication, April 14, 2006 and June 15, 2007)

Hypothesis $\mathrm{H}_{7}$ examined the effects organizational politics have on living wage implementation and contract compliance rates. Specifically, the hypothesis is that organizational politics would have a negative effect on the compliance rate. As shown in Table 6-11, organizational politics shows to have a significant negative effect.

The majority of those interviewed admitted that the implementation processes for a living wage is inherently political where longstanding business relationships and stakeholder self-interests are commonplace. However, the case studies illustrated that 
politics was a primary driver to getting the ordinance implemented in the first place through public rallies and local networking.

\section{Open-Ended Questions Results}

The survey concluded with two open-ended questions to gather a more in-depth perspective on how jurisdictions currently implement their ordinance. The first question asked respondents whether they believe government vending practices are an effective way to achieve social goals like the living wage. Greenberg (2004) believes that policies like the living wage are likely to succeed more under the authority of an administrative department or agency better designed to oversee its implementation beyond purchasing departments, for example, a city/county manager's office. However, in the case of Miami-Dade, such a situation can be somewhat misleading given that living wage responsibilities technically fall under the County Manager even though DBD and DPM are mainly responsible for managing and enforcing the LWO. Nevertheless, the jurisdiction's purchasing or procurement-related departments manage the majority of living wage ordinances.

Table 6-12 - Vending Solution for Social Goals Response Rate

Do you think that vending is an effective way to achieve social goals like the living wage? Why or why not? $(\mathrm{n}=26)$

\begin{tabular}{ll}
\hline \hline Yes & $42.3 \%$ \\
No & $30.8 \%$ \\
No comment & $26.9 \%$ \\
\hline
\end{tabular}

Table 6-12 shows that a plurality of those answering yes or no believe that vending practices address social goals like the living wage effectively. Respondents answering "yes" support the notion that vending practices are important because it is an effective way to ensure that employers pay their employees a living wage. They believe that it is a 
legitimate way for government to apply some control for assisting those in need. In addition, simply aiming to hire the lowest bidders on a contract is not always the best policy. There needs to be a balance between cost and quality. By paying a living wage, workers in most cases earn more than they would working elsewhere and this would give them the incentive to maintain a higher level of performance. Besides, jurisdictions try to make their living wage provisions clear and vendors aware of them before finalizing contracts and vendors always have the option not to bid on the contract if they do not want to pay a living wage.

On the other hand, those opposed to the question in Table 6-12 believe that vending services should not be the primary method to implementing a living wage and feel that eliminating the ordinance and allowing free markets to dictate is a more rational and effective approach. Moreover, respondents admitted there is pressure to "do more with less." Living wages make this difficult to achieve because they inflate the costs of contracts. When analyzing the issue from a cost-benefit perspective, living wages are less practical given the cost and labor needed to help a relatively small group of individuals. The overall rate of return would show from an economic standpoint that living wages are ineffective.

The second question asked respondents what else might help improve their implementation process. Table 6-13 reports the frequency of responses grouped into major factors. In some instances, respondents listed more than one major need. However, $20.7 \%$ of respondents mentioned that no additional steps would improve their implementation efforts. 
Table 6-13 - Needs Proposed to Improve Implementation Process

What else is needed to help your work unit become better capable of overseeing the implementation of the living wage ordinance? $(n=24)$

\begin{tabular}{lc}
\hline Need & Percent \\
\hline \hline Staffing & 34.5 \\
None & 20.7 \\
Greater Awareness & 10.3 \\
Policy Support & 10.3 \\
Additional Training & 10.3 \\
LWO Expansion & 6.9 \\
Stronger Penalties & 3.4 \\
Better Planning & 3.4 \\
\hline
\end{tabular}

As noted in both cases, Miami-Dade and Broward Counties stated that the lack of sufficient staffing to monitor and enforce the LWO is perhaps the most critical issue each faces. The majority of survey respondents appear to deal with the same issue. This also supports Luce's (2004) argument that living wages for the most part are either not sufficiently funded, understaffed, or both. One reason cited by respondents as to why additional staffing would help to relieve some of the administrative burden on those currently trying to manage it. According to survey statistics, jurisdictions averaged 1.66 FTE dedicated to monitoring the living wage with $34 \%$ of respondents claiming less than 0.5 or zero FTEs and one jurisdiction reporting 30 FTEs while jurisdictions in general have 138 living wage contracts to manage. According to one contract compliance officer in Miami-Dade County, monitoring one living wage contract from start to finish takes about 20 hours. (Anonymous, personal communications, April 5, 2006)

Several respondents suggested that a more aggressive awareness campaign would improve the implementation process - a point also mentioned by advisory board members in Miami-Dade and Broward Counties. Luce (2004) also supports this idea. The fact that living wage campaigns emerge from grassroots campaigns demonstrates 
that jurisdictions respond to organized public calls for better wages. By the same process, jurisdictions need the same pressure to remain diligent in monitoring, enforcing, and expanding the living wage. The majority of advisory board members in Miami-Dade and Broward Counties believe that if local community organizations and businesses become better informed and work with County leaders, the LWO in their respective counties would be more effective and help more people than they currently do. However, one cannot be too optimistic to the likelihood of this occurring given that there is not a substantial movement in either county to support it.

The need to educate government personnel and contractors of the process, effects, and purpose of a living wage, especially penalties for noncompliance, are essential to implementing a more effective living wage policy. As seen in the cases of the project managers and contract administrators in Miami-Dade and Broward Counties, the lack of knowledgeable administrators provided some contractors the opportunity to be noncompliant without fear of penalties or audits. Contractors also need better training or education given that some claimed to being unaware of the ordinance and the expectations behind it.

Lastly, respondents suggested that living wage ordinances should have stricter penalties. As seen in Miami-Dade County, the lack of strict enforcement has lead to some contractors to be in noncompliance with the ordinance and the County having a difficult time to maintaining contractors under compliance. It would appear, given the respondents' emphasis on staffing rather than on planning and penalties, that jurisdictions concern themselves more with addressing the current policy rather than taking proactive steps to ensure the policy's success. This is not to say that the sufficient staffing is not a 
necessity for policy implementation, but having stricter penalties to dissuade contractors from purposely violating the ordinance and an organizational commitment to enforce these penalties would reduce the demand for added staffing. For example, the MiamiDade County Manager's memorandum regarding the living wage's report on noncompliance mentioned that since Miami-Dade began enforcing its monetary sanctions for living wage violations, the ordinance's implementation is more effective. (MiamiDade County Manager, 2008) In fact, one contract compliance officer mentioned that contractors currently comply more with ordinance ever since Miami-Dade's enforcement efforts increased. (Anonymous, personal communications, March 19, 2008)

Overall, the issues and suggestions cited by the respondents surveyed seem to compare to those identified in the cases of Miami-Dade and Broward Counties. Most jurisdictions nationwide face similar issues that require policy changes suggested by administrators in both Counties. For example, respondents cited the need for additional personnel and funding, more stringent penalties, and better organization of staff and information. The responses also supported Luce's (2004) theory that living wage policies are inconsistent with the level of support and interest they generate during passage. This also would support Matland's (1995) argument that situations where policy conflict and ambiguity exist diminish the amount of administrative organization and information management needed for effective implementation. 


\section{CHAPTER VII}

\section{SUMMARY AND CONCLUSIONS}

This chapter discusses the overall findings for this study. The first section presents the conclusions to each hypothesis resulting from the surveys and interviews conducted. The second section presents the limitations of this study. The final section summarizes policy recommendations for Miami-Dade and Broward Counties and presents a discussion for the need for future research.

The aim of this dissertation was to examine the living wage ordinances in MiamiDade and Broward Counties while identifying the primary drivers in their respective implementation processes. Specifically, the focus was on evaluating how administrative and political factors influence a living wage policy. Overall, the surveys and interviews conducted supported the proposed research framework discussed in Chapter 2. Having surveyed jurisdictions nationwide implementing living wages also helped to infer that the majority of these primary drivers were common in most living wage policies.

\section{Findings}

Table 7-1 provides a summary of this study's hypotheses and the findings developed through quantitative and qualitative methods. Any hypothesis noted as being "supported" through quantitative measures demonstrated that a statistically significant relationship existed between the construct and the level of contract compliance at least at a .05 significance level. The qualitative results represented the coded case study results from Miami-Dade and Broward Counties. The frequencies relating to certain factors provided the necessary evidence to support this study's assumptions. 
Table 7-1: Summary of Findings

\begin{tabular}{|c|c|c|c|}
\hline & Hypothesis & $\begin{array}{c}\text { Quantitative } \\
\text { Study* }\end{array}$ & $\begin{array}{c}\text { Qualitative } \\
\text { Study** }\end{array}$ \\
\hline $\mathrm{H}_{1}$ & $\begin{array}{l}\text { Policy ambiguity will have a negative effect on } \\
\text { the compliance rate of a living wage-applicable } \\
\text { service contract. }\end{array}$ & Supported & Supported \\
\hline $\mathrm{H}_{2}$ & $\begin{array}{l}\text { Policy conflict will have a negative effect on the } \\
\text { compliance rate of a living wage-applicable } \\
\text { service contract. }\end{array}$ & Not Supported & Supported \\
\hline $\mathrm{H}_{3}$ & $\begin{array}{l}\text { Stakeholders will have a positive effect on the } \\
\text { compliance rate of a living wage-applicable } \\
\text { service contract. }\end{array}$ & Not Supported & Supported \\
\hline $\mathrm{H}_{4}$ & $\begin{array}{l}\text { An organizational culture promoting information } \\
\text { sharing will have a positive effect on the } \\
\text { compliance rate of a living wage-applicable } \\
\text { service contract. }\end{array}$ & Not Supported & Supported \\
\hline $\mathrm{H}_{5}$ & $\begin{array}{l}\text { An organizational culture emphasizing } \\
\text { monitoring and enforcement will have a positive } \\
\text { effect on the compliance rate of a living wage- } \\
\text { applicable service contract. }\end{array}$ & Supported & Supported \\
\hline $\mathrm{H}_{6}$ & $\begin{array}{l}\text { Inadequate organizational capacity will have a } \\
\text { negative effect on the compliance rate of a living } \\
\text { wage-applicable service contract. }\end{array}$ & Supported & Supported \\
\hline $\mathrm{H}_{7}$ & $\begin{array}{l}\text { Organizational politics will have a negative effect } \\
\text { on the compliance rate of a living wage- } \\
\text { applicable service contract. }\end{array}$ & Supported & Supported \\
\hline $\begin{aligned} * \\
* *\end{aligned}$ & $\begin{array}{l}\text { ported: Statistically significant }(\mathrm{p}<=.05) \\
\text { sported: } \text { Supported = high coded frequency }\end{array}$ & & \\
\hline
\end{tabular}

\section{Successful Implementation}

As mentioned, the dependent variable to analyze each construct was the contract compliance rates for each jurisdiction. One can analyze the effectiveness of living wages in different ways. For instance, research developed by Brennan (2005) and Nissen and Borum (2006) identified living wage effectiveness as the effect the LWO had on the recipients' quality of life. However, this study's focus was on the management of the LWO. Given the literature analysis on New Public Management and its emphasis on performance measurements, it is the author's opinion that utilizing a jurisdiction's 
contract compliance rate as the administrative indicator for policy effectiveness was sufficient. Both counties utilize their compliance rate as an effectiveness measure. Administrators in both counties defined contract compliance as contractors paying their employees living wage rates on a consistent and timely basis, posting information regarding the ordinance where it is visible to employees, offering health benefits when applicable, and cooperating with any and all payroll audits by providing accurate payrolls for the County to review. If a contractor fails to adhere to any of these conditions, Broward and Miami-Dade would consider them in violation of the LWO.

\section{Policy Ambiguity}

An objective of this study was to assess the effect ambiguity had on the LWO implementation policies in Miami-Dade and Broward Counties. Hypothesis $\mathrm{H}_{1}$ examined how ambiguities in the development and implementation of living wage policies and procedures interfered with the resulting management and enforcement of the ordinance. Matland (1995) stated that depending on the level of ambiguity the implementation approach one takes to executing a policy could vary. Due to the lack in clarity, administrative policies and controls would be limited thus allowing the implementation process to be more prone to political influences.

Based on interviews of Broward and Miami-Dade Counties, it appeared that both possessed levels of ambiguity in their implementation processes that lead to implementation challenges. Both counties cited concerns regarding uncertainties over which services to monitor and how to enforce contracts consistently. This amounted to frustrations amongst administrators in both counties, mostly in Miami-Dade, while contractors took the opportunity to circumvent the ordinance. Based on the surveys, 
policy ambiguity proved a problem for other jurisdictions as well as it showed to have a statistically significant negative relationship with contract compliance rates. In fact, several respondents felt that their jurisdictions should make a greater effort to clarify the language in their ordinances. Doing so would allow for a better understanding of the expectations placed on the jurisdictions, its administrators, and contractors.

\section{Policy Conflict}

An objective of this study was to identify potential policy conflicts in Miami-Dade and Broward Counties, their root causes, and the extent these conflicts affected the implementation process. Hypothesis $\mathrm{H}_{2}$ examined how conflicts in administrative roles and responsibilities interfered with the management of the ordinance. According to Matland (1995), conflicts cause policies to receive limited support due to opposing ideologies and priorities. Ambiguity and conflicts present a vague delineation of authority and the likelihood that stakeholders would focus more on establishing their authority on the policy than its outcome.

While survey results failed to reject the null hypothesis, the interviews demonstrated that policy conflicts played a negative influence in implementing a living wage, especially in Broward County. The LWAB was divided on its objectives and their priority. Conflicts between members of the LWAB and Broward administrators caused, particularly those in Purchasing, the implementation process to stall in some cases. Two LWAB members questioned the direction of the implementation policy. Three other LWAB members doubted the efforts and intentions of the county administrators. Two department directors questioned the overall purpose of the ordinance as well as the role and authority the LWAB should have over them. In 2006, the state began its effort to 
reform property taxes. At least two Broward BCC members placed greater scrutiny of living wage contracts by questioning its relevance to improving quality of life and the LWO's priority over other County responsibilities. Since its passage, the LWO caused tense relationships to develop and mixed support for its implementation.

\section{Stakeholders}

An objective of this study was to identify the main stakeholders in Miami-Dade and Broward Counties and their roles in the implementation process. Hypothesis $\mathrm{H}_{3}$ examined how specific stakeholders (elected officials, contractors, grassroots organizations, etc.) influenced the implementation of a living wage. The assumption was that each stakeholder would assist in some way to enhance and expand the LWO. However, given that each group had conflicting interests, this demonstrated to being unfeasible.

Interview results explained why the survey results failed to show any relationship. Given the stakeholders involved, their interests and actions conflicted with the LWO's purpose. Proponents, opponents, and uninterested parties were responsible for overseeing the monitoring and enforcement of the LWO in both counties. In Broward, LWAB members disagreed on the direction and purpose of the LWO, county administrators viewed the LWO as an administrative burden they were forced to manage, and one contract administrator did not view the LWO as a priority. In Miami-Dade, DBD argued with the BCC for additional funding and with uninterested project managers to assist in the monitoring efforts. The result is what Tullock (1965) described as parties maximizing their own utilities rather than focus on a collective effort to execute a policy. 


\section{Organizational Culture}

The author examined two aspects of organizational culture in this study. First, Hypothesis $\mathrm{H}_{4}$ examined whether prioritizing communication and information sharing and access played a positive role in the implementation process. According to Daft (1998), the organization and its stakeholders should have a common understanding in supporting an idea like information sharing for it to succeed. However, to develop a supportive culture for this, Trice and Beyer (1993) mention that the change must come through administrative policies and roles reflecting the organization's goals and priorities. The importance of having clear information accessible reflects to Weber's (1946) belief that an organization requires accurate and organized information at an administrator's disposal to manage effectively.

This component failed to show any relationship; however, the information access and stakeholder input variables were significant among jurisdictions surveyed. This demonstrated that communication was essential to maintaining productive working relationships with other stakeholders. Both counties demonstrated the importance of open and clear communication during the interviews conducted. Given that DBD in Miami-Dade County and Purchasing in Broward County relied on whistleblowers and other county personnel to notify them of noncompliance issues, the quality and timeliness of the information was critical to the policy's enforcement success.

The second aspect revolved around a jurisdiction's effort to monitor and enforce the ordinance. Hypothesis $\mathrm{H}_{5}$ examined how prioritizing the monitoring and enforcement of the living wage would play a role in the implementation process. In regards to the living wage, motivating departments to work together and provide the necessary resources to 
implement the living wage effectively was a formidable challenge. It is the author's opinion that without an organizational culture to promote widespread and consistent enforcement, the task of ensuring that contractors comply with living wage policies becomes ineffective.

According to the survey findings, a culture promoting the monitoring and enforcement of the ordinance was a statistically positive factor for the implementation process. As noted in the interviews, with Miami-Dade County having a lax penalty structure and enforcement effort, some contractors tried to circumvent the ordinance. Two Miami-Dade contract compliance officers and LWC members mentioned that without a consistent and aggressive enforcement effort in place, contractors would continue to be noncompliant. They proposed that Miami-Dade County must be diligent in its efforts to monitor the contractors and impose a structured and consistent enforcement policy that effectively penalizes noncompliant contractors based on the severity of the offense and repeat offenders. (Anonymous, personal communications, February 10; March 2; April 5; April 12, 2006)

The interviews also examined organizational culture from the standpoint of how departments accepted their responsibilities to the implementation process. While few administrators were opposed to the living wage's objective, many demonstrated some bitterness to the policy because of the resultant administrative burden. In addition to the lack of noted results, the majority of the department directors and senior-level management interviewed in Broward County questioned whether the living wage should even continue. To them, it only amounted to further frustrations given that many were 
working towards a policy they did not support or failed to see the results of their work.

(Anonymous, personal communications, July 14; July 17; August 20, 2006)

\section{Organizational Capacity}

An objective of this study was to examine the capacities Miami-Dade and Broward Counties had to implement their living wages and the extent to which limited resources affected their efforts. Ulrich and Lake (1990) mentioned that for an organization to respond to demands and changes in its internal and external environments effectively, it needs the proper resources to do so. Luce (2005) mentioned a jurisdiction's capabilities were limited to the capacities set by the personnel and funding dedicated to managing a living wage - a common problem in living wage policies. As Swanson (1996) stated:

"A popular saying comes to mind: Pit a good performer against a bad system and the system will almost always win. How else to explain the failure of high-aptitude experts? When the work system ties the hands of competent persons behind their backs and then punishes them for doing their best, they either quit and leave or quit and stay! Likewise, when a well-designed work process is coupled with organizational policies and procedures that hire employees lacking the capacity to perform the work, no reasonable amount of training will get the employees up to required performance standards." (p. 51)

As noted in the interviews, morale amongst contract compliance officers in MiamiDade and department directors in Broward were low given their overwhelming responsibilities to the living wage they had aside from their other tasks. This was preventing them from taking more aggressive and/or proactive steps to monitor and enforce the living wage. To them, their actions reflected the amount of support they felt was inadequate to implementing the LWO. As one Broward department director mentioned: 
"Government keeps preaching that we have to do more with less and they keep pouring more and more on us and expect to do it with even less. Everything cumulatively is seriously impacting our abilities to serve our best to the agencies and get things done. We do need more resources, and so far, they are not forthcoming. You can only stretch it so thin and still try to do things effectively and we are reaching that point where we are behind and we are not generally as effective as we could be or should be." (Anonymous, personal communication, July 17, 2006)

In addition, a Miami-Dade contract compliance officer mentioned that there was turnover due to the workload. (Anonymous, personal communication, April 12, 2006) It is the author's opinion also that there were LWAB members that lacked the capacity to assess the implementation process adequately and it caused tension and low morale amongst other Board members.

Hypothesis $\mathrm{H}_{6}$ examined to what extent limited resources affected a jurisdiction's ability to monitor and enforce a living wage. Interviews revealed that living wages in both counties did not receive the necessary administrative support and resources to implement it effectively. In both counties, the responsibilities of implementing the living wage were handed down to DBD and Purchasing without much consideration as to the effect it might have on their abilities to handle the LWO and other responsibilities at the same time. What frustrated the department directors and senior management administrators interviewed was that dealing with the living wage brought about occasional criticisms from elected officials and other administrators in regards to policy shortcomings. (Anonymous, personal communications, July 14; July 17; August 20, 2006) The response usually given by DBD and Purchasing was that departments were shorthanded and could not address all the demands to implement the ordinance. Elected officials, in response to additional funding requests, questioned why a program should 
receive additional funding without proving it was effective in the first place.

(Anonymous, personal communication, July 17, 2006) The result was that departments like DBD in Miami-Dade and Purchasing in Broward remained understaffed and without sufficient funding while still having the expectations of effectively implementing the ordinance. Survey findings supported the interviews by showing that the lack of organizational capacities proved to be a significant negative factor in the implementation process.

\section{Organizational Politics}

An objective of this study was to examine how organizational politics affects the living wage implementation processes in Miami-Dade and Broward Counties. Pfeffer (1981) mentioned that politics generally plays a critical role in policy implementation. Organizations routinely jockey to improve and preserve their decision-making authority resulting in the combination of negotiations and management of diverse interests that amounts to organizational actions. Hypothesis $\mathrm{H}_{7}$ examined the effect organizational politics had on the implementation of a living wage.

Based on the survey findings, organizational politics was a significant negative factor in the implementation process. One administrator involved with living wages in another jurisdiction mentioned that the "devil is in the details" and that politics, while helpful at times, tended to stray the policy from its original intention. (Anonymous, personal communication, July 19, 2007) The interviews highlighted the fact that organizations faced internal and external political forces during the implementation process. Specifically, it is the author's opinion that Miami-Dade seemed to be face external political challenges while Broward's challenges were internal. 
Miami-Dade County demonstrated it publicly supported the living wage. In some cases, the County amended its ordinance in order to clarify its requirements and expand its scope, during which, the LWC played an active role in overseeing the implementation process. However, Miami-Dade failed to provide the necessary resources DBD and DPM needed to adequately monitor and enforce the contract. According to two contract administrators, in regards to the LWO's enforcement, politics played an important role in the way contractors dealt with LWO violations and penalties. Those found noncompliant went through a lengthy and time-consuming County process to bring contractors back into compliance before penalizing them. The contractors normally appealed and negotiated the penalties. In some cases, contractors with longstanding relationships involved project managers, department directors, Commissioners, County Manager's Office, and/or the Mayor's Office to resolve the matters for them. This resulted in contractors being relieved of the penalties owed and repaying back wages at their convenience. (Anonymous, personal communications, April 5 and April 12, 2006)

There appeared to be a divide in Broward between opponents and proponents of the living wage in both the BCC and LWAB. Conflicting interests in the LWAB forced Board members to deviate from its set goals and purpose because they spent more time arguing rather than evaluating the County's implementation process. Since approving the ordinance on a 5-4 vote, Broward administrators have had mixed feelings on their feelings toward the policy as well and that prevented there from being significant gains implementing the ordinance. 


\section{Living Wages and Learning Organizations}

On May 9, 2000, LWC member Michael Ozegovich presented Miami-Dade's BCC with the LWC's first annual report. During his presentation, he asked the BCC "what are we supposed to be oversighting?" He continued by mentioning that the ordinance's language was "broad" and asked what the BCC's intention was for the ordinance and who the beneficiaries were because the LWC was not sure of how to evaluate the LWO. (Miami-Dade County, television broadcast, May 9, 2000) Since its passage, Miami-Dade County's implementation policy continued to evolve by establishing precedence on compliant services and addressing the requests made by the LWC. In fact, Purchasing administrators admitted to experiencing their own "growing pains" when learning to develop its living wage policy. (Anonymous, personal communications, July 12 and July $14,2006)$ In comparing the state of the LWOs in both counties at its infancy to their current forms, they illustrated the qualities expressed by Senge (1990) as examples of learning organizations.

Daft (1998) mentioned that a learning organization involves a paradigm shift where organizations accept and adapt a new way of thinking and/or acting. How an organization does this depends on its learning capabilities. The capabilities involve the financial and administrative capabilities as well as a supportive organizational culture willing to apply the change. Figure 6 illustrates how various organizational elements combine to develop an organization's initiative to learn. 


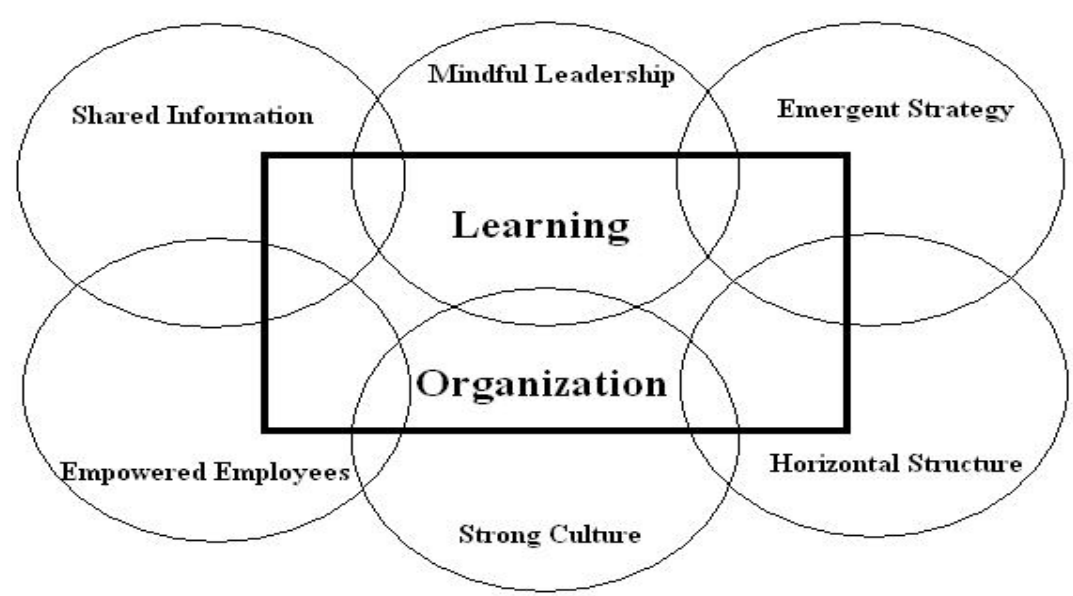

Figure 6 - Learning Organizational Elements (Daft, 1998)

Daft (1998) believes that an employee appropriately trained and informed on his/her role and responsibilities understands to act accordingly to meet the organization's expectations. Policy evaluations are an important component of the policy process where organizations must be willing to identify strengths and weaknesses in the policy and understand how to address them - a measure supported by Schön (1983). At this point, organizations should be open to applying new methods and ideas. This depends on having accurate information at the organization's disposal to assess the demands by each stakeholder and the organizations capacity to act. These factors can only succeed with an organization culture that would permit it. Given the organization's leadership and how it prioritizes the need for the policy's success, an organization only can go so far as the administrative support would allow. Part of the culture also involves coordinating with departments/agencies/stakeholders that can provide their expertise to develop a comprehensive and effective policy. As Senge (1990) mentioned, individuals within an organization learn best by sharing their experiences. By sharing information and supporting open ideas and communication, an organization is able to understand the dynamics of the policy at hand. (Oshry, 1995) 
Since the author conducted the interviews of Broward and Miami-Dade Counties administrators in 2006, there were several administrative and political challenges identified at the time affecting the implementation policies in both counties. Figure 7 illustrates the challenges noted in Miami-Dade and Broward Counties and how they related. Both Counties had a conflictive organizational culture regarding the LWO. Broward's BCC occasionally questioned the applicability of the living wage and its overall purpose. There were department directors and other senior management personnel in Broward who did not support the ordinance and preferred it eliminated. Senior management in DBD and several contract compliance officers in Miami-Dade questioned its overall purpose resulting in low morale due to the arduous effort it took to enforce it while receiving little credit in return. The monitoring efforts were inconsistent because of the limited resources in Miami-Dade and contract administrators, unclear on their role, in Broward failed to properly review and report payroll audits. Enforcement was also inconsistent given that contractors often negotiated their ways out of paying penalties and some wages in Miami-Dade while Broward claimed to have perfect compliance.

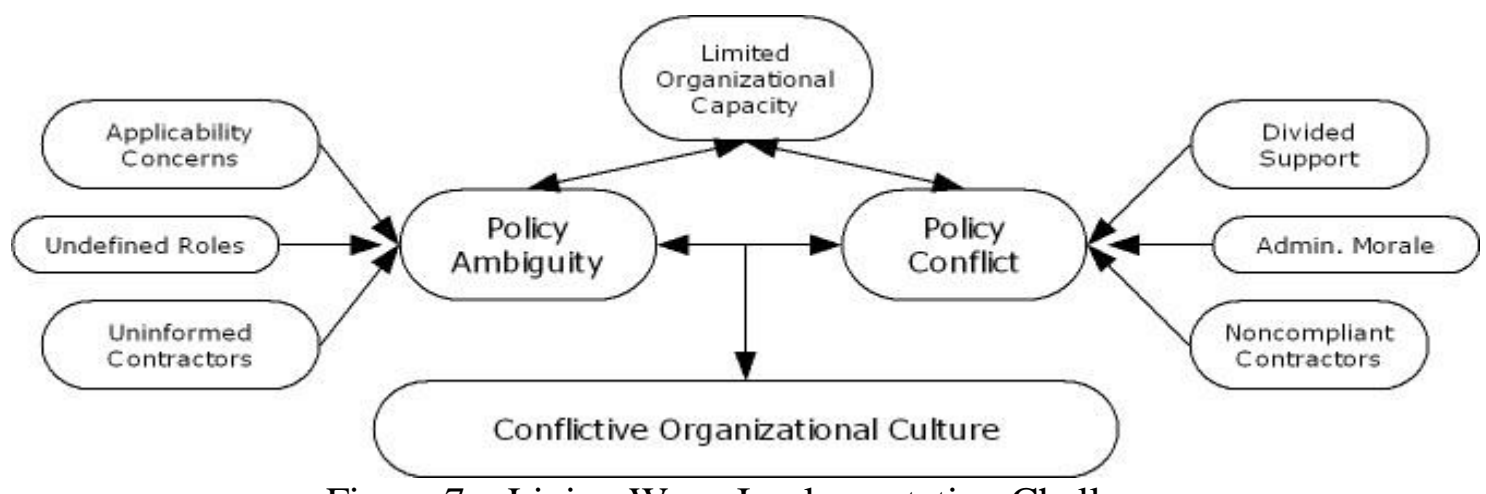

Figure 7 - Living Wage Implementation Challenges 
Table 7-2 presents the living wage contract compliance rates in Miami-Dade since 2004 based on the violation reports provided by DBD to the LWC. Even though the number of service contracts increased almost annually, the compliance rate managed to do so as well. In addition, the proportion of payrolls reviewed to total contracts increased during this time. A contract compliance officer mentioned that this is attributable to the County exhibiting less tolerance on noncompliant contractors. Contractors penalized have less success negotiating their fines since they must appeal to hearing officers that rarely overturn penalties ${ }^{19}$. In addition, the BCC amended ordinance in 2006 to incorporate a penalty schedule that escalates based on the severity and violation repetitions. (Anonymous, personal communications, March 18, 2008)

Table 7-2: Miami-Dade County Compliance Rates

\begin{tabular}{lcccc}
\hline \hline Report Date $^{\mathbf{2 0}}$ & $\begin{array}{c}\text { Total } \\
\text { Contracts }\end{array}$ & $\begin{array}{c}\text { Payrolls } \\
\text { Reviewed }\end{array}$ & Violations $^{\text {Rate }}$ & $\begin{array}{c}\text { Compliance } \\
\text { Rat }^{\text {R }}\end{array}$ \\
\hline \hline August 2004 & 133 & 93 & 10 & $89 \%$ \\
June 2005 & 246 & 208 & 23 & $89 \%$ \\
January 2007 & 200 & 200 & 18 & $91 \%$ \\
February 2008 & 221 & 200 & 11 & $94 \%$ \\
\hline
\end{tabular}

Since 2006, both counties made several improvements to limit its policy ambiguities, resolve conflicts, and improving its enforcement and monitoring efforts. This provides evidence that over time both counties learned from prior experiences to correct their policies. For example:

\footnotetext{
${ }^{19}$ Since Miami-Dade County implemented stricter penalties, it has collected over $\$ 15,000$ in penalties.

${ }^{20}$ Miami-Dade County Department of Business Development, Living Wage History of Violations, 2008.

${ }^{21}$ The compliance rate consists of the number of violations based on the payrolls reviewed.

${ }^{22}$ The information provided in the violation report in March 2008 is incomplete. The author compared the violation lists from previous meetings and noted that several companies were missing and did not match the latest report. The author notified a contract compliance officer about the missing information and was told that DPM would investigate the issue.
} 
- The county attorneys for both counties continue to provide legal opinions as to the scope of the ordinance and applicability. One Broward County Attorney administrator mentioned that policy ambiguities become less of a factor over time given precedence set in specific cases. (Anonymous, personal communications, August 20, 2006)

- Miami-Dade County conducted an impact analysis through the work of Nissen and Borum (2006) to assess the impact the LWO had on the quality of life of its recipients.

- In 2006, Miami-Dade County also amended its ordinance to clarify the health benefit requirements applicable to living wage recipients as well as establishing 90-day probationary periods whereby these health benefits would be available to the recipients.

- In March 2008, Broward conducted a workshop to propose new initiatives intended to enhance their LWO. Among the changes recommended, the Broward County Auditor is to review compliance reports, Purchasing is to develop an impact study and utilize an automated system for data collection and storage. (Del Marcus, 2008)

It is the author's opinion that factors like policy ambiguity and conflict are significant problems in living wage implementation in the early stages. However, assuming there is a commitment to support the LWO and improve its policy efforts, ambiguity and conflict are manageable in time. By examining Broward and Miami-Dade Counties, jurisdictions face somewhat of a learning curve when implementing a LWO. It is the author's opinion that both counties continue to deal with several challenges; 
however, by utilizing a rational management process in addition to administrative support, they can eventually correct their measures.

\section{Limitations}

Every research method and approach has its strength and weaknesses. While the triangulation of methods helped to incorporate the strengths of each to develop a more comprehensive and rigorous approach, some limitations remained. The following were the limitations that emerged while conducting this study:

- Interview access to contractors - One objective was to interview contractors contracted with Miami-Dade and/or Broward County required to pay the living wage. Similar to the approaches taken to examine county administrators and advisory board members, the purpose of interviewing these contractors was to gain their perspective into the process and to have a better understanding as to why contractors become noncompliant with the ordinance. While the author did not conduct any formal interviews with the contractors, there were several informal discussions with some business owners that declined to participate in interviews. The information generated through those discussions helped to develop the limited perspective contractors have on the living wage for this study.

- Quality of survey data - During the interviews conducted in Broward County, each administrator mentioned that there were no cases of noncompliance to date. However, a report by the Broward County Auditor revealed that there were noncompliant contractors overlooked. (Broward County Office of the County Auditor, 2006) Based on a random sample of 10 contracts taken by the County Auditor, three of the contracts were noncompliant. This challenged the survey 
finding that $56 \%$ of jurisdictions surveyed also mentioned having perfect compliance records and compliance rates. This was a significant limitation because the rate of compliance was the dependent variable used for this study's statistical analysis.

- Comparisons to other jurisdictions - A limitation with case study research is one's ability to generalize the findings in this study to other jurisdictions. Further comparisons drawn with jurisdictions noted for their successes, like Boston (Brenner, 2005), or failures like any jurisdictions that repealed its LWO would enhance this study's findings. Comparing the results from Broward and MiamiDade Counties to other jurisdictions would provide an added perspective noting the effectiveness, or lack thereof, in relations to policies in place nationwide.

\section{Policy Recommendations}

Because of the interviews and surveys conducted, the author provides the following policy recommendations to improve the management and implementation of the living wage ordinances in Miami-Dade and Broward Counties.

Divisions need more resources - This recommendation applies more to Miami-Dade than Broward County; however, both jurisdictions admitted that they were operating at or near capacity without considering their LWO responsibilities. Accurately monitoring and enforcing a living wage contract can be an arduous and time-consuming process because of the efforts needed to track down contractors and verify that the information they provided was accurate. The need for more resources is simply to meet the demand for an effectively implemented ordinance. One contract compliance officer mentioned that it normally takes about two weeks to conduct a thorough payroll audit. (Anonymous, 
personal communications, April 5, 2006) One Broward Purchasing administrator dedicated more than $30 \%$ of a week dealing with living wage issues. (Anonymous, personal communications, July 14, 2006) The survey supported the fact that jurisdictions do not allocate the necessary resources to monitor and enforce the living wage seeing as the average jurisdiction dedicated one FTE per 80 living wage contracts. It is the author's opinion that Broward needs an administrator solely committed to overseeing all living wage issues while Miami-Dade should provide sufficient personnel where contract compliance officers handle no more than 40 to 45 contracts annually.

Simplify the coverage - In several occasions, there were contracted services applicable to the living wage that were already paying above the stated rate beforehand. These services, like elevator and auto repair, technically apply to the living wage because of the general classification under "routine" services or maintenance. Aside from improving on the ordinance's language, a waiver should be available for contractors and specific services that prove they were paying employees above the living wage before the contract's effective date. This move would help make the implementation process more efficient because it would eliminate superfluous work and allow jurisdictions to focus solely on those contracts that need closer monitoring.

Contract administrators need to play a more significant role - While both counties have administrators dedicated to examining the progress of the ordinances, the fact is that the contract administrators and/or project managers interact with contractors on a closer basis than will any other department in either county. In addition, it was the original intentions of both Counties to have their contract administrators and project managers assist in monitoring contracts. (Anonymous, personal communications, April 5 and July 
14, 2006) It is the author's opinion that the first step needed is to streamline the process where these groups would be more involved in communications with contractors and other county administrators. The second step is to hold the contract administrators/project managers accountable for management of service contracts. Verifying the information and administrative actions by contract administrators/project managers is critical. These steps would result in each county's expansion of their monitoring and enforcement coverage. Broward County took preliminary steps to doing this by proposing that the County Auditor review compliance reports.

Improve the whistleblower policy and monitoring - Since both counties do not have the necessary resources to monitor each contractor constantly, both relied heavily on workers to notify them of noncompliance issues. Both counties should take more aggressive measures to educate workers of their living wage rights and options. By leaving this responsibility to employers, the possibility exists for workers to receive inaccurate information, if any at all. (Anonymous, personal communication, March 2, 2006) Providing living wage information on paychecks every six months is not enough. The biggest challenge is that workers normally fear losing their jobs if they report their employers and these workers are not entirely sure of their rights. (Anonymous, personal communication, April 5, 2006) It is the author's opinion that the process is either too confusing or intimidating for anyone to come forward with information. Both Counties should develop better methods for whistleblowers to report noncompliant contractors that would ensure their protection.

Increase awareness - Ever since the BCC threatened to eliminate Broward's LWO there has been an emerging movement to save it. In fact, commissioners were under fire 
by local proponents in 2007 for suggesting the possibility of repealing the ordinance. The special workshop in March 2008 provided evidence of local support given the relatively large attendance from various proponents. Luce (2004) stressed that a key ingredient to the living wage's success is continued public support. It is the author's opinion that while both counties made an effort to educate contractors and workers on the living wage, they both need additional steps to increase the awareness in local communities as well, however, this responsibility should fall mainly on the LWAB and LWC members. An informed community would help maintain the ordinance as a priority to elected officials. It also helps potential contractors understand the living wage and their role before bidding on a contract. Increasing awareness could also help to improve the compliance rates since workers would be more conscious of what their rights are. However, awareness campaigns mainly reflect the interest by each county and their advisory boards. Without an overwhelming support internally for the ordinance could limit the extent counties would support its awareness.

\section{Suggestions for Future Research}

According to the survey findings, Miami-Dade and Broward Counties represented two distinct cases comparable to other jurisdictions; however, the survey results showed that each situation was unique. Living wage ordinances bring about the promise of improving quality of life for many workers but it comes at a cost to local jurisdictions and taxpayers. If such a policy is to exist and enforced effectively, it must be some sort of assurance that it is addressing a social need as intended.

In passing living wage legislation, there are generally two parties involved grassroots advocates and elected officials. While both might not admit to it, their actions 
reflect that each was mainly concerned with short-term results. As Downs (1957)

predicted, elected officials wish to receive the credit from passing a politically appealing law while advocates are mainly concerned with creating the ordinance assuming their fight has been won and the ordinance would be implemented as proponents expect. Luce (2004) mentioned that interest on both sides drops dramatically from that point after. It is no coincidence that the crux of living wage research originally focused on the potential impacts of the ordinance with hardly any mention as how to implement it. Since then, literature emerged highlighting the social benefits living wages can have on local economies. (Brenner, 2005, and Nissen and Borum, 2006) Still, there appeared to be a research gap regarding the practice of implementing living wages this study helped to fill by identifying the administrative and political factors that exist in the process and better practices to implement a living wage effectively.

Nevertheless, there are still some policy questions and concerns that would require further research to better assess living wage policies and processes. The following are those questions/concerns:

- How many workers does the living wage affect and to what degree?

- What is the total administrative cost of implementing a living wage?

- What is the total cost to implement a living wage?

- How does a living wage affect businesses and their efforts to bid on government contracts?

- What effect would have a living wage have on the local working poverty level?

Each of these questions were posed to Miami-Dade and Broward County administrators to which no one was able to provide a definite answer. This study determined that an accurate measure for living wage implementation should be the rate of contract compliance. However, it is the author's opinion that to expand this to a policy 
perspective focused on determining if the living wage is effectively helping to meet the needs of local households at or near the poverty level, jurisdictions should be able to answer these questions with relative ease. Results need to be consistent with the rational implementation model discussed by Daft (1998) and Bowsher (1985). Policy ends and means need to be clear; sufficient resources must be allocated; and comprehensive and timely evaluations need to be conducted to improve the implementation process. It is the author's opinion that jurisdictions either do not have the information available, have not attempted to evaluate their living wage policy, and/or believe (based on inaccurate data) that their policy is successfully meeting its objectives. These five questions should be fundamental for any jurisdiction to answer in gauging what actions it should take to improve, maintain, or eliminate its living wage. In the end, the policy costs jurisdictions significant amounts each year without any way to determine the rate of return on the policy.

As of July 2007, Broward County was working towards developing a comprehensive report to answer these fundamental questions. This came after determining that the living wage enforcement was ineffective and faced recent political pressure to eliminate it as a cost-saving measure (Wyman, 2007). In Miami-Dade County, the study conducted by Nissen and Borum (2006) examined the effect the living wage had on workers. However, their sample size of 78 was not sufficient to infer statistically to the larger population of contracted workers. It is the author's opinion that the study was a good start to evaluating the impact of the living wage in Miami-Dade County. It should serve as supplementary information to gauge the ordinance's outcomes. Miami-Dade County, 
like Broward, should be able to answer the questions listed to justify the living wage's purpose and need for further funding or termination.

To answer these questions accurately, the author believes that both counties should invoke the New Public Management ideals and practices Kettl (2000) and Osborne and Plastrik (2000) discussed. The public expects government to be more results-oriented, transparent, and accountable for its actions. To do so, governments need to align resources and organizational climate to accomplish its goals and objectives. Failing to do so can lead to an abandonment of the policy. Ultimately, governments need to dedicate more time and resources towards implementing performance measurements and conducting systematic evaluations. Their focus needs to be on the outputs and outcomes of their implemented policies.

While living wage policies are growing in numbers throughout the country, it also has quickly become a hotly debated issue as well. It is the author's opinion that regardless of the fact whether one is in favor or opposed to it, elected officials making policy decisions without having critical data to support their actions is an example of poor governance. These actions support Luce's (2004) argument that once a government passes a LWO, the ordinance does not receive the same level of attention and effort for implementation as it did originally. However, this study supported Luce's (2004) claim that grassroots organizations are responsible for the success of the living wage as much as anyone else because without public support before, and more importantly after the law is created, living wages will be in a state in which operating results fail to square with legislative expectations. 


\section{BIBLIOGRAPHY}

Allison, G. T. (1999). Essence of decision: Explaining the Cuban Missile Crisis $\left(2^{\text {nd }}\right.$ $E d$.). New York, NY. Longman.

Anonymous (personal communication, June 16, 2005)

Anonymous (personal communication, February 1, 2006)

Anonymous (personal communications, February 2, 2006)

Anonymous (personal communication, February 3, 2006)

Anonymous (personal communication, February 9, 2006)

Anonymous (personal communications, February 10, 2006)

Anonymous (personal communication, February 15, 2006)

Anonymous (personal communications, February 22, 2006)

Anonymous (personal communications, March 1, 2006)

Anonymous (personal communication, March 2, 2006)

Anonymous (personal communication, March 17, 2006)

Anonymous (personal communications, March 28, 2006)

Anonymous (personal communications, July 13, 2006)

Anonymous (personal communications, July 14, 2006)

Anonymous (personal communications, July 17, 2006)

Anonymous (personal communications, August 20, 2006)

Anonymous (personal communications, September 29, 2006)

Anonymous (personal communications, June 15, 2007)

Anonymous (personal communications, June 18, 2007)

Anonymous (personal communications, June 20, 2007) 
Anonymous (personal communications, June 25, 2007)

Anonymous (personal communications, July 20, 2007)

Anonymous (personal communication, October 8, 2007)

Bardach, E. (1977). The implementation Game: What happens after a bill becomes a law. Cambridge, MA: The MIT Press.

Bickman, L. \& Rog D. J. (1998). Handbook of applied social research methods. Thousand Oaks, CA: Sage Publications, Inc.

Blau, P. M. \& Scott, W. R. (1962). The concept of formal organization. In Shafritz, J. M. \& Ott, J. S. (Eds.) (2001) Classics of organization theory $\left(5^{\text {th }}\right.$ ed.). Belmont, CA: Wadsworth Group/Thompson Learning.

Boleman, L. E. \& Deal, T. E. (2003). Reframing organizations: Artistry, choice, and leadership. San Francisco, CA: Jossey-Bass.

Bowsher, C. A. (1985). Government financial management at the crossroads. Public Budgeting and Finance, Vol. 5, No. 2, pp. 9-22.

Brenner, M. D. (2005). The economic impact of the Boston Living Wage Ordinance. Industrial Relations, Vol. 44, No. 1, pp. 59-83

Brewer, G.D., \& deLeon, P. (1983). The foundations of policy analysis. Homewood, IL: The Dorsey Press.

Brodkin, E. (1990). Implementation as policy politics. In Palumbo, D. J. \& Calista, D. J. (Eds.). (1990). Implementation and the policy process: Opening up the black box. New York, NY: Greenwood Press.

Broward County. Broward County Living Wage Ordinance. Retrieved June 1, 2005, from http://www.broward.org/purchasing/livwage.pdf.

Broward County Purchasing Division. (2006). Living Wage Ordinance 2002-45 implementation. Broward County, FL: Author.

Brudney, J. L., O’toole, L. J., Jr., \& Rainey, H. G. (Eds.). (2000). Advancing public management: New developments in theory, methods, and practice. Washington, D.C.: Georgetown University Press.

Burns, T. \& Stakler, G. M. (1961). Mechanistic and organic systems. In Shafritz, J. M. \& Ott, J. S. (Eds.) (2001) Classics of organization theory $\left(5^{\text {th }}\right.$ ed.). Belmont, CA: Wadsworth Group/Thompson Learning. 
Cordle, I. P. (2007, October 12). MIA security firm shortchanged county. The Miami Herald, pp. 1B.

Daft, R. L. (1998). Organization theory and design ( $6^{\text {th }} e d$.). Cincinnati, OH: SouthWestern College Publishing.

Dahl, R. A. (1967). Pluralist democracy in the United States: Conflict and consent. Chicago, IL: Rand McNally \& Company.

De Lollis, B. (1999, November 10). Businessmen to leave airport, citing 'nasty' politics. The Miami Herald, pp. 11A.

DeFede, J. (1998, December 17). Airpot sleaze aplenty. The Miami New Times.

DeFede, J. (1993, April 28). Is this any way to run an airport? The Miami New Times.

Del Marcus, J. (2008, March 20). Fair pay: Broward County to strengthen living wage ordinance. The SunPost.

Demaris, A. (1992). Logit modeling: Practical Applications. Thousand Oaks, CA: Sage Publications.

Dennis, A. R. \& Valacich, J. S. (2001). Conducting experimental research in information systems. Communication of the AIS. Vol. 7, No. 5. 1-41.

Dluhy, M. J. \& Frank, H. A. (1999). Miami's fiscal crisis: Two years later. Municipal Finance Journal. Vol. 20, No. 1, pp. 1-19.

Downs, A. (1957). An Economic Theory of Democracy. New York: Harper Collins Publishers.

Edwards, D. \& Thomas, J. C. (2005). Developing a municipal performancemeasurement system: Reflections of the Atlanta Dashboard. Public Administration Review. Vol. 65, No. 3. 369-376.

Follett, M. P. (1926). The giving of orders. In Shafritz, J. M. \& Ott, J. S. (Eds.) (2001) Classics of organization theory $\left(5^{\text {th }}\right.$ ed.). Belmont, CA: Wadsworth Group/Thompson Learning.

Frederickson, H. G. \& Johnston J. M. (Eds.). (1999). Public management reform and innovation: Research, theory, and application. Tuscaloosa, AL: University of Alabama Press.

Frederickson, H. G. \& Smith, K. B. (2003). The public administration theory primer. Cambridge, MA: Perseus Books Group. 
Fung, A \& Wright, E. O. (2003). Deepening democracy: Institutional innovations in empowered participatory governance. New York, NY: Verso Books.

Goodnow, F. J. (1900). Politics and administration. In Shafritz, J. M. \& Ott, J. S. (2001). Classics of organization theory $\left(5^{\text {th }}\right.$ ed.). Belmont, CA: Wadsworth Group/Thomson Learning.

Greene, R. (1999, September 13). Airport bolsters security after smuggling busts. The Miami Herald, pp. A1.

Grotto, J. \& Hiassen, S. (2007, October 3). Millions for deals, not for merchants. The Miami Herald, pp A1.

Gujarati, D. N. (2003). Basic econometrics $\left(4^{\text {th }}\right.$ Ed.). Boston, MA: McGraw-Hill.

Horton, D., Alexaki, A., Bennett-Lartey, S., Brice, K. N., Campilan, D., Carden, F., de Souza Silva, J., Duong, L. T., Khadar, I., Boza, A. M., Muniruzzaman, I. K., Perez, J., Chang, M. S., Vernooy, R., Watts, J. Chapter 2. The Basics of Capacity, Organizational Capacity Development, and Evaluation. Retrieved October 10, 2007, from http://www.idrc.ca/en/ev-43616-201-1-DO_TOPIC.html.

Howell, D.C. (2002). Statistical methods for psychology ( $5^{\text {th }}$ ed.). Pacific Grove, CA: Duxbury.

Jacques, E. (1990). In praise of hierarchy. In Shafritz, J. M. \& Ott, J. S. (Eds.) (2001) Classics of organization theory $\left(5^{\text {th }}\right.$ ed.). Belmont, CA: Wadsworth Group/Thompson Learning.

Janesick, V. J. (2000). The choreography of qualitative research design. In Denzin, N. K. \& Lincoln, Y. S. (Eds.). The handbook of qualitative research $\left(2^{\text {nd }} \mathrm{Ed}\right.$. $)$. Thousand Oaks, CA. Sage Publications.

Jevons, W. S. (1965). The theory of political economy ( $5^{\text {th }} e d$.). New York, NY: Sentry Press.

Korten, T. (2005, March 24). A feast of thieves, part 2. The Miami New Times.

Koven, S.G. (1999). Public budgeting in the United States: The cultural and ideological setting. Washington, D.C.: Georgetown University Press.

Leibenstein, H. (1960). Economic theory and organizational analysis. New York, NY: Harper \& Brothers.

Liao, T. F. (1994). Interpreting probability models: Logit, probit, and other generalized linear models. Thousand Oaks, CA: Sage Publications. 
Lipsky, M. (1978). Standing the study of public policy implementation on its head. In Burnham, W. D. \& Weinberg, M. W. (Eds.). American politics and public policy. Cambridge, MA: The MIT Pres..

Living Wage Resource Center. Living wage impact: Research summaries and citations. Retrieved June 22, 2007, from http://www.livingwagecampaign.org/impact.php.

Lofland, J. \& Lofland, L. H. (1984). Analyzing social settings: A guide to qualitative observation and analysis ( $2^{\text {nd }}$ Ed.). Belmont, CA. Wadsworth Publishing Company.

Long, J. S. (1997). Regression models for categorical and limited dependent variables. Thousand Oaks: Sage Publications.

Long, N. E. (1949). Power and administration. In Stillman, R. J. (Ed.). (2000) Public administration: Concepts and cases. New York, NY: Houghton Mifflin Company.

Lowi, T. J. (1969). The end of liberalism; ideology, policy, and the crisis of public authority. New York, NY: W. W. Norton \& Company.

Luce, S. (2004). Fighting for a living wage. Ithaca, NY: Cornell University Press.

Luce, S. (2005). The role of community involvement in implementing living wage ordinances. Industrial Relations, Vol. 44, No. 1, January 2005.

MacRae, D \& Whittington D. (1997). Expert advice for policy choice: Analysis and discourse. Washington, D.C.: Georgetown University Press.

Matland, R. E. (1995). Implementation: The concept of an ambiguity-conflict model. In Stillman, R. J. (Ed.). (2000) Public administration: Concepts and cases. New York, NY: Houghton Mifflin Company.

May, J. V. \& Wildavsky, A. B. (Eds.). (1978). The policy cycle. Beverly Hills, CA: Sage Publications, Inc.

Meltzer, A. H., Cukierman, A., \& Richard, S. F. (1991). Political economy. New York, NY: Oxford University Press.

Menendez, A. (2007, October 3). Let's rethink our strategies to fight poverty. The Miami Herald, pp. B1.

Miami-Dade County. Government organization-Miami-Dade County. Retrieved March 26, 2005, from http://www.miamidade.gov/info/govorg/. 
Miami-Dade County Code, Living Wage Ordinance, 2002-45.

Miami-Dade County Living Wage Commission. (2004). Commission meeting on August 19, 2004. Miami, FL.

Miami-Dade County Living Wage Commission. (2004). Commission meeting on September 16, 2004. Miami, FL.

Miami-Dade County Living Wage Commission. (2004). Commission meeting on October 21, 2004. Miami, FL.

Miami-Dade County Living Wage Commission. (2004). Commission meeting on November 18, 2004. Miami, FL.

Miami-Dade County Living Wage Commission. (2004). Commission meeting on December 16, 2004. Miami, FL.

Miami-Dade County Living Wage Commission. (2005). Commission meeting on March 17, 2005. Miami, FL.

Miami-Dade County Living Wage Commission. (2005). Commission meeting on June 16, 2005. Miami, FL.

Miami-Dade County Living Wage Commission. (2004). Needs Assessment Report: Recommendations for the effective implementation of the Miami-Dade County Living Wage Ordinance. Paper presented at the August 19, 2004, meeting of the Miami-Dade County Living Wage Commission, Miami, FL.

Miami-Dade County Living Wage Commission. (2005). Needs Assessment Report: Recommendations for the effective implementation of the Miami-Dade County Living Wage Ordinance.

Milakovich, M. E. \& Gordon, G. J. (2004). Public administration in America ( $8^{\text {th }}$ ed.). Belmont, CA: Wadsworth/Thomson Learning.

Mintzberg, H. (1979). The five basic parts of the organization. In Shafritz, J. M. \& Ott, J. S. (Eds.) (2001) Classics of organization theory $\left(5^{\text {th }}\right.$ ed.). Belmont, CA: Wadsworth Group/Thompson Learning.

Mohr, L. B. (1995). Impact analysis for program evaluation $\left(2^{\text {nd }}\right.$ Ed.). Thousand Oaks, CA. Sage Publications.

Morgan, C. (2000, January 2). Another year in Miami toilet seats, dogs, call girls, hit men: a review of 1999. The Miami Herald, pp. 1B. 
Mossberger, K. \& Stoker G. (2001). The evolution of urban regime theory: The challenge of conceptualization. Urban Affairs Review, Vol. 36, No. 6, July 2001. 810-835.

Murphy, K. R. \& Myors, B. (1998). Statistical power analysis: A simple and general model for traditional and modern hypothesis tests. Mahwah, NJ: Lawrence Erlbaum Associates, Publishers.

Niedt, C., Ruiters, G., Wise, D., \& Shoenberger, E. (1999). The effects of a living wage in Baltimore (EPI Working Paper 119). Washington, DC: Economic Policy Institute: Research and Ideas for Working People. Retrieved June 8, 2005, from http://www.epinet.org/Workingpapers/BUILD.pdf

Nissen, B. \& Borum, J. W. (2006). A difference that matters: The impact of the MiamiDade Living Wage Ordinance on employees covered by the ordinance. Miami, FL, Florida International University Research Institute on Social and Economic Policy.

Nissen, B, with assistance from Cattan, P. (1998). The impact of a living wage ordinance on Miami-Dade County. Miami, FL, Florida International University Center for Labor Research and Studies

Nissen, B. \& Carrasco, T. (2004). The impact of a living wage ordinance on the City of Miami. Miami, FL, Florida International University Center for Labor Research and Studies

Osborne, D. \& Gaebler, T. (1993). Reinventing government: How the entrepreneurial spirit is transforming the public sector. New York: Plume Book.

Osborne, D. \& Plastrik, P. (2000). The reinventor's fieldbook: Tools for transforming your government. San Francisco, CA: Jossey-Bass.

Padgett, D. K. (1998). Qualitative methods in social work research: Challenges and rewards. Thousand Oaks, CA. Sage Publications.

Palumbo, D. J. \& Calista, D. J. (Eds.). (1990). Implementation and the policy process: Opening up the black box. New York, NY: Greenwood Press.

Palumbo, D. J., Maynard-Moody, S., \& Wright, P. (1984). Measuring degrees of successful implementation. Evaluation Review, Vol. 8, No. 1, February 1984. 45 $-73$.

Parsons, W. (1995). Public policy: An introduction to the theory and practice of policy analysis. Northhampton, MA: Edward Elgar. 
Patton, C.V. \& Sawicki, D.S. (1993). Basic methods of policy analysis and planning (2 ${ }^{\text {nd }}$ ed.). Englewood Cliffs, NJ: Prentice Hall.

Peters, B. G. (2002). The politics of tool choice. In Salamon, L. M. (Ed.). The tools of government: A guide to the new governance. New York, NY: Oxford University Press.

Pfeffer, J. (1981). Power in organizations. Marshfield, MA: Pitman Publishers.

Pierre, J. (Ed.). (1998). Partnerships in urban governance: European and American experience. New York: St. Martin's Press, Inc.

Pinzur, M. I. (2007, October 2). Dade OK's deal for fed's housing takeover. The Miami Herald, pp. 5B.

Pressman, J. L. \& Wildavsky, A. B. (1973). Implementation: How great expectations in Washington are dashed in Oakland; Or, why it's amazing that federal programs work at all, this being a saga of the Economic Development Administration as told by two sympathetic observers who seek to build morals on a foundation of ruined hopes. Los Angeles, CA: University of California Press.

Ragin, C. C. (1987). The comparative method: Moving beyond qualitative and quantitative strategies. Los Angeles, CA: University of California Press.

Rayner, J. C. W. \& Best, D. J. (1989). Smooth tests of goodness of fit. New York, NY: Oxford University Press.

Rein, M. \& Rabinovitz, F. F. (1978). Implementation: A theoretical perspective. In Burnham, W. D. \& Weinberg, M. W. (Eds.). American politics and public policy. Cambridge, MA: The MIT Pres..

Rosen, H. S. (2002). Public finance (6 $6^{\text {th }}$ ed.). Boston, MA: McGraw Hill.

Rosenbloom, D. H. (1995). The use of case studies in public administrative education in the USA. Journal of Management History. Vol. 1, No. 1, 1995. 33-46.

Rosenbloom, D. H. \& Kravchuck R. S. (2002). Public administration: Understanding management, politics, and law in the public sector (5 $5^{\text {th }}$ ed.). Boston, MA: McGraw Hill.

Rossi, P. H. \& Freeman, H. E. Evaluation: A systematic approach $\left(5^{\text {th }}\right.$ ed.). Newbury Park, CA: Sage Publications, Inc.

Ryan, J. A. (1971). A living wage. New York, NY: Arno. 
Salamon, L. M. (Ed.). (2002). The tools of government: A guide to the new governance. New York, NY: Oxford University Press.

Schein, E. H. (1993). Defining organizational culture. In Shafritz, J. M. \& Ott, J. S. (Eds.) (2001) Classics of organization theory $\left(5^{\text {th }}\right.$ ed.). Belmont, CA: Wadsworth Group/Thompson Learning.

Schön, D. A. (1983). The reflective practitioner: How professionals think in action. New York, NY: Basic Books.

Senge, P.M. (1990). The fifth discipline: The art and practice of the learning organization. New York: Currency Doubleday.

Shadish, W. R., Cook, T. D., \& Campbell, D. T. (2002). Experimental and quasiexperimental designs for generalized causal inference. Boston, MA. Houghton Mifflin Company.

Shafritz, J. M. \& Hyde, A. C. (Eds.). (1997). Classics of Public Administration (4 ${ }^{\text {th }}$ ed.). New York: Harcourt Brace College Publishers.

Shafritz, J. M. \& Ott, J. S. (2001). Classics of organization theory $\left(5^{\text {th }}\right.$ ed.). Belmont, CA: Wadsworth Group/Thomson Learning.

Simeone, R., Carnevale, J., \& Millar A. (2005). A systems approach to performancebased management: The National Drug Control Strategy. Public Administration Review. Vol. 65, No. 2. 191-202.

Simon, H.A. (1946). The proverbs of administration. Public Administration Review, Vol. 6, 53-67.

Singleton, R., Jr., Straits, B. C., Straits, M. M., McAllister, R. J. (1988). Approaches to social research. New York: Oxford University Press.

Swanson, R.A. (1996). Analysis for improving performance: Tools for diagnosing organizations and documenting workplace expertise. San Francisco, CA: BerrettKoehlers Publishers.

Tanfani, J. (1999, December 9). MIA employees charged with theft. The Miami Herald, pp. 3B.

Tullock, G. (1965). The politics of bureaucracy. Washington, D.C.: Public Affairs Press.

Ulrich, D. \& Lake, D. (1990). Organizational capacity: Competing from the inside out. New York, NY: John Wiley \& Sons. 
Van Meter, D. S. \& Van Horn, C. E. (1975). The policy implementation process: A conceptual framework. Administration \& Society, Vol. 6, No. 4, February 1975. $445-471$.

Waldo, D. (1980). The enterprise of public administration: A summary view. Novato,CA: Chandler \& Sharp Publishers, Inc.

Walker, A. H \& Lorsch, J. W. (1968). Organizational choice: Product versus function. In Shafritz, J. M. \& Ott, J. S. (Eds.) (2001) Classics of organization theory $\left(5^{\text {th }}\right.$ ed.). Belmont, CA: Wadsworth Group/Thompson Learning.

Walton, M. (1986). The Deming management method: W. Edwards Deming, the genius who revitalized Japanese industry, offers his unorthodox system to make "Made in America” a guarantee of quality - again! New York: Perigee Books.

Weber, M. (1946). Bureaucracy. In Stillman, R. J. (Ed.). (2000) Public administration: Concepts and cases. New York, NY: Houghton Mifflin Company.

Weimer D.L. \& Vining, A.R (1999). Policy analysis: Concepts and practice ( $3^{\text {rd }}$ ed.). Saddle River, NJ: Prentice Hall.

Weiss, N. A. (1999). Introductory statistics ( $\left.5^{\text {th }} e d.\right)$. New York, NY: Addison-Wesley.

WhoseFlorida.com. AFSCME updates. Retrieved March 26, 2005, from http://www.whoseflorida.com/afscme_updates.htm.

Wildavsky, A. B. (1979). Speaking truth to power: The art and craft of policy analysis. Boston, MA: Little, Brown and Company.

Wilson, J. Q. (1989). Bureaucracy and the Public Interest. In Stillman, R. J. (Ed.). (2000) Public administration: Concepts and cases. New York, NY: Houghton Mifflin Company.

Wilson, W. (1887). The study of administration. In Stillman, R. J. (Ed.). (2000) Public administration: Concepts and cases. New York, NY: Houghton Mifflin Company.

Wyman, S. (2006, March 12). Wage law tax impact unknown: An analysis of its effects begins two years after adoption. The South Florida Sun-Sentinel, pp. B1.

Wyman, S. (2007, June 27). County weighs up living wage law leaders are law: Leaders are looking for ways to cut expenses. The South Florida Sun-Sentinel, pp. B1.

Yin, R. K. (1994). Case study research: Design and methods $\left(2^{\text {nd }} E d\right)$. Thousand Oaks, CA. Sage Publications. 
Appendix A

Instructions to Survey Participants 


\section{INSTRUCTIONS TO SURVEY PARTICIPANTS}

[NAME],

Several weeks ago, I contacted you regarding a survey I am conducting for my dissertation research on the implementation of living wages to which you expressed interest in participating. This email is to notify you that the survey is complete and is available online at the following address:

http://chua2.fiu.edu/faculty/carrascot/livingwage/

The survey should take you no more that 20 minutes. The first set of questions will ask you specific questions on your monitoring and enforcement practices. The rest of the questions will gauge your opinion on the operating environment. Again, this survey is confidential and voluntary.

You will be prompted to provide a username and password. Please provide the following information:

Username: [USERNAME]

Password: [PASSWORD]

I would like to thank you in advance again for taking part in the survey. Your contribution will play an important part of my study's ultimate findings. If you have any questions, feel free to email me at ppp78@msn.com or call me at 305-609-3391.

Sincerely,

Theo Carrasco

Doctoral Candidate, Florida International University 
Appendix B

Survey Instrument 


\section{SURVEY INSTRUMENT}

Thank you again for taking the time to participate in this study.

This set of questions focuses on the technical aspect of how your jurisdiction implements its living/prevailing wage ordinance (LWO). This section requires specific information on contract and budget totals. Please be as specific as possible.

1. What year was the LWO passed?

2. Given the expiration of contracts after that date, what year did the LWO actually cover all employers (contractors, vendors, etc.) and workers it was intended to cover?

3. How many total service contracts does this jurisdiction currently have?

4. How many of those contracts are covered by the LWO?

5. What percentage of covered employers (contractors, vendors, etc.) do you estimate are adhering to LWO regulations?

6. Do you have a living wage advisory board?

7. What is the total operating budget for your work unit? (Estimate if precise figures are not available.)

8. What is the budget for monitoring, enforcement, and/or evaluation of the LWO? (Estimate if precise figures are not available.)

9. How many employees do you have dedicated to monitoring, enforcing, and evaluating the LWO? (For less than a full-time employee, use a percentage. Estimate if you have to.)

10. How often are vendor payrolls reviewed?

11. How often are random site visits performed?

12. Do you have information on the LWO posted online? What is the website address?

This portion of the survey focuses on the operating environment for the jurisdiction's living/prevailing wage ordinance (LWO). The goal is to have a better understanding of the influential factors driving the implementation process of the living/prevailing wage.

Political Factors - The aim of this section is to examine how political influences might affect administrative action. For the purposes of this study, "political influence" may include such factors as elected official override of traditional personnel processes, influence over program audits, ignoring/downplaying technical advice on program operations, and failure to incorporate workforce demographics and area economic trends into program operations.

\section{[1-Strongly Disagree - 5-Strongly Agree]}

13. Elected officials support the passage of the LWO, but not its implementation.

14. Political influence limits the overall effectiveness of LWO implementation efforts. 
15. The LWO receives sufficient funding for successful implementation.

16. LWO ordinance language and governing regulations are clear and unambiguous to all stakeholders.

17. LWO ordinance "loopholes" contribute to lackluster employer compliance.

18. Elected officials generally act quickly to resolve loopholes in the ordinance.

19. Ambiguity in the LWO policy offers the opportunity for political interference.

$$
\text { [1-Low - 5-High] }
$$

20. Please rate the political influence each of the following groups has on the implementation process:

a. Elected officials

b. Contractors

c. Grassroots groups (e.g. church, labor, and/or community action groups)

d. Bureaucratic politics (e.g. competition amongst government subdivisions)

21. How active is the advisory board's role in enforcing and/or improving the LWO?

Organizational Culture and Dynamics - This survey examines factors within your work unit and jurisdiction overall. The management and enforcement component inquires about the implementation effort. The contractors/vendors section examines the relationship between them and your jurisdiction in the context of LWO implementation.

$$
\text { [1-Strongly Disagree - 5-Strongly Agree] }
$$

\section{Jurisdiction}

22. We strive to improve LWO implementation based on past mistakes and current program trends.

23. Information on program results is easily accessible and shared openly with ALL stakeholders.

24. We have sufficient data to monitor the effectiveness of our implementation of the LWO.

25. Policymaking reflects input provided by all stakeholders. (e.g. elected officials, administrators, vendors, and grassroots groups)

26. Administrative orders and objectives are clear to those involved in monitoring and enforcing the LWO.

\section{Monitoring and Enforcement}

27. Enforcement of contract compliance is consistent regardless of the vendor.

28 . We apply more stringent standards to invoke and implement penalties against repeat offenders.

29. Penalties for LWO non-compliance are fair with the significance of the violation.

30. Upon being reported, violations are investigated in a timely manner.

31. Penalties are applied in a timely manner after adjudication.

32. Businesses frequently attain waivers to avoid paying the living/prevailing wage.

33. We are understaffed and cannot implement the ordinance effectively. 


\section{Contractors/Vendors}

34. Changes to the LWO, its monitoring, and enforcement are met with vendor resistance

35 . Vendors are generally at odds over LWO regulations.

36. Contractors/vendors understand what the LWO is and what is required of them.

37. Contractors/vendors are constantly trying to find loopholes to avoid LWO obligations.

38. Contractors/vendors fulfill their obligations to inform employees about the LWO.

Grassroots Involvement - This section looks at grassroots organizations (church, labor, union groups, etc.) that might have an interest in the living/prevailing wage.

$$
\text { [1-Lowest - 5-Highest] }
$$

39. How would you rate the involvement of grassroots organizations during passage of the ordinance?

40. How would you rate their current level of involvement?

[Open-ended]

41. Some would argue that achieving best practice (i.e. obtaining lowest price bids from as many vendors as possible) in the procurement process conflicts with other policy objectives, such as, implementing a LWO. Do you think that vending is an effective way to achieve social goals such as a living wage? Why or why not?

42. What else is needed to help your work unit become better capable of overseeing the implementation of the LWO? 
Appendix C

Survey Frequency Results 
Sample Characteristics

Statistics

\begin{tabular}{|c|c|c|c|c|c|c|c|}
\hline & & $\begin{array}{c}\text { Years of LW } \\
\text { Implementati } \\
\text { on }\end{array}$ & $\begin{array}{l}\text { Total LW } \\
\text { Contracts }\end{array}$ & $\begin{array}{c}\text { Compliance } \\
\text { Rate }\end{array}$ & $\begin{array}{c}\text { Presence of a } \\
\text { LW Ov ersight } \\
\text { Board }\end{array}$ & $\begin{array}{l}\text { Total LW } \\
\text { Budget }\end{array}$ & $\begin{array}{c}\text { Total FTE } \\
\text { dedicated } \\
\text { to LW }\end{array}$ \\
\hline \multirow[t]{2}{*}{$\mathrm{N}$} & Valid & 29 & 23 & 26 & 30 & 25 & 30 \\
\hline & Missing & 3 & 9 & 6 & 2 & 7 & 2 \\
\hline \multicolumn{2}{|c|}{ Mean } & 6.41 & 173.17 & .9338 & .13 & 75431.32 & 1.79 \\
\hline \multicolumn{2}{|c|}{ Median } & 6.00 & 50.00 & 1.0000 & .00 & 15000.00 & 1.00 \\
\hline \multicolumn{2}{|c|}{ Std. Dev iation } & 1.900 & 245.341 & .14303 & .346 & 175871.1 & 5.364 \\
\hline
\end{tabular}

Years of LW Implementation

\begin{tabular}{|ll|r|r|r|r|}
\hline & & & & \multicolumn{2}{c|}{$\begin{array}{c}\text { Cumulat iv e } \\
\text { Percent }\end{array}$} \\
\hline Valid & 2 & Frequency & Percent & Valid Percent \\
& 4 & 1 & 3.1 & 3.4 & 3.4 \\
& 5 & 2 & 6.3 & 6.9 & 10.3 \\
& 6 & 7 & 21.9 & 24.1 & 34.5 \\
& 7 & 6 & 18.8 & 20.7 & 55.2 \\
& 8 & 6 & 18.8 & 20.7 & 75.9 \\
& 9 & 3 & 9.4 & 10.3 & 86.2 \\
& 10 & 1 & 3.1 & 3.4 & 89.7 \\
& Total & 3 & 9.4 & 10.3 & 100.0 \\
Missing & 99 & 29 & 90.6 & 100.0 & \\
Total & & 32 & 9.4 & & \\
\hline
\end{tabular}

Total LW Contracts

\begin{tabular}{|c|c|c|c|c|c|}
\hline & & Frequency & Percent & Valid Percent & $\begin{array}{c}\text { Cumulat iv e } \\
\text { Percent }\end{array}$ \\
\hline \multirow[t]{22}{*}{ Valid } & 2 & 1 & 3.1 & 4.3 & 4.3 \\
\hline & 4 & 1 & 3.1 & 4.3 & 8.7 \\
\hline & 5 & 1 & 3.1 & 4.3 & 13.0 \\
\hline & 14 & 1 & 3.1 & 4.3 & 17.4 \\
\hline & 15 & 1 & 3.1 & 4.3 & 21.7 \\
\hline & 16 & 1 & 3.1 & 4.3 & 26.1 \\
\hline & 26 & 1 & 3.1 & 4.3 & 30.4 \\
\hline & 32 & 1 & 3.1 & 4.3 & 34.8 \\
\hline & 40 & 1 & 3.1 & 4.3 & 39.1 \\
\hline & 45 & 1 & 3.1 & 4.3 & 43.5 \\
\hline & 50 & 2 & 6.3 & 8.7 & 52.2 \\
\hline & 69 & 1 & 3.1 & 4.3 & 56.5 \\
\hline & 70 & 1 & 3.1 & 4.3 & 60.9 \\
\hline & 128 & 1 & 3.1 & 4.3 & 65.2 \\
\hline & 217 & 1 & 3.1 & 4.3 & 69.6 \\
\hline & 230 & 1 & 3.1 & 4.3 & 73.9 \\
\hline & 250 & 1 & 3.1 & 4.3 & 78.3 \\
\hline & 300 & 2 & 6.3 & 8.7 & 87.0 \\
\hline & 500 & 1 & 3.1 & 4.3 & 91.3 \\
\hline & 620 & 1 & 3.1 & 4.3 & 95.7 \\
\hline & 1000 & 1 & 3.1 & 4.3 & 100.0 \\
\hline & Total & 23 & 71.9 & 100.0 & \\
\hline Missing & 99 & 9 & 28.1 & & \\
\hline Total & & 32 & 100.0 & & \\
\hline
\end{tabular}




\section{Compliance Rate}

\begin{tabular}{|c|c|c|c|c|c|}
\hline & & Frequency & Percent & Valid Percent & $\begin{array}{c}\text { Cumulativ e } \\
\text { Percent }\end{array}$ \\
\hline \multirow[t]{8}{*}{ Valid } & .40 & 1 & 3.1 & 3.8 & 3.8 \\
\hline & .60 & 1 & 3.1 & 3.8 & 7.7 \\
\hline & .80 & 2 & 6.3 & 7.7 & 15.4 \\
\hline & .90 & 2 & 6.3 & 7.7 & 23.1 \\
\hline & .95 & 2 & 6.3 & 7.7 & 30.8 \\
\hline & .99 & 2 & 6.3 & 7.7 & 38.5 \\
\hline & 1.00 & 16 & 50.0 & 61.5 & 100.0 \\
\hline & Total & 26 & 81.3 & 100.0 & \\
\hline Missing & 99.00 & 6 & 18.8 & & \\
\hline Total & & 32 & 100.0 & & \\
\hline
\end{tabular}

Presence of a LW Oversight Board

\begin{tabular}{|c|c|c|c|c|c|}
\hline & & Frequency & Percent & Valid Percent & $\begin{array}{c}\text { Cumulative } \\
\text { Percent }\end{array}$ \\
\hline \multirow[t]{3}{*}{ Valid } & no & 26 & 81.3 & 86.7 & 86.7 \\
\hline & yes & 4 & 12.5 & 13.3 & 100.0 \\
\hline & Total & 30 & 93.8 & 100.0 & \\
\hline Missing & NA & 2 & 6.3 & & \\
\hline Total & & 32 & 100.0 & & \\
\hline
\end{tabular}

Total LW Budget

\begin{tabular}{|c|c|c|c|c|c|}
\hline & & Frequency & Percent & Valid Percent & $\begin{array}{c}\text { Cumulat iv e } \\
\text { Percent }\end{array}$ \\
\hline \multirow[t]{13}{*}{ Valid } & 0 & 11 & 34.4 & 44.0 & 44.0 \\
\hline & 5000 & 1 & 3.1 & 4.0 & 48.0 \\
\hline & 15000 & 3 & 9.4 & 12.0 & 60.0 \\
\hline & 50000 & 2 & 6.3 & 8.0 & 68.0 \\
\hline & 56000 & 1 & 3.1 & 4.0 & 72.0 \\
\hline & 60000 & 1 & 3.1 & 4.0 & 76.0 \\
\hline & 65000 & 1 & 3.1 & 4.0 & 80.0 \\
\hline & 121760 & 1 & 3.1 & 4.0 & 84.0 \\
\hline & 125000 & 1 & 3.1 & 4.0 & 88.0 \\
\hline & 158023 & 1 & 3.1 & 4.0 & 92.0 \\
\hline & 300000 & 1 & 3.1 & 4.0 & 96.0 \\
\hline & 850000 & 1 & 3.1 & 4.0 & 100.0 \\
\hline & Total & 25 & 78.1 & 100.0 & \\
\hline Missing & 99 & 7 & 21.9 & & \\
\hline Total & & 32 & 100.0 & & \\
\hline
\end{tabular}

Total FTE dedicated to LW

\begin{tabular}{|ll|r|r|r|r|}
\hline & & & & & Cumulat ive \\
Prequency & Percent & Valid Percent & \multicolumn{1}{c|}{ Percent } \\
\hline Valid & 0 & 5 & 15.6 & 16.7 & 16.7 \\
& 0 & 1 & 3.1 & 3.3 & 20.0 \\
& 0 & 2 & 6.3 & 6.7 & 26.7 \\
& 1 & 3 & 9.4 & 10.0 & 36.7 \\
& 1 & 2 & 6.3 & 6.7 & 43.3 \\
& 1 & 10 & 31.3 & 33.3 & 76.7 \\
& 2 & 3 & 9.4 & 10.0 & 86.7 \\
& 2 & 3 & 9.4 & 10.0 & 96.7 \\
& 30 & 1 & 3.1 & 3.3 & 100.0 \\
Missing & Total & 30 & 93.8 & 100.0 & \\
Total & 99 & 32 & 6.3 & & \\
\hline
\end{tabular}




\section{Political Factors}

Statistics

\begin{tabular}{|c|c|c|c|c|c|c|c|c|}
\hline & & $\begin{array}{c}\text { Elected } \\
\text { officials } \\
\text { support the } \\
\text { passage of } \\
\text { the LWO, } \\
\text { but not its } \\
\text { implementa } \\
\text { tion. }\end{array}$ & $\begin{array}{c}\text { Political } \\
\text { influence } \\
\text { limits the } \\
\text { overall } \\
\text { effectiveness } \\
\text { of LWO } \\
\text { implementati } \\
\text { on eff orts. }\end{array}$ & $\begin{array}{l}\text { The LWO } \\
\text { receives } \\
\text { sufficient } \\
\text { funding for } \\
\text { successf ul } \\
\text { implementa } \\
\text { tion. } \\
\end{array}$ & $\begin{array}{c}\text { LWO } \\
\text { ordinance } \\
\text { language and } \\
\text { governing } \\
\text { regulations } \\
\text { are clear and } \\
\text { unambiguous } \\
\text { to all } \\
\text { stakeholders. }\end{array}$ & $\begin{array}{c}\text { LWO } \\
\text { ordinance } \\
\text { "loopholes" } \\
\text { contribute to } \\
\text { lackluster } \\
\text { employer } \\
\text { compliance. }\end{array}$ & $\begin{array}{c}\text { Elected } \\
\text { officials } \\
\text { generally act } \\
\text { quickly to } \\
\text { resolve } \\
\text { loopholes in } \\
\text { the ordinance. }\end{array}$ & $\begin{array}{c}\text { Ambiguity in } \\
\text { the LWO } \\
\text { policy off ers } \\
\text { the } \\
\text { opportunity } \\
\text { for political } \\
\text { interference. }\end{array}$ \\
\hline \multirow[t]{2}{*}{$\mathrm{N}$} & Valid & 28 & 28 & 28 & 28 & 28 & 27 & 29 \\
\hline & Missing & 4 & 4 & 4 & 4 & 4 & 5 & 3 \\
\hline \multicolumn{2}{|c|}{ Mean } & 2.32 & 2.61 & 2.71 & 2.64 & 2.21 & 3.30 & 2.28 \\
\hline \multicolumn{2}{|c|}{ Median } & 2.00 & 2.00 & 3.00 & 2.00 & 2.00 & 3.00 & 2.00 \\
\hline \multicolumn{2}{|c|}{ Std. Deviation } & 1.188 & 1.286 & 1.213 & 1.162 & .917 & .993 & 1.032 \\
\hline
\end{tabular}

Elected officials support the passage of the LWO, but not its implementation.

\begin{tabular}{|c|c|c|c|c|c|}
\hline & & Frequency & Percent & Valid Percent & $\begin{array}{c}\text { Cumulative } \\
\text { Percent }\end{array}$ \\
\hline \multirow[t]{5}{*}{ Valid } & Strongly Disagree & 9 & 28.1 & 32.1 & 32.1 \\
\hline & Disagree & 8 & 25.0 & 28.6 & 60.7 \\
\hline & Undecided & 4 & 12.5 & 14.3 & 75.0 \\
\hline & Agree & 7 & 21.9 & 25.0 & 100.0 \\
\hline & Total & 28 & 87.5 & 100.0 & \\
\hline Missing & 99 & 4 & 12.5 & & \\
\hline Total & & 32 & 100.0 & & \\
\hline
\end{tabular}

Political influence limits the overall effectiveness of LWO implementation efforts.

\begin{tabular}{|ll|r|r|r|r|}
\hline & & & & Cumulative \\
& & Frequency & Percent & Valid Percent & \multicolumn{2}{c|}{ Percent } \\
\hline Valid & Strongly Disagree & 7 & 21.9 & 25.0 & 25.0 \\
& Disagree & 8 & 25.0 & 28.6 & 53.6 \\
& Undecided & 3 & 9.4 & 10.7 & 64.3 \\
& Agree & 9 & 28.1 & 32.1 & 96.4 \\
& Strongly Agree & 1 & 3.1 & 3.6 & 100.0 \\
& Total & 28 & 87.5 & 100.0 & \\
Missing & 99 & 4 & 12.5 & & \\
Total & 32 & 100.0 & & \\
\hline
\end{tabular}


The LWO receives sufficient funding for successful implementation.

\begin{tabular}{|c|c|c|c|c|c|}
\hline & & Frequency & Percent & Valid Percent & $\begin{array}{c}\text { Cumulative } \\
\text { Percent }\end{array}$ \\
\hline \multirow[t]{6}{*}{ Valid } & Strongly Disagree & 5 & 15.6 & 17.9 & 17.9 \\
\hline & Disagree & 8 & 25.0 & 28.6 & 46.4 \\
\hline & Undecided & 7 & 21.9 & 25.0 & 71.4 \\
\hline & Agree & 6 & 18.8 & 21.4 & 92.9 \\
\hline & Strongly Agree & 2 & 6.3 & 7.1 & 100.0 \\
\hline & Total & 28 & 87.5 & 100.0 & \\
\hline Missing & 99 & 4 & 12.5 & & \\
\hline Total & & 32 & 100.0 & & \\
\hline
\end{tabular}

NO ordinance language and governing regulations are clear and unambiguous to a stakehol ders.

\begin{tabular}{|c|c|c|c|c|c|}
\hline & & Frequency & Percent & Valid Percent & $\begin{array}{c}\text { Cumulative } \\
\text { Percent }\end{array}$ \\
\hline \multirow[t]{6}{*}{ Valid } & Strongly Disagree & 4 & 12.5 & 14.3 & 14.3 \\
\hline & Disagree & 11 & 34.4 & 39.3 & 53.6 \\
\hline & Undecided & 6 & 18.8 & 21.4 & 75.0 \\
\hline & Agree & 5 & 15.6 & 17.9 & 92.9 \\
\hline & Strongly Agree & 2 & 6.3 & 7.1 & 100.0 \\
\hline & Total & 28 & 87.5 & 100.0 & \\
\hline Missing & 99 & 4 & 12.5 & & \\
\hline Total & & 32 & 100.0 & & \\
\hline
\end{tabular}

LWO ordinance "loopholes" contribute to lackluster employer compliance.

\begin{tabular}{|c|c|c|c|c|c|}
\hline & & Frequency & Percent & Valid Percent & $\begin{array}{c}\text { Cumulative } \\
\text { Percent }\end{array}$ \\
\hline \multirow[t]{5}{*}{ Valid } & Strongly Disagree & 7 & 21.9 & 25.0 & 25.0 \\
\hline & Disagree & 10 & 31.3 & 35.7 & 60.7 \\
\hline & Undecided & 9 & 28.1 & 32.1 & 92.9 \\
\hline & Agree & 2 & 6.3 & 7.1 & 100.0 \\
\hline & Total & 28 & 87.5 & 100.0 & \\
\hline \multirow[t]{3}{*}{ Missing } & 99 & 3 & 9.4 & & \\
\hline & Sy stem & 1 & 3.1 & & \\
\hline & Total & 4 & 12.5 & & \\
\hline Total & & 32 & 100.0 & & \\
\hline
\end{tabular}


Elected officials generally act quickly to resolve loopholes in the ordinance.

\begin{tabular}{|ll|r|r|r|r|}
\hline & & & & Cumulative \\
& & Prequency & Percent & Valid Percent & Percent \\
\hline Valid & Strongly Disagree & 1 & 3.1 & 3.7 & 3.7 \\
& Disagree & 4 & 12.5 & 14.8 & 18.5 \\
& Undecided & 11 & 34.4 & 40.7 & 59.3 \\
& Agree & 8 & 25.0 & 29.6 & 88.9 \\
& Strongly Agree & 3 & 9.4 & 11.1 & 100.0 \\
& Total & 27 & 84.4 & 100.0 & \\
Missing & 99 & 4 & 12.5 & & \\
& Sy stem & 1 & 3.1 & & \\
Total & Total & 5 & 15.6 & & \\
\hline
\end{tabular}

Ambiguity in the LWO policy offers the opportunity for political interference.

\begin{tabular}{|ll|r|r|r|r|}
\hline & & & & Cumulative \\
& & Frequency & Percent & Valid Percent & \multicolumn{1}{c|}{ Percent } \\
\hline Valid & Strongly Disagree & 8 & 25.0 & 27.6 & 27.6 \\
& Disagree & 9 & 28.1 & 31.0 & 58.6 \\
& Undecided & 8 & 25.0 & 27.6 & 86.2 \\
& Agree & 4 & 12.5 & 13.8 & 100.0 \\
& Total & 29 & 90.6 & 100.0 & \\
Missing & 99 & 3 & 9.4 & & \\
Total & & 32 & 100.0 & & \\
\hline
\end{tabular}


Stakeholders

Statistics

\begin{tabular}{|c|c|c|c|c|c|c|}
\hline & & $\begin{array}{l}\text { Please rate } \\
\text { the political } \\
\text { influence } \\
\text { each of the } \\
\text { following } \\
\text { groups has } \\
\text { on the } \\
\text { implementati } \\
\text { on process - } \\
\text { elected } \\
\text { officials } \\
\end{array}$ & $\begin{array}{l}\text { Please rate } \\
\text { the political } \\
\text { influence } \\
\text { each of the } \\
\text { following } \\
\text { groups has } \\
\text { on the } \\
\text { implementati } \\
\text { on process - } \\
\text { contractors } \\
\end{array}$ & $\begin{array}{l}\text { Please rate } \\
\text { the political } \\
\text { influence } \\
\text { each of the } \\
\text { f ollowing } \\
\text { groups has } \\
\text { on the } \\
\text { implementati } \\
\text { on process - } \\
\text { grassroots } \\
\end{array}$ & $\begin{array}{c}\text { Please rate } \\
\text { the political } \\
\text { influence } \\
\text { each of the } \\
\text { following } \\
\text { groups has } \\
\text { on the } \\
\text { implementatio } \\
\text { n process - } \\
\text { bureaucracy } \\
\end{array}$ & $\begin{array}{l}\text { Please rate } \\
\text { the political } \\
\text { influence } \\
\text { each of the } \\
\text { following } \\
\text { groups has } \\
\text { on the } \\
\text { implementatio } \\
\text { n process - } \\
\text { LW adv isory } \\
\text { boards }\end{array}$ \\
\hline \multirow[t]{2}{*}{$\mathrm{N}$} & Valid & 29 & 29 & 29 & 29 & 20 \\
\hline & Missing & 3 & 3 & 3 & 3 & 12 \\
\hline \multicolumn{2}{|c|}{ Mean } & 3.28 & 2.03 & 3.14 & 2.10 & 1.95 \\
\hline \multicolumn{2}{|c|}{ Median } & 4.00 & 2.00 & 4.00 & 2.00 & 1.50 \\
\hline \multicolumn{2}{|c|}{ Std. Dev iation } & 1.437 & 1.210 & 1.356 & 1.319 & 1.050 \\
\hline
\end{tabular}

lease rate the political influence each of the following groups has on thi implementation process - el ected officials

\begin{tabular}{|ll|r|r|r|r|}
\hline & & Frequency & Percent & Valid Percent & $\begin{array}{c}\text { Cumulative } \\
\text { Percent }\end{array}$ \\
\hline Valid & Low & 6 & 18.8 & 20.7 & 20.7 \\
& 2 & 2 & 6.3 & 6.9 & 27.6 \\
& 3 & 5 & 15.6 & 17.2 & 44.8 \\
& 4 & 10 & 31.3 & 34.5 & 79.3 \\
& High & 6 & 18.8 & 20.7 & 100.0 \\
& Total & 29 & 90.6 & 100.0 & \\
Missing & 99 & 3 & 9.4 & & \\
Total & & 32 & 100.0 & & \\
\hline
\end{tabular}

lease rate the political influence each of the following groups has on thi implementation process - contractors

\begin{tabular}{|ll|r|r|r|r|}
\hline & & & & & Cumulative \\
& & Frequency & Percent & Valid Percent & Percent \\
\hline Valid & Low & 13 & 40.6 & 44.8 & 44.8 \\
& 2 & 8 & 25.0 & 27.6 & 72.4 \\
& 3 & 3 & 9.4 & 10.3 & 82.8 \\
& 4 & 4 & 12.5 & 13.8 & 96.6 \\
& High & 1 & 3.1 & 3.4 & 100.0 \\
& Total & 29 & 90.6 & 100.0 & \\
Missing & 99 & 3 & 9.4 & & \\
Total & & 32 & 100.0 & & \\
\hline
\end{tabular}


'lease rate the political influence each of the following groups has on thi implementation process - grassroots

\begin{tabular}{|ll|r|r|r|r|}
\hline & & & & & Cumulative \\
& & Frequency & Percent & Valid Percent & Percent \\
\hline Valid & Low & 6 & 18.8 & 20.7 & 20.7 \\
& 2 & 3 & 9.4 & 10.3 & 31.0 \\
& 3 & 4 & 12.5 & 13.8 & 44.8 \\
& 4 & 13 & 40.6 & 44.8 & 89.7 \\
& High & 3 & 9.4 & 10.3 & 100.0 \\
& Total & 29 & 90.6 & 100.0 & \\
Missing & 99 & 3 & 9.4 & & \\
Total & & 32 & 100.0 & & \\
\hline
\end{tabular}

'lease rate the political influence each of the following groups has on thi implementation process - bureaucracy

\begin{tabular}{|ll|r|r|r|r|}
\hline & & & & & Cumulative \\
& & Frequency & Percent & Valid Percent & Percent \\
\hline Valid & Low & 14 & 43.8 & 48.3 & 48.3 \\
& 2 & 5 & 15.6 & 17.2 & 65.5 \\
& 3 & 5 & 15.6 & 17.2 & 82.8 \\
& 4 & 3 & 9.4 & 10.3 & 93.1 \\
& High & 2 & 6.3 & 6.9 & 100.0 \\
& Total & 29 & 90.6 & 100.0 & \\
Missing & 99 & 3 & 9.4 & & \\
Total & & 32 & 100.0 & & \\
\hline
\end{tabular}

'lease rate the political influence each of the following groups has on th implementation process - LW advisory boards

\begin{tabular}{|ll|r|r|r|r|}
\hline & & Frequency & Percent & Valid Percent & $\begin{array}{c}\text { Cumulative } \\
\text { Percent }\end{array}$ \\
\hline Valid & Low & 10 & 31.3 & 50.0 & 50.0 \\
& 2 & 2 & 6.3 & 10.0 & 60.0 \\
& 3 & 7 & 21.9 & 35.0 & 95.0 \\
& 4 & 1 & 3.1 & 5.0 & 100.0 \\
& Total & 20 & 62.5 & 100.0 & \\
Missing & 99 & 12 & 37.5 & & \\
Total & & 32 & 100.0 & & \\
\hline
\end{tabular}


Organizational Culture

\begin{tabular}{|c|c|c|c|c|c|c|}
\hline \multicolumn{7}{|c|}{ Statistics } \\
\hline & & $\begin{array}{l}\text { We strive to } \\
\text { improve LWO } \\
\text { implement atio } \\
\text { n based on } \\
\text { past mistakes } \\
\text { and current } \\
\text { program } \\
\text { trends. }\end{array}$ & $\begin{array}{l}\text { Inf ormation on } \\
\text { program } \\
\text { results is } \\
\text { easily } \\
\text { accessible } \\
\text { and shared } \\
\text { openly with } \\
\text { ALL } \\
\text { stakeholders. }\end{array}$ & $\begin{array}{l}\text { We hav e } \\
\text { suff icient data } \\
\text { to monitor the } \\
\text { eff ectiveness } \\
\text { of our } \\
\text { implementatio } \\
\mathrm{n} \text { of the LWO. }\end{array}$ & $\begin{array}{l}\text { Policy making } \\
\text { ref lects input } \\
\text { provided by all } \\
\text { stakeholders. } \\
\text { (e.g. elected } \\
\text { off icials, } \\
\text { administrator } \\
\text { s, v endors, } \\
\text { and } \\
\text { grassroots } \\
\text { groups) }\end{array}$ & $\begin{array}{l}\text { Administrative } \\
\text { orders and } \\
\text { objectiv es are } \\
\text { clear to those } \\
\text { involv ed in } \\
\text { monitoring } \\
\text { and enf orcing } \\
\text { the LWO. }\end{array}$ \\
\hline \multirow[t]{2}{*}{$\mathrm{N}$} & Valid & 28 & 28 & 28 & 29 & 29 \\
\hline & Missing & 4 & 4 & 4 & 3 & 3 \\
\hline \multicolumn{2}{|c|}{ Mean } & 3.71 & 3.43 & 2.89 & 3.28 & 2.41 \\
\hline \multicolumn{2}{|c|}{ Median } & 4.00 & 4.00 & 3.00 & 4.00 & 2.00 \\
\hline \multicolumn{2}{|c|}{ Std. Dev iation } & 1.013 & .920 & .994 & .922 & 1.053 \\
\hline
\end{tabular}

We strive to improve LWO implementation based on past mistakes and current program trends.

\begin{tabular}{|ll|r|r|r|r|}
\hline & & & & Cumulative \\
& & Frequency & Percent & Valid Percent & Percent \\
\hline Valid & Strongly Disagree & 1 & 3.1 & 3.6 & 3.6 \\
& Disagree & 3 & 9.4 & 10.7 & 14.3 \\
& Undecided & 4 & 12.5 & 14.3 & 28.6 \\
& Agree & 15 & 46.9 & 53.6 & 82.1 \\
& Strongly Agree & 5 & 15.6 & 17.9 & 100.0 \\
& Total & 28 & 87.5 & 100.0 & \\
Missing & 99 & 4 & 12.5 & & \\
Total & 32 & 100.0 & & \\
\hline
\end{tabular}

Information on program results is easily accessible and shared openly with ALL stakeholders.

\begin{tabular}{|ll|r|r|r|r|}
\hline & & & & Cumulative \\
& & Frequency & Percent & Valid Percent & Percent \\
\hline Valid & Disagree & 6 & 18.8 & 21.4 & 21.4 \\
& Undecided & 6 & 18.8 & 21.4 & 42.9 \\
& Agree & 14 & 43.8 & 50.0 & 92.9 \\
& Strongly Agree & 2 & 6.3 & 7.1 & 100.0 \\
& Total & 28 & 87.5 & 100.0 & \\
Missing & 99 & 4 & 12.5 & & \\
Total & & 32 & 100.0 & & \\
\hline
\end{tabular}


We have sufficient data to monitor the effectiveness of our implementation of the LWO.

\begin{tabular}{|ll|r|r|r|r|}
\hline & & & & Cumulative \\
& & Frequency & Percent & Valid Percent & $\begin{array}{r}\text { Percent } \\
\hline \text { Valid }\end{array}$ Strongly Disagree \\
& Disagree & 6.3 & 7.1 & 7.1 \\
& Undecided & 25.0 & 28.6 & 35.7 \\
& Agree & 10 & 31.3 & 35.7 & 71.4 \\
& Strongly Agree & 7 & 21.9 & 25.0 & 96.4 \\
& Total & 1 & 3.1 & 3.6 & 100.0 \\
Missing & 99 & 28 & 87.5 & 100.0 & \\
Total & 4 & 12.5 & & \\
\hline
\end{tabular}

Policymaking reflects in put provided by all stakeholders. (e.g. elected officials, administrators, vendors, and grassroots groups)

\begin{tabular}{|ll|r|r|r|r|}
\hline & & & & \multicolumn{2}{c|}{$\begin{array}{c}\text { Cumulative } \\
\text { Percent }\end{array}$} \\
\hline Valid & Strongly Disagree & 1 & 3.1 & 3.4 & 3.4 \\
& Disagree & 6 & 18.8 & 20.7 & 24.1 \\
& Undecided & 6 & 18.8 & 20.7 & 44.8 \\
& Agree & 16 & 50.0 & 55.2 & 100.0 \\
& Total & 29 & 90.6 & 100.0 & \\
Missing & 99 & 3 & 9.4 & & \\
Total & 32 & 100.0 & & \\
\hline
\end{tabular}

Administrative orders and objectives are clear to those involved in monitoring and enforcing the LWO.

\begin{tabular}{|c|c|c|c|c|c|}
\hline & & Frequency & Percent & Valid Percent & $\begin{array}{c}\text { Cumulative } \\
\text { Percent }\end{array}$ \\
\hline \multirow[t]{6}{*}{ Valid } & Strongly Disagree & 4 & 12.5 & 13.8 & 13.8 \\
\hline & Disagree & 16 & 50.0 & 55.2 & 69.0 \\
\hline & Undecided & 3 & 9.4 & 10.3 & 79.3 \\
\hline & Agree & 5 & 15.6 & 17.2 & 96.6 \\
\hline & Strongly Agree & 1 & 3.1 & 3.4 & 100.0 \\
\hline & Total & 29 & 90.6 & 100.0 & \\
\hline Missing & 99 & 3 & 9.4 & & \\
\hline Total & & 32 & 100.0 & & \\
\hline
\end{tabular}


Statistics

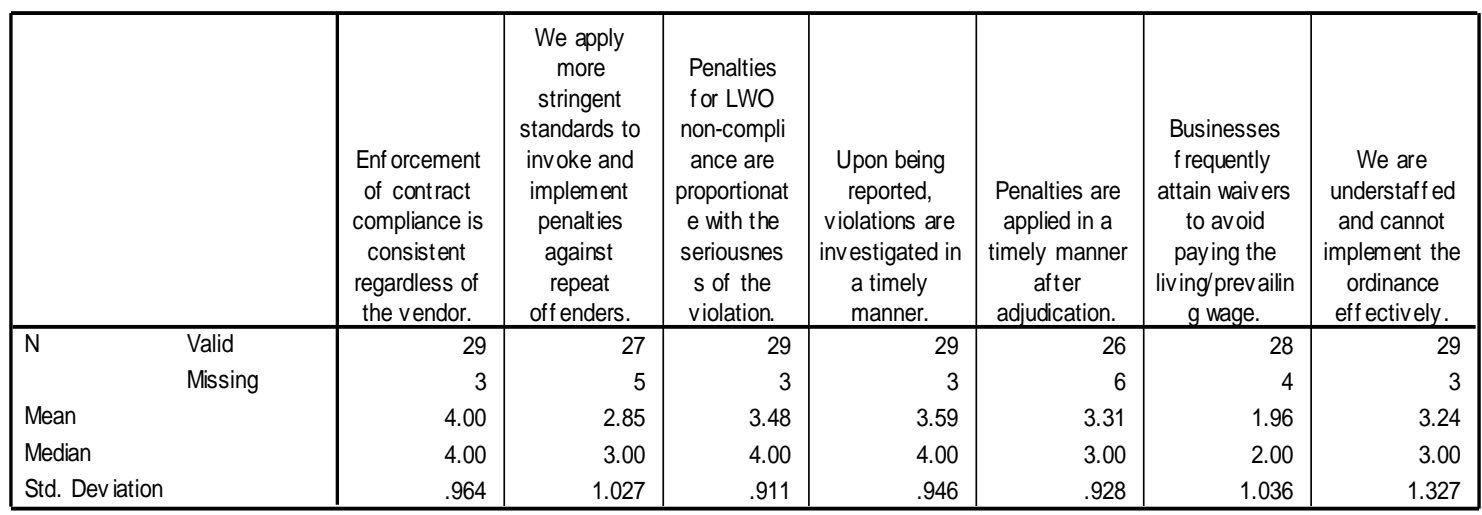

Enforcement of contract compliance is consistent regardless of the vendor.

\begin{tabular}{|ll|r|r|r|r|}
\hline & & & & Cumulative \\
& & Frequency & Percent & Valid Percent & Percent \\
\hline Valid & Disagree & 3 & 9.4 & 10.3 & 10.3 \\
& Undecided & 4 & 12.5 & 13.8 & 24.1 \\
& Agree & 12 & 37.5 & 41.4 & 65.5 \\
& Strongly Agree & 10 & 31.3 & 34.5 & 100.0 \\
& Total & 29 & 90.6 & 100.0 & \\
Missing & 99 & 3 & 9.4 & & \\
Total & 32 & 100.0 & & \\
\hline
\end{tabular}

Ve apply more stringent standards to invoke and implement penalties against repeal offenders.

\begin{tabular}{|ll|r|r|r|r|}
\hline & & & & Cumulative \\
& & Frequency & Percent & Valid Percent & Percent \\
\hline Valid & Strongly Disagree & 3 & 9.4 & 11.1 & 11.1 \\
& Disagree & 6 & 18.8 & 22.2 & 33.3 \\
& Undecided & 11 & 34.4 & 40.7 & 74.1 \\
& Agree & 6 & 18.8 & 22.2 & 96.3 \\
& Strongly Agree & 1 & 3.1 & 3.7 & 100.0 \\
& Total & 27 & 84.4 & 100.0 & \\
Missing & 99 & 5 & 15.6 & & \\
Total & 32 & 100.0 & & \\
\hline
\end{tabular}


Penal ties for LWO non-compliance are proportionate with the seriousness of the violation.

\begin{tabular}{|ll|r|r|r|r|}
\hline & & & & Cumulative \\
& & Frequency & Percent & Valid Percent & Percent \\
\hline Valid & Strongly Disagree & 1 & 3.1 & 3.4 & 3.4 \\
& Disagree & 2 & 6.3 & 6.9 & 10.3 \\
& Undecided & 11 & 34.4 & 37.9 & 48.3 \\
& Agree & 12 & 37.5 & 41.4 & 89.7 \\
& Strongly Agree & 3 & 9.4 & 10.3 & 100.0 \\
& Total & 29 & 90.6 & 100.0 & \\
Missing & 99 & 3 & 9.4 & & \\
Total & & 32 & 100.0 & & \\
\hline
\end{tabular}

Upon being reported, violations are investigated in a timely manner.

\begin{tabular}{|c|c|c|c|c|c|}
\hline & & Frequency & Percent & Valid Percent & $\begin{array}{c}\text { Cumulative } \\
\text { Percent }\end{array}$ \\
\hline \multirow[t]{6}{*}{ Valid } & Strongly Disagree & 1 & 3.1 & 3.4 & 3.4 \\
\hline & Disagree & 2 & 6.3 & 6.9 & 10.3 \\
\hline & Undecided & 9 & 28.1 & 31.0 & 41.4 \\
\hline & Agree & 13 & 40.6 & 44.8 & 86.2 \\
\hline & Strongly Agree & 4 & 12.5 & 13.8 & 100.0 \\
\hline & Total & 29 & 90.6 & 100.0 & \\
\hline Missing & 99 & 3 & 9.4 & & \\
\hline Total & & 32 & 100.0 & & \\
\hline
\end{tabular}

Penal ties are applied in a timely manner after adjudication.

\begin{tabular}{|ll|r|r|r|r|}
\hline & & & & Cumulative \\
& & Frequency & Percent & Valid Percent & \multicolumn{1}{c|}{ Percent } \\
\hline Valid & Strongly Disagree & 1 & 3.1 & 3.8 & 3.8 \\
& Disagree & 2 & 6.3 & 7.7 & 11.5 \\
& Undecided & 14 & 43.8 & 53.8 & 65.4 \\
& Agree & 6 & 18.8 & 23.1 & 88.5 \\
& Strongly Agree & 3 & 9.4 & 11.5 & 100.0 \\
& Total & 26 & 81.3 & 100.0 & \\
Missing & 99 & 6 & 18.8 & & \\
Total & 32 & 100.0 & & \\
\hline
\end{tabular}


Businesses frequently attain waivers to avoid paying the living/prevailing wage.

\begin{tabular}{|ll|r|r|r|r|}
\hline & & & & \multicolumn{2}{c|}{$\begin{array}{c}\text { Cumulative } \\
\text { Percent }\end{array}$} \\
\hline Valid & Strongly Disagree & 12 & 37.5 & 42.9 & 42.9 \\
& Disagree & 8 & 25.0 & 28.6 & 71.4 \\
& Undecided & 5 & 15.6 & 17.9 & 89.3 \\
& Agree & 3 & 9.4 & 10.7 & 100.0 \\
& Total & 28 & 87.5 & 100.0 & \\
Missing & 99 & 4 & 12.5 & & \\
Total & & 32 & 100.0 & & \\
\hline
\end{tabular}

We are understaffed and cannot implement the ordinance effecti vely.

\begin{tabular}{|ll|r|r|r|r|}
\hline & & & & Cumulative \\
& & Frequency & Percent & Valid Percent & \begin{tabular}{c} 
Percent \\
\hline Valid
\end{tabular} Strongly Disagree \\
& Disagree & 4 & 12.5 & 13.8 & 13.8 \\
& Undecided & 12.5 & 13.8 & 27.6 \\
& Agree & 8 & 25.0 & 27.6 & 55.2 \\
& Strongly Agree & 7 & 21.9 & 24.1 & 79.3 \\
& Total & 6 & 18.8 & 20.7 & 100.0 \\
Missing & 99 & 29 & 90.6 & 100.0 & \\
Total & 3 & 9.4 & & \\
\hline
\end{tabular}

Statistics

\begin{tabular}{|c|c|c|c|c|c|c|}
\hline & & $\begin{array}{l}\text { Changes to } \\
\text { the LWO, its } \\
\text { monitoring, } \\
\text { and } \\
\text { enforcement } \\
\text { are met with } \\
\text { vendor } \\
\text { resistance. }\end{array}$ & $\begin{array}{l}\text { Vendors are } \\
\text { generally at } \\
\text { odds over } \\
\text { LWO } \\
\text { regulations. }\end{array}$ & $\begin{array}{c}\text { Contractors/ve } \\
\text { ndors } \\
\text { understand } \\
\text { what the LWO } \\
\text { is and what is } \\
\text { required of } \\
\text { them. }\end{array}$ & $\begin{array}{l}\text { Contractors/v } \\
\text { endors are } \\
\text { constantly } \\
\text { try ing to find } \\
\text { loopholes to } \\
\text { av oid LWO } \\
\text { obligations. }\end{array}$ & $\begin{array}{l}\text { Contractor } \\
\text { s/vendors } \\
\text { f ulf ill their } \\
\text { obligation } \\
\text { s to inf orm } \\
\text { employee } \\
\text { s about } \\
\text { the LWO. }\end{array}$ \\
\hline \multirow[t]{2}{*}{$\overline{\mathrm{N}}$} & Valid & 28 & 28 & 29 & 28 & 28 \\
\hline & Missing & 4 & 4 & 3 & 4 & 4 \\
\hline \multicolumn{2}{|c|}{ Mean } & 2.57 & 2.82 & 2.21 & 2.68 & 2.64 \\
\hline \multicolumn{2}{|c|}{ Median } & 2.00 & 3.00 & 2.00 & 3.00 & 2.50 \\
\hline \multicolumn{2}{|c|}{ Std. Dev iation } & 1.103 & 1.090 & .774 & 1.124 & .951 \\
\hline
\end{tabular}


hanges to the LWO, its monitoring, and enforcement are met with vendor resistance

\begin{tabular}{|ll|r|r|r|r|}
\hline & & & & Cumulative \\
& & Frequency & Percent & Valid Percent & Percent \\
\hline Valid & Strongly Disagree & 4 & 12.5 & 14.3 & 14.3 \\
& Disagree & 12 & 37.5 & 42.9 & 57.1 \\
& Undecided & 5 & 15.6 & 17.9 & 75.0 \\
& Agree & 6 & 18.8 & 21.4 & 96.4 \\
& Strongly Agree & 1 & 3.1 & 3.6 & 100.0 \\
& Total & 28 & 87.5 & 100.0 & \\
Missing & 99 & 4 & 12.5 & & \\
Total & 32 & 100.0 & & \\
\hline
\end{tabular}

Vendors are generally at odds over LWO regulations.

\begin{tabular}{|ll|r|r|r|r|}
\hline & & & & Cumulative \\
& & Frequency & Percent & Valid Percent & Percent \\
\hline Valid & Strongly Disagree & 3 & 9.4 & 10.7 & 10.7 \\
& Disagree & 9 & 28.1 & 32.1 & 42.9 \\
& Undecided & 7 & 21.9 & 25.0 & 67.9 \\
& Agree & 8 & 25.0 & 28.6 & 96.4 \\
& Strongly Agree & 1 & 3.1 & 3.6 & 100.0 \\
& Total & 28 & 87.5 & 100.0 & \\
Missing & 99 & 4 & 12.5 & & \\
Total & 32 & 100.0 & & \\
\hline
\end{tabular}

Contractors/vendors understand what the LWO is and what is required of them.

\begin{tabular}{|ll|r|r|r|r|}
\hline & & & & Cumulative \\
& & Frequency & Percent & Valid Percent & \begin{tabular}{c} 
Percent \\
\hline Valid
\end{tabular} Strongly Disagree \\
& Disagree & 6.3 & 6.9 & 6.9 \\
& 22 & 68.8 & 75.9 & 82.8 \\
& Undecided & 3 & 9.4 & 10.3 & 93.1 \\
& Agree & 1 & 3.1 & 3.4 & 96.6 \\
& Strongly Agree & 1 & 3.1 & 3.4 & 100.0 \\
& Total & 29 & 90.6 & 100.0 & \\
Missing & 99 & 3 & 9.4 & & \\
Total & 32 & 100.0 & & \\
\hline
\end{tabular}


ontractors/vendors are constantly trying to find loopholes to avoid LWO obligation:

\begin{tabular}{|ll|r|r|r|r|}
\hline & & & & Cumulative \\
& & Frequency & Percent & Valid Percent & Percent \\
\hline Valid & Strongly Disagree & 5 & 15.6 & 17.9 & 17.9 \\
& Disagree & 7 & 21.9 & 25.0 & 42.9 \\
& Undecided & 9 & 28.1 & 32.1 & 75.0 \\
& Agree & 6 & 18.8 & 21.4 & 96.4 \\
& Strongly Agree & 1 & 3.1 & 3.6 & 100.0 \\
& Total & 28 & 87.5 & 100.0 & \\
Missing & 99 & 4 & 12.5 & & \\
Total & & 32 & 100.0 & & \\
\hline
\end{tabular}

Contractors/vendors fulfill their obligations to inform employees about the LWO.

\begin{tabular}{|ll|r|r|r|r|}
\hline & & & & Cumulative \\
& & Frequency & Percent & Valid Percent & Percent \\
\hline Valid & Strongly Disagree & 2 & 6.3 & 7.1 & 7.1 \\
& Disagree & 12 & 37.5 & 42.9 & 50.0 \\
& Undecided & 9 & 28.1 & 32.1 & 82.1 \\
& Agree & 4 & 12.5 & 14.3 & 96.4 \\
& Strongly Agree & 1 & 3.1 & 3.6 & 100.0 \\
& Total & 28 & 87.5 & 100.0 & \\
Missing & 99 & 4 & 12.5 & & \\
Total & 32 & 100.0 & & \\
\hline
\end{tabular}




\section{Grassroots}

Statistics

\begin{tabular}{|c|c|c|c|}
\hline & & $\begin{array}{l}\text { How would } \\
\text { y ou rate the } \\
\text { inv olvement of } \\
\text { grassroots } \\
\text { organizations } \\
\text { during } \\
\text { passage of } \\
\text { the } \\
\text { ordinance? }\end{array}$ & $\begin{array}{l}\text { How would } \\
\text { you rate their } \\
\text { current level of } \\
\text { involv ement? }\end{array}$ \\
\hline \multirow[t]{2}{*}{$\bar{N}$} & Valid & 27 & 29 \\
\hline & Missing & 5 & 3 \\
\hline \multicolumn{2}{|c|}{ Mean } & 4.15 & 2.31 \\
\hline \multicolumn{2}{|c|}{ Median } & 5.00 & 2.00 \\
\hline \multicolumn{2}{|c|}{ Std. Dev iation } & 1.199 & 1.442 \\
\hline
\end{tabular}

How would you rate the involvement of grassroots organizations during passage of the ordinance?

\begin{tabular}{|ll|r|r|r|r|}
\hline & & & & \multicolumn{2}{c|}{$\begin{array}{c}\text { Cumulative } \\
\text { Percent }\end{array}$} \\
\hline Valid & Strongly Disagree & 2 & 6.3 & 7.4 & 7.4 \\
& Undecided & 5 & 15.6 & 18.5 & 25.9 \\
& Agree & 5 & 15.6 & 18.5 & 44.4 \\
& Strongly Agree & 15 & 46.9 & 55.6 & 100.0 \\
& Total & 27 & 84.4 & 100.0 & \\
Missing & 99 & 5 & 15.6 & & \\
Total & & 32 & 100.0 & & \\
\hline
\end{tabular}

How would you rate their current level of involvement?

\begin{tabular}{|ll|r|r|r|r|}
\hline & & & & Cumulative \\
& & Frequency & Percent & Valid Percent & \begin{tabular}{c} 
Percent \\
\hline Valid
\end{tabular} Strongly Disagree \\
& Disagree & 4 & 40.6 & 44.8 & 44.8 \\
& 4 & 12.5 & 13.8 & 58.6 \\
& Undecided & 5 & 15.6 & 17.2 & 75.9 \\
& Agree & 4 & 12.5 & 13.8 & 89.7 \\
& Strongly Agree & 3 & 9.4 & 10.3 & 100.0 \\
& Total & 29 & 90.6 & 100.0 & \\
Missing & 99 & 3 & 9.4 & & \\
Total & 32 & 100.0 & & \\
\hline
\end{tabular}




\section{Sum of all Variables}

Statistics

\begin{tabular}{|l|rr|r|r|r|r|r|}
\hline & $\begin{array}{c}\text { Sum of all } \\
\text { policy } \\
\text { ambiguity } \\
\text { variables }\end{array}$ & $\begin{array}{c}\text { Sum of all } \\
\text { policy conflict } \\
\text { variables }\end{array}$ & $\begin{array}{c}\text { Sum of all } \\
\text { stakeholder } \\
\text { variables }\end{array}$ & $\begin{array}{c}\text { Sum of all org. } \\
\text { culture } \\
\text { (information) } \\
\text { variables }\end{array}$ & $\begin{array}{c}\text { Sum of all org. } \\
\text { culture } \\
\text { (monitoring) } \\
\text { variables }\end{array}$ & $\begin{array}{c}\text { Sum of all } \\
\text { org. capacity } \\
\text { variables }\end{array}$ & $\begin{array}{c}\text { SUm of all } \\
\text { org. politics } \\
\text { variables }\end{array}$ \\
\hline N & Valid & 27 & 28 & 20 & 26 & 25 & 28 \\
Missing & 5 & 4 & 12 & 6 & 7 & 28 \\
Mean & 11.85 & 10.71 & 12.70 & 13.19 & 22.36 & 5.93 & 4.93 \\
Median & 11.00 & 11.00 & 13.00 & 13.00 & 22.00 & 6.00 & 5.00 \\
Std. Deviation & 3.559 & 3.660 & 4.497 & 2.857 & 3.839 & .900 & 2.159 \\
\hline
\end{tabular}

Sum of all policy ambiguity variables

\begin{tabular}{|c|c|c|c|c|c|}
\hline & & Frequency & Percent & Valid Percent & $\begin{array}{c}\text { Cumulative } \\
\text { Percent }\end{array}$ \\
\hline \multirow[t]{15}{*}{ Valid } & 6 & 1 & 3.1 & 3.7 & 3.7 \\
\hline & 7 & 2 & 6.3 & 7.4 & 11.1 \\
\hline & 8 & 1 & 3.1 & 3.7 & 14.8 \\
\hline & 9 & 3 & 9.4 & 11.1 & 25.9 \\
\hline & 10 & 6 & 18.8 & 22.2 & 48.1 \\
\hline & 11 & 1 & 3.1 & 3.7 & 51.9 \\
\hline & 12 & 2 & 6.3 & 7.4 & 59.3 \\
\hline & 13 & 3 & 9.4 & 11.1 & 70.4 \\
\hline & 14 & 1 & 3.1 & 3.7 & 74.1 \\
\hline & 15 & 2 & 6.3 & 7.4 & 81.5 \\
\hline & 16 & 1 & 3.1 & 3.7 & 85.2 \\
\hline & 17 & 2 & 6.3 & 7.4 & 92.6 \\
\hline & 18 & 1 & 3.1 & 3.7 & 96.3 \\
\hline & 19 & 1 & 3.1 & 3.7 & 100.0 \\
\hline & Total & 27 & 84.4 & 100.0 & \\
\hline Missing & 99 & 5 & 15.6 & & \\
\hline Total & & 32 & 100.0 & & \\
\hline
\end{tabular}


Sum of all policy conflict variables

\begin{tabular}{|ll|r|r|r|r|}
\hline & & Frequency & Percent & Valid Percent & $\begin{array}{c}\text { Cumulative } \\
\text { Percent }\end{array}$ \\
\hline Valid & 4 & 1 & 3.1 & 3.6 & 3.6 \\
& 5 & 2 & 6.3 & 7.1 & 10.7 \\
& 6 & 1 & 3.1 & 3.6 & 14.3 \\
& 7 & 1 & 3.1 & 3.6 & 17.9 \\
& 8 & 3 & 9.4 & 10.7 & 28.6 \\
& 9 & 2 & 6.3 & 7.1 & 35.7 \\
& 10 & 2 & 6.3 & 7.1 & 42.9 \\
& 11 & 4 & 12.5 & 14.3 & 57.1 \\
& 12 & 5 & 15.6 & 17.9 & 75.0 \\
& 13 & 1 & 3.1 & 3.6 & 78.6 \\
& 14 & 2 & 6.3 & 7.1 & 85.7 \\
& 15 & 2 & 6.3 & 7.1 & 92.9 \\
& 16 & 1 & 3.1 & 3.6 & 96.4 \\
& 20 & 1 & 3.1 & 3.6 & 100.0 \\
& Total & 28 & 87.5 & 100.0 & \\
Missing & 99 & 4 & 12.5 & & \\
Total & & 32 & 100.0 & & \\
\hline
\end{tabular}

Sum of all stakeholder variables

\begin{tabular}{|c|c|c|c|c|c|}
\hline & & Frequency & Percent & Valid Percent & $\begin{array}{c}\text { Cumulative } \\
\text { Percent }\end{array}$ \\
\hline \multirow[t]{14}{*}{ Valid } & 5 & 2 & 6.3 & 10.0 & 10.0 \\
\hline & 7 & 1 & 3.1 & 5.0 & 15.0 \\
\hline & 9 & 1 & 3.1 & 5.0 & 20.0 \\
\hline & 10 & 1 & 3.1 & 5.0 & 25.0 \\
\hline & 11 & 3 & 9.4 & 15.0 & 40.0 \\
\hline & 12 & 1 & 3.1 & 5.0 & 45.0 \\
\hline & 13 & 3 & 9.4 & 15.0 & 60.0 \\
\hline & 14 & 3 & 9.4 & 15.0 & 75.0 \\
\hline & 15 & 1 & 3.1 & 5.0 & 80.0 \\
\hline & 17 & 1 & 3.1 & 5.0 & 85.0 \\
\hline & 18 & 1 & 3.1 & 5.0 & 90.0 \\
\hline & 19 & 1 & 3.1 & 5.0 & 95.0 \\
\hline & 23 & 1 & 3.1 & 5.0 & 100.0 \\
\hline & Total & 20 & 62.5 & 100.0 & \\
\hline \multirow[t]{3}{*}{ Missing } & 99 & 11 & 34.4 & & \\
\hline & Sy stem & 1 & 3.1 & & \\
\hline & Total & 12 & 37.5 & & \\
\hline Total & & 32 & 100.0 & & \\
\hline
\end{tabular}


Sum of all org. culture (information) variables

\begin{tabular}{|c|c|c|c|c|c|}
\hline & & Frequency & Percent & Valid Percent & $\begin{array}{c}\text { Cumulativ e } \\
\text { Percent }\end{array}$ \\
\hline \multirow[t]{12}{*}{ Valid } & 7 & 1 & 3.1 & 3.8 & 3.8 \\
\hline & 8 & 1 & 3.1 & 3.8 & 7.7 \\
\hline & 9 & 1 & 3.1 & 3.8 & 11.5 \\
\hline & 10 & 1 & 3.1 & 3.8 & 15.4 \\
\hline & 11 & 4 & 12.5 & 15.4 & 30.8 \\
\hline & 12 & 2 & 6.3 & 7.7 & 38.5 \\
\hline & 13 & 4 & 12.5 & 15.4 & 53.8 \\
\hline & 15 & 6 & 18.8 & 23.1 & 76.9 \\
\hline & 16 & 4 & 12.5 & 15.4 & 92.3 \\
\hline & 17 & 1 & 3.1 & 3.8 & 96.2 \\
\hline & 18 & 1 & 3.1 & 3.8 & 100.0 \\
\hline & Total & 26 & 81.3 & 100.0 & \\
\hline \multirow[t]{3}{*}{ Missing } & 99 & 5 & 15.6 & & \\
\hline & Sy stem & 1 & 3.1 & & \\
\hline & Total & 6 & 18.8 & & \\
\hline Total & & 32 & 100.0 & & \\
\hline
\end{tabular}

Sum of all org. culture (monitoring) variables

\begin{tabular}{|c|c|c|c|c|c|}
\hline & & Frequency & Percent & Valid Percent & $\begin{array}{l}\text { Cumulative } \\
\text { Percent }\end{array}$ \\
\hline \multirow[t]{14}{*}{ Valid } & 13 & 1 & 3.1 & 4.0 & 4.0 \\
\hline & 16 & 1 & 3.1 & 4.0 & 8.0 \\
\hline & 18 & 1 & 3.1 & 4.0 & 12.0 \\
\hline & 19 & 2 & 6.3 & 8.0 & 20.0 \\
\hline & 20 & 1 & 3.1 & 4.0 & 24.0 \\
\hline & 21 & 5 & 15.6 & 20.0 & 44.0 \\
\hline & 22 & 2 & 6.3 & 8.0 & 52.0 \\
\hline & 23 & 3 & 9.4 & 12.0 & 64.0 \\
\hline & 24 & 1 & 3.1 & 4.0 & 68.0 \\
\hline & 25 & 3 & 9.4 & 12.0 & 80.0 \\
\hline & 26 & 2 & 6.3 & 8.0 & 88.0 \\
\hline & 27 & 2 & 6.3 & 8.0 & 96.0 \\
\hline & 31 & 1 & 3.1 & 4.0 & 100.0 \\
\hline & Total & 25 & 78.1 & 100.0 & \\
\hline \multirow[t]{3}{*}{ Missing } & 99 & 5 & 15.6 & & \\
\hline & Sy stem & 2 & 6.3 & & \\
\hline & Total & 7 & 21.9 & & \\
\hline Total & & 32 & 100.0 & & \\
\hline
\end{tabular}


Sum of all org. capacity variables

\begin{tabular}{|ll|r|r|r|r|}
\hline & & & & & Cumulative \\
& & Frequency & Percent & Valid Percent & \multicolumn{1}{c|}{ Percent } \\
\hline Valid & 4 & 1 & 3.1 & 3.6 & 3.6 \\
& 5 & 7 & 21.9 & 25.0 & 28.6 \\
& 6 & 15 & 46.9 & 53.6 & 82.1 \\
& 7 & 3 & 9.4 & 10.7 & 92.9 \\
& 8 & 2 & 6.3 & 7.1 & 100.0 \\
& Total & 28 & 87.5 & 100.0 & \\
Missing & 99 & 4 & 12.5 & & \\
Total & & 32 & 100.0 & & \\
\hline
\end{tabular}

Sum of all org. politics variables

\begin{tabular}{|ll|r|r|r|r|}
\hline & & Frequency & Percent & Valid Percent & $\begin{array}{c}\text { Cumulative } \\
\text { Percent }\end{array}$ \\
\hline Valid & 2 & 6 & 18.8 & 21.4 & 21.4 \\
& 3 & 2 & 6.3 & 7.1 & 28.6 \\
& 4 & 5 & 15.6 & 17.9 & 46.4 \\
& 5 & 2 & 6.3 & 7.1 & 53.6 \\
& 6 & 6 & 18.8 & 21.4 & 75.0 \\
& 7 & 2 & 6.3 & 7.1 & 82.1 \\
& 8 & 5 & 15.6 & 17.9 & 100.0 \\
& Total & 28 & 87.5 & 100.0 & \\
Missing & 99 & 4 & 12.5 & & \\
Total & & 32 & 100.0 & & \\
\hline
\end{tabular}


Appendix D

Interview Consent Form 


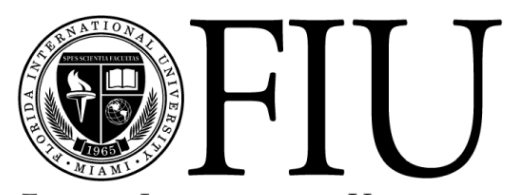

FLORIDA INTERNATIONAL UNIVERSITY

Miami's public research university

\section{CONSENT TO PARTICIPATE IN A RESEARCH STUDY \\ ASSESSING ADMINISTRATIVE AND POLITICAL FACTORS IN IMPLEMENTING A LIVING WAGE ORDINANCE}

You are being asked to be in a research study. The investigator of this study is Teodoro Carrasco and he is a doctoral student at FIU. The study will include about 70 people who are the involved with implementing a living wage ordinance. Your participation will require 1 hour of your time. We are looking to examine how Miami-Dade and Broward County implement their respective living wage ordinances. The results of the study will aid the development of better implementation efforts for living wage policies.

At an agreed upon site and time convenient for you, the investigator will ask you questions about your views on the living wage ordinance, what is your involvement in its implementation, your opinion on how it is implemented, and whether improvements, if any, need to be made. The interview will last a maximum of 1 hour.

Your interview will be identified by a random number not your name. All of your answers are private and will not be shared with anyone unless required by law. Your responses will be compared to those of the other respondents. We will present the research results as a group. You may ask questions about the study at any time. You may also choose to stop your participation before you finish the interview.

If you would like more information about this research after you are done, you may contact Dr. Howard Frank at 305-348-0410. If you would like to talk with someone about being a subject in this study you may also contact Dr. Jonathan Tubman, the Chairperson of the FIU Institutional Review Board at 305-348-3024 or 305-348-2494.

Your signature below indicates that all questions have been answered to your liking. You are aware of your rights and you would like to be in the study.

$\overline{\text { Signature of Participant }}+\frac{\text { Printed Name }}{} \quad$ Date

I have explained the research procedure, subject rights and answered questions asked by the participant. I have offered him/her a copy of this informed consent form. 
VITA

\section{TEODORO ENRIQUE CARRASCO}

May 10, 1976

$2000-2002$

2001

2001

2002 - Present

$2005-2006$

$2006-2007$
Born, Coral Gables, Florida

B.A., Political Science

Florida International University

Miami, Florida

Graduate Assistant

Florida International University

Miami, Florida

Master of Public Administration

Florida International University

Miami, Florida

Outstanding Student Scholar Award

Florida International University

Miami, Florida

Adjunct Professor

Florida International University

Miami, Florida

Chancellor's List

Florida International University

Miami, Florida

National Dean's List

Florida International University

Miami, Florida

\section{PUBLICATIONS AND PRESENTATIONS}

Nissen, B. \& Carrasco, T. (2004). The impact of a living wage ordinance on the City of Miami. Miami, FL, Florida International University Center for Labor Research and Studies 